$2^{8} / \gamma^{5} / 8^{\circ}$

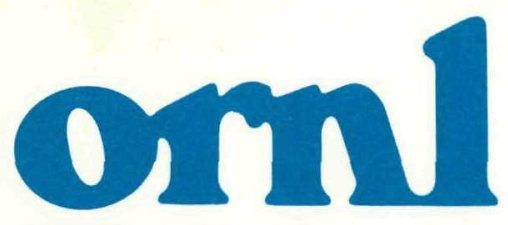

OAK

RIDGE

NATIONAL

LABORATORY

UNION

CARBIDE

\title{
SMOLDERING COMBUSTION HAZARDS OF THERMAL INSULATION MATERIALS
}

\author{
T. J. OHLEMILLER AND F. E. ROGERS \\ GUGGENHEIM LABORATORIES \\ PRINCETON UNIVERSITY \\ PRINCETON, NEW JERSEY
}

PART OF

THE NATIONAL PROGRAM

FOR

BUILDING THERMAL ENVELOPE SYSTEMS

AND INSULATING MATERIALS

\section{OPERATED BY}

UNION CARBIDE CORPORATION FOR THE UNITED STATES DEPARTMENT OF ENERGY
Prepared for the

U.S. Department of Energy

Conservation and Solar Energy

Office of Buildings and Community Systems Buildings Division 


\section{DISCLAIMER}

This report was prepared as an account of work sponsored by an agency of the United States Government. Neither the United States Government nor any agency Thereof, nor any of their employees, makes any warranty, express or implied, or assumes any legal liability or responsibility for the accuracy, completeness, or usefulness of any information, apparatus, product, or process disclosed, or represents that its use would not infringe privately owned rights. Reference herein to any specific commercial product, process, or service by trade name, trademark, manufacturer, or otherwise does not necessarily constitute or imply its endorsement, recommendation, or favoring by the United States Government or any agency thereof. The views and opinions of authors expressed herein do not necessarily state or reflect those of the United States Government or any agency thereof. 


\section{DISCLAIMER}

Portions of this document may be illegible in electronic image products. Images are produced from the best available original document. 


\section{Printed in the United States of America. Available from National Technical Information Service \\ U.S. Department of Commerce \\ 5285 Port Royal Road, Springfield, Virginia 22161 NTIS price codes-Printed Copy: A07 Microfiche A01}

This report was prepared as an account of work sponsored by an agency of the United States Government. Neither the United States Government nor any agency thereof, nor any of their employees, makes any warranty, express or implied, or assumes any legal liability or responsibility for the accuracy, completeness, or usefulness of any information, apparatus, product, or process disclosed, or represents that its use would not infringe privately owned rights. Reference herein to any specific commercial product, process, or service by trade name, trademark. manufacturer, or otherwise, does not necessarily constitute or imply its endorsement, recommendation, or favoring by the United States Government or any agency thereof. The views and opinions of authors expressed herein do not necessarily state or reflect those of the United States Government or any agency thereof. 
ORNL/SUb-7686/1

Dist. Category UC-95d

Contract No. W-7405-eng-26

SMOLDERING COMBUSTION HAZARDS OF THERMAL INSULATION MATERIALS

T. J. Ohlemiller and F. E. Rogers

Guggenheim Laboratories

Princeton University

Princeton, New Jersey

\section{Part of}

The National Program for

Building Thermal Envelope Systems and

Insulating Materials

Date Published: July 1980

Research sponsored by the Office of Buildings and

Community Systems, Buildings Division,

U.S. Department of Energy

OAK RIDGE NATIONAL LABORATORY

Oak Ridge, Tennessee 37830

operated by

UNION CARBIDE CORPORATION

for the

DEPARTMENT OF ENERGY

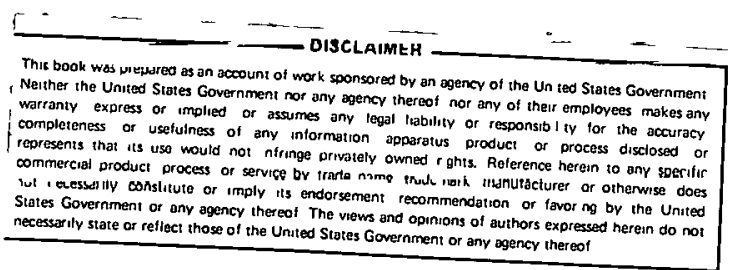


1. DOE/CS-0059: The National Program Plan for Building Thermal Envelope Systems and Insulating Materials (January 1979).

2. ORNL/SUB-7556/I: Assessment of the Corrosiveness of Cellulosic Insulating MateriaTs (June 1979).

3. ORNL/SUB-7504/3: Recessed Light Fixture Test Facility (July 1979).

4. ORNL/SUB-7559/I: Problemis Associated with the Use of UreaFormaldehyde Foam for Residential Insulation (September 1979).

5. ORNL/Sub-7551/I: Interim Progress Report on an Investigation of Energy Transport in Porous InsuTator Systems (october 1979).

6. ORNL/Sub-79/13660/I: Minnesota Retrof it Insulation In Situ Test Program Extension and Review (February 1980).

7. ORNL/Sub-78-97726/I: A Field Study of Moisture Damage in Walls Insulated Without a Vapor Barrier (May 1980).

8. ORNL/TM-7266: An Experimental Study of Thermal Resistance Values (R-Values) of Low-Density Mineral-Fiber Building Insulation Batts Commercialty Available in 1977 (April 1980).

9. ORNL/TM-6494: A Technique for Measuring the Apparent Conductivity of Flat Insulations (October 1979). 


\section{FOREWORD}

This is one of a series of reports to be published describing research, development, and demonstration activities in support of the National Program for Building Thermal Envelope Systems and Insulating Materials. The National Program involves several federal agencies and many other organizations in the public and private sectors who are addressing the national objective of decreasing energy wastes in the heating and cooling of buildings. Results described in this report are part of the National Program through delegation of management responsibilities for the DOE lead role to the Oak Ridge National Laboratory.

Ted S. Lundy

Program Manager

Building Thermal Envelope Systems and Insulating Materials

Oak Ridge National Laboratory

E. C. Freeman

Program Manager, Buildings Division

Office of Buildings and Community Systems

Department of Energy 
TABLE OF CONTENTS

Page

Abstract . . . . . . . . . . . . . . . . . . . . . . . . 1

1. INTRODUCTION. . . . . . . . . . . . . . . . . . . 2

2. SUMMARY OF THERMAL ANALYTICAL RESULTS ON CELLULOSIC INSULATION. • • • . . 4

3. CONFIGURATIONAL EFFECTS ON SMOLDER IGNITABILITY . . . . . . . . . . . . 6

A. Nature and Description of Ignition Testing. . . . . . . . . . . . 6

Nature of Ignition. . . . . . . . . . . . . . . . . . 6

Ignition Variability in Real Installations. . . . . . . . . . . . . . 7

Assessment of Configuration Effects... . . . . . . . . . . . . 8

Apparatus Description . . . . . . . . . . . . . . . . . . . 8

Configuration Tested. . . . . . . . . . . . . . . . . . . 10

Test Procedure. . . . . . . . . . . . . . . . . . 12

B. Summary of Test Results . . . . . . . . . . . . . . . . . 14

Variability in Materials and Test Results . . . . . . . . . . 14

Effect of Retardant . . . . . . . . . . . . . . . 15

Effect of Bulk Density. . . . . . . . . . . . . . . . . . 16

Effect of Heat Source Configurations. . . . . . . . . . . . . 16

Other Observations. . . . . . . . . . . . . . . . . . . . . 17

C. Simplified Model of Smolder Ignition. . . . . . . . . . . . . . 18

Nature of.Model . . . . . . . . . . . . . . . . . . . . . . 19

Model Solution. . . . . . . . . . . . . . . . . . . 22

4. CONCLUSIONS . . . . . . . . . . . . . . . . . . . . 25

5. REFERENCES. . . . . . . . . . . . . . . . . . . . . 27

6. FIGURE 1. ATTIC MOCK-UP SHOWING VARIOUS HEAT SOURCE POSITIONS. . . . . 28

7. TABLE II SUMMARY OF SMOLDER IGNITION TEST RESULTS FOR A SINGLE

COMMERCIAL CELLULOSIC INSULATION. . . . . . . . . . . . . . . . 29

8. TABLE III BORDERLINE (MINIMUM) IGNITION TEMPERATURES FOR A COMMERCIAL

CELLULOSIC INSULATION IN VARIOUS CONFIGURATIONS . . . . . . . . . . . 34

APPENDIX I - CELLULOSIC INSULATION MATERIAL

I. OVERALI DEGRADATION IINETICS AND THERMOCHEMISTRY

APPENDIX II - CELLULOSIC INSULATION MATERIAL

II. EFFECT OF ADDITIVES ON SOME SMOLDER CHARACTERISTICS

APPENDIX III - PYROLYSIS KINETICS OF A POLYURETHANE FOAM BY THERMOGRAVIMETRY A GENERAL KINETIC METHOD 


\section{ABSTRACT}

The present report extends the work in the attached Appendices on smolder ignitability in cellulosic insulation and on thermal analytical characterization of the oxidation of this material.

Thermal analysis (TGA and DSC) shows that both retarded and unretarded cellulosic insulation oxidizes in two overall stages, both of which are exothermic. The second stage (oxidation of the char left as a residue of the first stage) is much more energetic on a unit mass basis than the first. However, kinetics and a sufficient exothermicity make the first stage responsible for ignition in most realistic circumstances. Existing smolder retardants such as boric acid have their major effect on the kinetics of the second oxidation stage and thus produce only a rather small $\left(20^{\circ} \mathrm{C}\right)$ increase in smolder ignition temperature.

Several simplified analogs of attic insulations have been tested to determine the variability of minimum smolder ignition temperature. These employed planar or tubular constant temperature heat sources in a thermal environment quite similar to a realistic attic application. Go/no-go tests provided the borderline (minimum) ignition temperature for each configuration. The wide range $\left(150^{\circ} \mathrm{C}\right)$ of minimum ignition temperatures confirmed the predominant dependence of smolder ignition on heat flow geometry. Other factors (bulk density, retardants) produced much less effect on ignitability. 


\section{INTRODUCTION}

The increased cost of energy has made improved thermal insulation desirable for many residential and commercial buildings. At least one study ${ }^{1}$ has recommended cellulosic loose-fill insulation materials as the best buy on the basis of cost and effectiveness. However, substantial safety questions have been raised regarding these materials ${ }^{2}$ : their conservation benefits may be offset by an increased fire risk. It has been shown ${ }^{3,4}$ that commercial products can be induced to smolder by heat sources that may exist in a significant fraction of use situations. This smoldering is a hazard both due to its generation of toxic gases and its potential to for transition to flaming combustion .

Smoldering is at the heart of this fire safety hazard, but it is not a we11-understood combustion phenomenon. As a consequence, there is a need for improved methods to assess the potential hazards of insulation materials. The need is really twofold: to improve the understanding of the smolder behavior of cellulosic insulations and to utilize that understanding in recommending procedures for hazard assessment. The present work addresses this need in part.

The present work is part of a smolder study program proposed by the authors. It was initiated for DOE in April of 1979 but arose from a base provided by previous NBS-supported smolder studies. This is a final report on the work done for DOE at Princeton. The work will continue at the National Bureau of Standards under DOE sponsorship and the direction of one of the authors (Ohlemiller).

Here we have emphasized primarily the ignitability of cellulosic 
insulation as influenced by both chemical and physical factors. Thermal analysis (both TGA and DSC) has been the main tool, thus far, in characterizing the overall chemistry (oxidative and non-oxidative) of cellulose weight loss and heat production. Techniques have been worked out for quantifying the kinetics of these processes so that they can be fit into approximate smolder mode1s. (See Appendix 1,2,3)

The physical factor of main focus affecting ignitability is insulationbed/heat-source geometry. The earlier work of Bowes and Townshend ${ }^{5}$ and Thomas and Bowes ${ }^{6}$ provides a framework for assessing the influence of this and other physical factors on ignitability. We have adapted the testing methods of these authors, first employing them for one-dimensional heat flow configurations (see Appendix 2) and then expanding them to configurations that resemble attic insulation applications. The test method is simple but tedious: it is designed to ascertain the lowest heat source temperature (in a given configuration) that will just cause ignition after an indefinitely long time. This information is quite pertinent to hazard assessment in insulation usage. As will be seen there is no unique ignition temperature for a given insulation; it varies strongly with configuration.

Most of the chemical information obtained in this program on cellulosic insulation ts contained in the paper that comprises Appendices 1 and 3 . Here we will, therefore, only briefly summarize it. The l-D ignition studies (begun under NBS sponsorship at Princeton) are largely contained in Appendix 2. Our main emphasis here will be in describing the more realistic, multi-dimensional ignition studies completed at Princeton. These configurational studies are not yet complete. They will continue at NBS and will form the subject of a separate paper. 
I I. SUMMARY OF THERMAL ANALYTICAL RESULTS ON CELLULOSIC INSULATION

Thermal analysis (TGA and DSC) techniques have been used to derive kinetic parameters for the oxidation and pyrolysis (inert) of untreated and commercial cellulosic insulation. The method used to derive the kinetic parameters from thermogravimetric curves is discussed in detail in Appendix 3. The application of this method to cellulosic insulation material is given in Appendix 1. These kinetic parameters have been successfully used in a aimple mathematical model (Appendix 2) to predict the smolder ignition temperature of cellulosic insulation as a function of bed depth. The killetic parameters are summarized in Table $I$. The complexities of the non-equivalent weight loss and heat flow processes require different rate laws - a fact which is further discussed in Appendix 1. 
TABLE I

CELLULOSIC INSULATION MATERIAL $^{\text {(a) }}$

\section{OXIDATION KINETIC PARAMETERS}

SOURCE: TGA

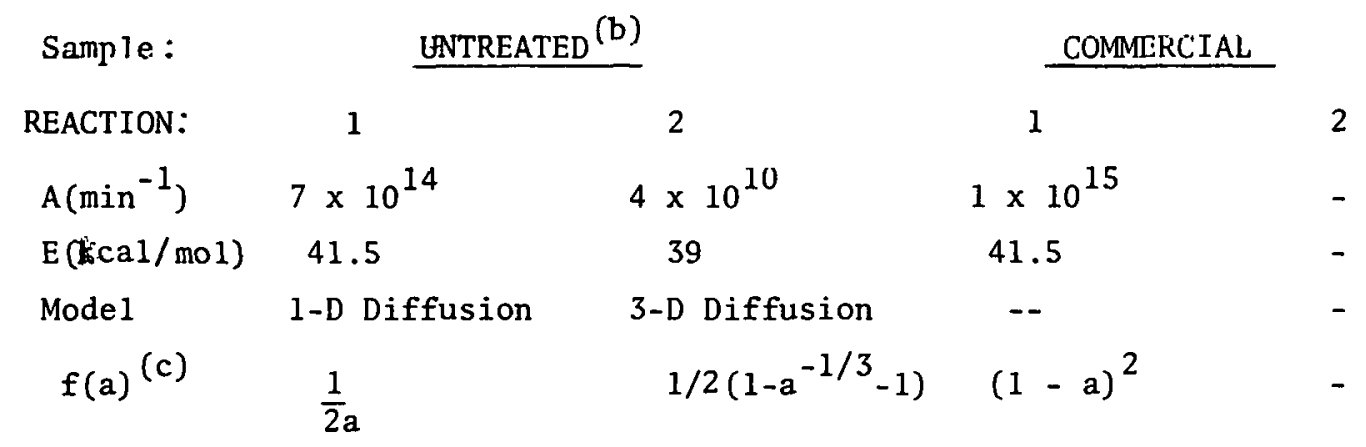

SOURCE : DSC

Sample :

UNTREATED

COMMERCIAL

REACTION :

1

2

1

2

$A\left(\min ^{-1}\right)$

$6 \times 10^{14}$

$3 \times 10^{11}$

$\mathrm{E}(\mathrm{kcal} / \mathrm{mol})$

41.5

39.3

$3 \times 10^{14}$

$2 \times 10^{11}$

$f(a)$ (c)

$(1-a)^{2}$

$(1-a)^{2}$

41.5

39.3

$M(g){ }^{(d)}$

$\mathrm{M}_{\mathrm{o}}$

$0.25 \mathrm{M}_{\mathrm{O}}$

$(1-a)^{2}$

$(1-a)^{2}$

$\mathrm{Q}(\mathrm{cal} / \mathrm{g})^{(\mathrm{e})} \quad 1000$

6000

$\mathrm{M}_{\mathrm{O}}$

$0.40 \mathrm{M}_{\mathrm{o}}$

780

2200

(a) Source of Insulation: Monotherm Inc., New Brunswick, N. I.

(b) Prepared by Monotherm Inc., without additives.

(c) Rate Law: da/dt $=A$ exp [-E/RT] $f(a)$

(d) $M_{0}=$ dry weight $\left(110^{\circ} \mathrm{C}\right)$ of insulation.

(e) $Q$ is heat of oxidation in DSC rate expression: $d q / d t=M Q A \exp [-E / R T] f(a),(c a 1 / s e c)$ 


\section{CONFIGURATIONAL EFFECTS ON SMOLDER IGNITABILITY}

A. Nature and Description of Ignition Testing

Nature of Ignition - Ignition occurs in an insulation material when the chemical (oxidative) heat generation rate exceeds the ability of the material to absorb and dissipate heat. This heat generation is forced by the proximity of the insulation to some heat source which raises the insulation temperature locally. If the heat source is insufficient to cause ignition, the result after some time, will be instead a steady state (actually quasi-steady) in which heat flows from the source and from some weak reactions in the insulation to ambient. Indefinite exposure to this sub-ignition heat source will not lead to ignition (we ignore for now the chemical question of long term aging effects). It is apparent that there will be some heat source strength (here characterized as source temperature) that is just sufficient to cause ignition; it is this minimum or borderline source temperature in which we are interested. However, since this borderline imbalance that causes ignition is between heat release and heat dissipation, factors which affect heat dissipation will change the borderline ignition temperature; the ignition temperature, far from being unique, depends on a host of factors influencing heat flow.

This dependence of ignition temperature on heat flow is most easily seen in the 1-D casc (Appcndix 2). Here one surface of an insulation layer is held at some elevated temperature while the other (parallel) surface of the layer loses heat to ambient. The results in the Appendix show that the minimum hot surface temperature needed to produce ignition can vary from more than $300^{\circ} \mathrm{C}$ at $3 \mathrm{~cm}$ layer thickness to about $270^{\circ} \mathrm{C}$ at $7 \mathrm{~cm}$ layer thickness; extrapolation to thicknesses of 20 to $30 \mathrm{~cm}$ found in insulation usage implies ignition 
temperatures of $230-240^{\circ} \mathrm{C}$. This variation in ignition temperature is easily understood in light of the above balance argument. It is the insulation within a few millimeters of the hot surface which is actually generating heat; the remainder of the layer insulates this reaction zone. The thicker the layer, the greater the thermal insulation of the reaction zone (also, the reaction zone itself thickens). Then a lower heat generation rate is required to overcome the attendant lower heat loss rate; ignition can thus occur at a lower source temperature.

It should be noted that this kind of ignition event is not unique. That is, one could adapt some other ignition testing sequence involving, for example, some heat source at a fixed temperature and testing for the amount of time required for this source to give ignition. For most effective hazard assessment however, we want to look at the worst case which is still realistic. The procedure adopted here does this - it finds the lowest temperature source yielding ignition when the exposure time is arbitrarily long (as it may well be in installed insulation cases).

Ignition Variability in Real Installations. Real insulation installations expose the material to a variety of heat sources (recessed light fixtures, furnace vents, overloaded junction boxes or electrical conductors, etc.). The geometric configuration and attendant heat flow problems vary widely. We expect, from the preceding arguments, that each of these would provoke smolder ignition at different minimum source temperatures. Thus all heat sources are not equally hazardous.

It clearly is not realistic to tcst all possible heat sources to ascertain minimum ignition conditions; there is however a definite need for quantitative 
information on how such differing sources rank. This information will provide a context in which one can interpret the results of a fixed smolder tendency assessment test. Thus, it may be desirable for practical reasons to assess the smolder ignition temperatures of various insulation products on the market by means of a simplified variant of the 1-D test described in Appendix 2 . One needs a quantitative estimate of what the results of that test will mean in terms of real attic installations.

Assessment of Configuration Effects. The present work is an attempt to help bridge this gap. Our goal is twofold: to measure the range of ignition temperatures that are exhibited by one insulation in geometric configurations spanning actual usage; to extend existing ignition models to these more complicated geometries so as to have a basis for extrapolating and interpolating parameter effects.

We have chosen several geometric configurations that are simpler than the real world of installed insulations but which should serve the two objectives above quite we11. They range from "open" to "closed" geometries. By "open" we mean that the lines of hear fluw dle divergent; "closcd" mcans heat flow lines are convergent. The heat flow.out from an immersed wire in an insulation bed is an example of an open geometry. The heat flow inward from two planar hot surfaces furming a concave $90^{\circ}$ corncr is an example of a closed geomętry. Both examples are used here together with intermediate cases. Apparatus Description. The actual apparatus is intended to provide a thermal environment that resembles an attic Insulation iublallation. Fig. I shows a sketch of the attic mockup in which the insulation and various heat 
sources are placed. Because of size limitations imposed by the necessity of placing the mock-up in a laboratory fume hood, the joist spacing is 12 in. rather than the more typical 16 in. for attics. Nevertheless, the insulation bed (always $8 \mathrm{in}$. deep) is contained in the trough formed by 2 " $\mathrm{x} 8^{\prime \prime}$ joists and a "floor" material. In all the present tests the "floor" is $1 / 4$ in. asbestos board but this can readily be replaced by gypsum board if desired. The outer surfaces of the $2 \times 8^{\prime} \mathrm{s}$ see more insulation, in this case, mineral wool. The outer surface of the "floor" is exposed only to ambient air; the metal container box is open on the bottom below the sample and the whole apparatus is supported about 3 in. above the laboratory bench surface.

The heat sources are designed to provide good temperature uniformity over most of the surface in contact with the test insulation. The planar sources are a sandwich structure: two $3 / 16$ in. thick brass plates spread the neat from the actual resistance element (ARi Inc. flexible coil heater that zig-zags back and forth at about one inch intervals). The back of the sandwich is covered by a 1 in. thick block of ceramic fiber insulation. The long rod-like source (\#4 in Fig. 1) is a 3/16 in. OD copper tube enclosing an ARi coil heater. The surface of all heaters facing the test insulation is coated with a graphite paint to give a reproducible emissivity. All heat sources exhibit a uniform temperature within about $\pm 1^{\circ} \mathrm{C}$ except near ends or edges where they drop off about $5^{\circ} \mathrm{C}$. In normal usage there are two thermocouples attached to a given heat source near its center. Both are 30 gage chromel/alumel; the junction of each is held under the head of a brass screw tightly against the heater surface that faces the test insulation. (In the case of the $3 / 16$ in. tube, the junctions 
were soldered in the tube surface). One thermocouple goes to a constant temperature controller which holds the heat source at the desired temperature to within about $1^{\circ} \mathrm{C}$; the other thermocouple output is recorded.

The heat sources are set in place in the attic mock-up in such a way as to minimize air infiltration around their edges. We are thus testing a "worst case" situation with regard to oxygen supply to the ignition zone; i.e., al1 $0_{2}$ must flow or diffuse through the insulation bed. As will be seen, this never proved to be a limiting factor in ignition.

Configurations Tested. Referring to Fig. 1, one sees four heat source placements. A large number of tests was done with heat source 1 only, i.e., an 8 in. high by 10 in. wide planar vertical hot wall against one end of an insulation bed. This is analogous to the side of a recessed light fixture, a chimney or a large furnace vent. This was tested at a nominal insulation bulk density, a higher bulk density and at the nominal density with unretarded insulation. A configuration incorporating heat sources 1 and 2 simultaneously was tested at nominal retarded insulation density; source 2 is 4 in. wide and 10 in. 1ong. This combination forms a $90^{\circ}$ corner, a "closed" genmetry as discussed above. This extreme version is probably rarely found in attic insulation practice though it may be approached with some complexly-shaped recessed light fixtures. This is the worst case among configurations tested. Heat source placement 3 has been tested thus far only with the source ( 8 in. $x$ $10 \mathrm{In.}$ identical to source 1) flush with the attic "floor". (Further work w1ll be done with this source and source 2 at another depth, simplified analogs of recessed light fixtures). This configuration is an extension of the type of test described in Appendix 2; here the heat flow is no 1onger 1-D. Heat suurce 4 is analogous to an over-heated electrical wire or conduit immersed 
at mid-depth in an 8 in. insulation bed. As will be seen below, this is the least hazardous configuration tested.

In all configurations, two or more additional thermocouples were incorporated as a means of monitoring the state of the test insulation. In the planar heat source cases, two 0.020 in. diameter stainless steel sheath chromel/alumel thermocouples were placed with their junctions near the center of the heat source but about $1 / 4$ in. away from it, in the test bed. (One similarly placed thermocouple was used in the $3 / 16$ in. tubular heat source case.) These two thermocouples are near the position at which thermal runaway (ignition) usually begins. Their behavior indicates, in the case of ignition, when it is occurring and, in the case of no ignition, how far, roughly, from the borderline the conditions are. A third thermocouple was placed about $11 / 2$ in. out from the heat source center in the sample bed. This thermocouple serves to monitor the gradient in temperature perpendicular to the heat source center. This gradient is the main heat loss path from the incipient reaction zone. Once the gradient has stabilized at its minimum value during a test any longer exposure is increasingly unlikely to lead to ignition because of reactant consumption (see Appendix 2). This thermocouple thus serves to indicate when a non-ignition test case can be terminated. All thermocouples were oriented parallel to the heat source surface (parallel to isotherms) so as to minimize lead conduction effects.

In several of the tests, gas samples were taken from the region just off the heat source center (between the two closer thermocouples mentioned ahove). A six inch syringe needle was anchored in place for this purpose. When samples 
were taken, a gas tight, 1 cc syringe was plugged into the hub of the needle, the needle was flushed repeatedly with the sampled gas and then a final $1 \mathrm{cc}$ sample was withdrawn slowly ( $1 \mathrm{cc}$ in $45-60 \mathrm{sec}$ ) so as to minimize local disturbances. The samples were analyzed for $\mathrm{CO}, \mathrm{CO}_{2}, \mathrm{O}_{2}$ and $\mathrm{N}_{2}$ by gas chromatography.

In all of the configurations tested, it was deemed wasteful to fill the entire attic mock-up with insulation. Instead, the region near the heat source and out to where the temperature dropped to about $30^{\circ} \mathrm{C}$ was occupied by the test material. Beyond this was a wire basket of mineral wool packed at about $6 \mathrm{lb} / \mathrm{ft}^{3}$. This bulk density gives a reasonable match to the cellulosic insulation in thermal properties and flow resistance. The test bed effectively looks infinitely long to the heat source.

In all tests the attic mock-up was necessarily placed in a laboratory fume hood. Air flow rate past the top surface of the insulation was in the range of 0-1 ft/sec, not a major disturbance.

l'cst proccdurc. Ns notod abovo, all sample test beds of insulation were about $8 \mathrm{in.} \mathrm{deep.} \mathrm{To} \mathrm{maxımıze} \mathrm{reproducıbılıty} \mathrm{and} \mathrm{minımıze} \mathrm{bulk} \mathrm{density}$ gradients in beds of this depth, special packing procedures were followed. First the insulation, previously equilibrated with $45-55 \%$ relative humidity air, was ball-milled for two hours to fluff it. (This is more time than is needed for this purpose alone. This was used in the 1-D tests described in Appendix 2 as a means of adding retardants. Here we retain the same preparation so that the data can be compared.) 'l'he mılled insulation was weighed out in four equal segments, each intended to contribute 2 in. in depth to the test bed. Each segment was very carefully distributed by hand in the 
test bed; remaining depth was checked at several points after each 2 in. addition to assure even distribution. For the nominal density cases, a slight amount ( 1/4 in.) of packing of the 2 in. segments was typically needed. This was accomplished mainly with the weight of a 6 in. square $x$ $1 / 16$ in. thick piece of aluminum plate. For the higher density cases, packing was done by gently compressing each of the four segments into the appropriate depth $(2,4,6,8$ in.) using the aluminum plate.

A record was kept of the room humidity and it varied from 40 to $60 \%$ during the period that these tests were performed. However, it was found that up to two weeks is needed for a 6 to 8 in. layer to equilibrate with ambient humidity. This implies that only the top inch or so of the test beds could have been affected by the room humidity during the longest test (24 hours).

The tests themselves are go/no-go in nature. This means that one selects a heat source temperature and holds it until it is clear that ignition has occurred or will not occur. Non-ignition tests can be terminated when the third thermocouple ( 1 1/2 in. from heat source, as mentioned above) ceases to indicate an increasing temperature. In some cases the exposure was continued for a substantially longer time (another 12 hours or so) but this always proved to be unnecessary -- ignition never occurred in these extended exposures. If ignition did not occur for the selected source temperature, the next test (with a new bed of insulation prepared as above) was run with a higher source temperature. How much higher to go was inferred from the previous test behavior at the location of the two thermocouples $1 / 4 \mathrm{in}$. from the source. If these thermocouples came within $\pm 2^{\circ} \mathrm{C}$ of the source temperature, the next test 
temperature was $5^{\circ} \mathrm{C}$ or more higher. The goal is to determine the borderline ignition temperature (as discussed at the beginning of this Section) to within about $5^{\circ} \mathrm{C}$ for each configuration tested. Generally, the position of the borderline was confirmed by performing two tests just above it and two just below.

The gas sampling was done primarily to ascertain if $0_{2}$ depletion appreciably inhibited ignition in any of these deeply buried source cases. Samples were taken at rather wide intervals ( $\sim 1$ hour) during thermal equilibration of the bed and more rapidly when it became clear that ignition was developing.

None of the test cases that gave ignition required more than 9 hours to do so. The thermal equilibration time of the bed is a function of its thicrness and the heat source placement. The equilibration of a 1-D bed is discussed in Appendix 2 where it is shown that the time increases with the square of the bed depth. One can estimate that a 1-D bed, 8 in. deep, wil1 require around ten hours to reach the point of imperceptible $\left(<1^{\circ} \mathrm{C}\right)$ changes. The present 2 or 3-D heat flow cases are not greatly different in this respect.

\section{B. Summary of Test Results}

Table II shows the conditions and results of all tests conducted thus far with the attic mock-up apparatus shown in Fig. 1 and with the 1-D hot plate as discussed in Appendix 2. 'lable III indicates the borderline ignition temperatures only for the various conditions tested.

Variability in Materials and Test Results. Before examining the test results, one should know about the level of precision inherent in the materials and test procedures. All of the materials tested here were obtained 
from a single manufacturer and were produced on the same day. Nevertheless, there are some indications of point to point variation in material properties. Drying tests $\left(24\right.$ hours at $\left.105-110^{\circ} \mathrm{C}\right)$ on $20-25 \mathrm{~g}$. samples gave water contents from 9.2 to $10.9 \%$. Ashing of commercial samples ( 4 hour heating to $660^{\circ} \mathrm{C}$ ) gave residue levels from 20.1 to $21.4 \%$. Perfect homogeneity of material properties is thus not indicated though the property variations are not serious.

The test procedure itself is probably not capable of much better than about $5^{\circ} \mathrm{C}$ resolution of the position of the minimum ignition borderline when more than one operator does the test preparation. This is a judgment based on our experience with the attic mock-up and extensive 1-D flat plate tests as described in Appendix 2. Probably the most crucial point is the inherent slight variation in packing of the test insulation. Fortunately, a $5^{\circ} \mathrm{C}$ uncertainty in ignition temperature does not significantly obscure any of the trends of behavior examined here.

Effect of Retardant. This subject is examined much more extensively in Appendix 2 where boric acid, sulfur and a commercial blend are reported on. Here we performed just two tests with unretarded material (ash content $31 / 2 \%$; obtained from same manufacturer who prepared it by his normal commercial procedure but with emptied retardant hoppers). The results are in good agreement with those in Appendix 2 and confirm the conclusion that retardants in present use manage to raise the smolder ignition temperature only about $20^{\circ} \mathrm{C}$. As discussed in Appendix 2, this appears to be due to the fact that these materials are most effective on the second overall stage of oxidation (i.e., char oxidation) but it is the less-affected first stage of oxidation that yields ignition. 
Effect of Bulk Density. The results here again confirm those in Appendix

2. Here a $20 \%$ increase in bulk density lowers the minimum ignition temperature just enough to be discernible in this test. This will be checked also in future work with another configuration.

The relatively minor effect of bulk density (in this range) is explicable by the model to be discussed below. It should be noted that the flow permeability of the insulation varies rapidly with bulk density. If one were to compress the material sufficiently so as to sharply cut its permeability (and raise its thermal conductivity) some greater effect would be expected. This is not likely to occur in a realistic bulk density range, however.

Effect of Heat Source Configurations. Inspection of Table III indicates that this clearly causes a wider variation in minimum ignition temperature than does any other factor. For the configurations in the Table we have a $150^{\circ} \mathrm{C}$ variation in minimum ignition temperature. The closed geometry of the $90^{\circ}$ corner gives the lowest ignition temperature making it the most hazardous configuration tested. The open geometry of the immersed tubular source gives the highest ignition temperature making it the least hazardous configuration tèsted. It should be noted that further configuration testing is planned but these are not expected to fall outside this ignition temperature range; the additional configurations are intended to assess the impact of 2 and 3-D heat conduction effects on configurations resembling idealized recessed light fixtures.

We believe that these geometry effects are largely intelligible in terms of the heat balance effects on ignition discussed at the beginning of this Section. The model described below is an attempt to rationalize all these trends in this context. 
Other Observations. A possible role as a smolder "retardant" for moisture content in the insulation was discerned in the course of these tests but it has not been confirmed. It was apparent when removing non-ignited test insulation from the mock-up that moisture had shifted from the hotter material to the cooler material. The heat to cause this movement comes from the heat source and the reaction zone next to the heat source. The reaction zone cannot run away to ignition until the conductive heat loss from the reaction zone to the adiacent insulation decreases below the heat generation leve1. The thermal demands of shifting the water out of the hotter $\left(>100^{\circ} \mathrm{C}\right)$ regions of the sample bed may be sufficient to significantly increase the solid reactant consumption near the heat source (see Appendix 2 for a discussion of solid reactant depletion effects). A level of water that causes total depletion of the first oxidation stage reactant near the heat source, leaving char, could raise the ignition temperature $90-100^{\circ} \mathrm{C}$. (Any other material of equal endothermicity at low temperatures would function similarly.)

An initial attempt to produce a very dry insulation for partial testing of this idea was not successful. The lowest relative humidity attainable in our conditioning room was $25 \%$; this lowered the moisture content of the commercial material from about $9 \%$ to about $7 \%$. This appears to be too minor a change to produce discernible results. Some attempts may be made to quantify these ideas and test them in the future.

As was noted previously, oxygen depletion was not found to be a major factor in inhibiting smolder ignition in any of these tests. All of the gas chromatographic analyses have not yet been quantified but it is apparent by inspection that they are consistent with the following. For test 13 in the 
vertical plate configuration (heat source \#1) no smolder occurred $\left(\sim 5^{\circ} \mathrm{C}\right.$ below borderline source temp.). The $0_{2}$ level decayed during the test to a minimum level of about $16-17 \%$ (recall air is $21 \% \mathrm{O}_{2}$ ) then gradually rose to about $19 \%$ by the end of the test. For test 14 in the same series smolder did occur. The $\mathrm{O}_{2}$ lèvel was comparable to test 13 right up until thermal runaway occurred at which point it dropped to about $3 \%$. We infer that $\mathrm{O}_{2}$ depletion does not significantly hinder the development of thermal runaway though it may cause a minor distension of the latter stages of it. The oxidative rate slowdown implicit in an $0_{2}$ level decrease from $21 \%$ to $16-17 \%$ is negligible in the present context, especially since we have found from thermal analysis that the oxidation rate varies with only about the $1 / 2$ power of $\mathrm{O}_{2}$ level.

Fuel depletion effects are not necessarily negligible (see Appendix 2). This is especially true in the case of the $3 / 16$ in. tubular heat source (\#4 in Fig. 1) which yields such a high ignition temperature. Such a source may fully consume all of the first oxidation stage reactant and dissipate the heat without igniting; ignition can then occur with the more energetic but higher temperature char oxidation or a blend of the two. This complicates considerably the task of modeling ignition in this sort of configuration; the model below cannot fully account for these complications.

C. Simplified Model of Smolder Ignition

We wish to model the preceding smolder ignition behavior for two principal reasons: first, if successful, the model confirms our understanding of what is important in this problem; second, if successful, it provides a basis for extrapolating our limited experimental results and for predicting a semi- 
quantitative relation between results in a simplified smolder hazard test and the behavior in actual installations.

Nature of Model. The model we propose here is essentially a generalization of that presented in References 5 and 6 . The model there is for one-dimensional heat flow; here we cover a variety of two-dimensional rectangular geometry cases. The model is based on the energy balance ideas developed above. It seeks to find the highest-source-temperature, steady-state temperature profile which can exist in the presence of the exothermic oxidation of the fuel bed. That is, it finds the ignition borderline by approaching it from below so that the mathematical simplifications of a steady-state solution can be employed. As was just pointed out, time dependent fuel depletion occurs in all near-ignition conditions so that the real system is never in a steady-state. It is quasisteady for all conditions of interest, however, since the rate of fuel depletion is relatively small on the time scale of ignition. The effects of fuel depletion can be estimated after-the-fact using the steady-state model as in Appendix 2 .

The model we are considering can be expressed simply as the following,

$$
\nabla \cdot(\lambda(\mathrm{T}) \nabla \mathrm{T})=-\mathrm{Q} Z \exp (-\mathrm{E} / \mathrm{RT})
$$

with the general boundary conditions

$$
\left.\begin{array}{rl}
T & =T_{p}=\text { constant } \\
-\lambda \frac{\partial T}{\partial x} & =h_{\text {eff }}\left(T-T_{s}\right)
\end{array}\right\} \quad \begin{aligned}
& \text { on part or all of } \\
& \text { each of four rectangular } \\
& \text { boundaries }
\end{aligned}
$$

llere

$$
\begin{aligned}
& \nabla=i \frac{\partial}{\partial x}+j \frac{\partial}{\partial y} \\
& T=\text { temperature } \\
& \lambda=\text { thermal conductivity of insulation bed }
\end{aligned}
$$


$Q=$ hcat release/gram of fuel reacted

$Z=$ pre-exponential factor

$E=$ activation energy

$R=$ universal gas constant

$\mathrm{T}_{\mathrm{p}}=$ imposed constant wall temperature

$h_{\text {eff }}=$ effective heat transfer coefficient over a given boundary

In generalizing from References 4 and 5 we have made certain changes that can be accommodated because the temperature is solved for by computer. The thermal conductivity of the hed of insulation is allowed to vary with trmperature (using data from Ref. 7). The chemical reaction term is not simplified by means of the Zeldovich-Frank-Kamenetskii approximation. The boundary conditions are fairly general permitting a mix of an imposed temperature along part of any bed boundary and convective loss (or adiabaticity) along the remainder. On the other hand, we retain the key assumption of a zcro order reaction (no depletion effects) since it removes the need to couple in specics equations.

From the thermal analytical results of Section II, in particular the DSC results, we have the kinetics of heat release in the form

$$
\frac{\mathrm{d} \varepsilon}{\mathrm{dt}}=\mathrm{Qk}(1-\varepsilon)^{\mathrm{n}}
$$

for the first overall stage and for the second stage of oxidation of the commercial cellulosic insulation; the kinetic parameters are different for each stage. Here $\varepsilon$ is the fraction reacted, $n$ is the reartinn nrier with respect to the fuel and $k$ is a composite Arrhenius factor, i.e.,

$$
k=Z \cdot A_{v} C_{O x}^{m} \exp (-E / R T)
$$


where $Z^{\prime}$ is the true effective frequency factor for the oxidation, $A_{V}$ is the available reactive surface area per unit bed volume and $\mathrm{C}_{\mathrm{Ox}}$ is the oxygen concentration at the fuel surface. In incorporating this into the above model we in effect say that

$$
Z \equiv\left[Z, A_{v} C_{0 x}^{m} \rho_{b u l k}(1-\varepsilon)^{n}\right] \simeq \text { constant }
$$

i.e., this is where the no depletion assumption enters. We have demonstrated experimentally that $\mathrm{C}_{0 \mathrm{x}}$ does not change appreciably; we can explore the effects of fuel depletion by inserting various fixed values of $\varepsilon$ as in Appendix 2 .

An important element of the model developed in References 4 and 5 was the extraction of an analytical expression for the conditions of criticality (i.e., borderline ignition). This took the form of a dimensionless parameter $\delta$ whose critical value was dependent only on two other dimensionless heat loss parameters $\alpha$ and $\theta_{0}$, i.e.,

$$
\delta_{\text {crit }}=F\left(\alpha, \theta_{0}\right)
$$

where

$$
\begin{aligned}
& \delta=\left(\frac{Q Z E l^{2}}{4 \lambda R_{p}^{2}}\right) \exp \left(-E / R T_{p}\right) \\
& a=(1, \ell / 2 \lambda) \\
& \theta_{0}=\left(E / R_{p}^{2}\right)\left(T_{A}-T_{p}\right)
\end{aligned}
$$

The entire problem, in this $1-D$ case, could be reduced to a single graph showing the dependence of $\delta_{c}$ on $\alpha$ and $\theta_{0}$.

Here we cannot solve the general problem posed above in analytical form. The problem could be posed in analogous non-dimensional form again yielding 
a $\delta$; however, this parameter's critical value would now be dependent on a substantially larger number of dimensionless parameters and we would gain little. We choose to retain the dimensional form of the equations with their greater intuitive meaning.

In dimensional form, our goal is to find the maximum value of $T_{p}$ (for fixed values of the other parameters) that just permits the steady-state solution to exist. We are forced to approach this goal in a manner wholly analogous to the actual experiments, i.e., go/no-go tests on the computer. Fortunately, this can be done much more cheaply and quickly on the computer.

Model solution. The oquation for $\mathrm{T}$ above is non-linear both because of $\lambda(\mathrm{T})$ and because of the reaction term on the right hand side. When the equation is quasi-linearized and the derivative terms are replaced by central differences, it becomes

$$
\begin{aligned}
& T_{i+1, j}^{k+1}\left[\lambda^{k}+\left(\frac{b}{2}\right)\left(T_{i+1, j}^{k}-T_{i-1, j}^{k}\right)\right]+T_{i=1, j}^{k+1}\left[\lambda^{k}-\left(\frac{b}{2}\right)\left(T_{i+1, j}^{k}-T_{i-1, j}^{k}\right)\right] \\
& \quad+T_{i, j+1}^{k+1}\left[\lambda^{k}+\left(\frac{b}{2}\right)\left(T_{1, j+1}^{k}-T_{1, j-1}^{k}\right)\right]+T_{i, j-1}^{k+1}\left[\lambda^{k}-\left(\frac{b}{2}\right)\left(T_{1, j+1}^{k}-T_{1, j-1}^{k}\right)\right] \\
& \quad+T_{i j}^{k+1}\left[-4 \lambda^{k}+Q \underline{z} \oint^{2} \exp \left(-E / R T_{i j}^{k}\right)\left(E / R\left(T_{i j}^{k}\right)^{2}\right)\right] \\
& =\left(-Q z \delta^{2} \exp \left(-L / R T_{i j}^{k}\right)\left[1=\left(E / R\left(T_{i j}^{k}\right)^{2}\right) T_{i j}^{k}\right]\right. \\
& \left.\quad+\left(\frac{b}{4}\right)\left(T_{1+1, j}^{k}-T_{i-1, j}^{k}\right)^{2}+\left(T_{i, j 1 i}^{k}-T_{1, j=1}^{k}\right)^{2}\right)
\end{aligned}
$$

Here $\delta$ is the space step size, the same in the $x$ and $y$ directions. The subcript $i$ refers to the $i^{\text {th }}$ node in the $x$ direction; $j$ refers to the $j^{\text {th }}$ node in the $y$ direction. The superscript $k$ is an iteration counter, the constant $b$ is from the relation

$$
\lambda\left(\mathrm{I}^{\prime}\right) \equiv a+b \mathrm{~b}
$$


The above equation is solved for $\mathrm{T}_{i, j}$ at each interior point by repeated application of the successive over-relaxation algorithm (SOR, see Ref. 8):

$$
\begin{aligned}
T_{i j}^{k+1} & =(1-\omega) T_{i j}^{k}+\left(\frac{\omega}{\alpha_{0}}\right)\left[\alpha_{1} T_{i+1, j}^{k}+\alpha_{2} T_{i-1, j}^{k+1}+\alpha_{3} T_{i, j+1}^{k}\right. \\
& \left.+\alpha_{4} T_{i, j-1}^{k+1}-g_{i j}^{k}\right]
\end{aligned}
$$

here $\omega$ is the over-relaxation parameter whose optimum value is in the range $1 \leq \omega \leq 2$

And

$$
\begin{aligned}
& \alpha_{1}=\left[\lambda^{k}+\left(\frac{b}{2}\right)\left(T_{i+1, j}^{k}-T_{i-1, j}^{k}\right)\right] \\
& \alpha_{2}=\left[\lambda^{k}-\left(\frac{b}{2}\right)\left(T_{i+1, j}^{k}-T_{i-1, j}^{k}\right)\right] \\
& \alpha_{3}=\left[\lambda^{k}+\left(\frac{b}{2}\right)\left(T_{i, j+1}^{k}-T_{i, j-1}^{k}\right)\right] \\
& \alpha_{4}=\left[\lambda^{k}-\left(\frac{b}{2}\right)\left(T_{i, j+1}^{k}-T_{i, j-1}^{k}\right)\right] \\
& \alpha_{0}=\left[4 \lambda^{k}-Q Z \delta^{2} \exp \left(-E / R T_{i j}^{k}\right)\left(E / R\left(T_{i j}^{k}\right)^{2}\right)\right] \\
& g_{i j}=-Q Z \delta^{2} \exp \left(-E / R T_{i j}^{k}\right)\left[1-\left(E / R\left(T_{i j}^{k}\right)^{2}\right) T_{i j}^{k}\right] \\
&\left.+\left(\frac{b}{4}\right)\left(T_{i+1, j}^{k}-T_{i-1, j}^{k}\right)^{2}+\left(T_{i, j+1}^{k}-T_{i, j-1}^{k}\right)^{2}\right)
\end{aligned}
$$

The computer program that solves for $\mathrm{T}_{i j}^{\mathrm{k}+1}$ is complete and available but has not yet been applied to cases analogous to the preceding experiments. A given case costs about five dollars on an IBM 3033.

The adequacy of the above model for achieving the modeling goals set out above has not yet been tested. However, Appendix 2 shows that in the 1-D case such a model is generally quite good. Reference 9 shows that a somewhat 
simpler 2-D model was reasonably successful, especially in revealing the behavioral trends, when the important geometric parameters of the problem are varied. 
IV. CONCLUSIONS

The present work is not yet complete so it is not possible to fully interpret the results. However, the work to date largely confirms the various trends discerned in the work reported in the Appendices. We restate and amplify the conclusions reported there.

Smolder ignition is more dependent on heat flow geometry than any other variable. In the present work we have shown that the same commercial cellulosic insulation material exhibits minimum ignition temperatures that vary over a $150^{\circ} \mathrm{C}$ range, depending on the size and placement of the ignition heat source. No other factor comes close to this in its impact on ignitability. In particular, present day smolder retardants only succeed in raising the minimum smolder ignition temperature by about $20^{\circ} \mathrm{C}$ above that of the base cellulosic material. We infer that there is a substantial need for more effective ignition retardants. Differential scanning calorimetry (DSC) shows excellent potential as a scrcening device for candidate retardants. Using techniques discussed in Appendix 3, one can quantify these DSC results and employ them in an ignition model such as that developed here to predict minimum ignition temperature.

Smolder ignitability, as measured by the go/no-go type of test used here, is not highly sensitive to such experimental variables as insulation packing density, conductivity, minor cross-flow currents, etc. (Keasonable care is certainly required in controlling these factors of course.) This type of ignition measurement thus has reasonable potential as a basis for smolder ignition hazard testing. One would have to settle on a single geometry and set of conditions (e.g., 1-D heat flow on a flat plate heat source with a fixed layer thickness such as $5 \mathrm{~cm}$ and a nominal settled 
density).. A classification scheme could then be developed, e.g., Class A material does not ignite in this test below $\mathrm{T}^{\circ} \mathrm{C}$; Class $\mathrm{B}$ material ignites in the range from $\mathrm{T}$ to $(\mathrm{T}-20)^{\circ} \mathrm{C}$; Class $\mathrm{C}$ material ignites below $(\mathrm{T}-20)^{\circ} \mathrm{C}$. The value of $\mathrm{T}$ depends on the particular test configuration adopted. It is clearly important to know the relation between such test results and actual installed insulation performance. When the present work is complete, a first approximation to this relation should be available.

It should be noted that the test suggested above is for resistance to smolder ignition. Resistance to smolder propagation need not he in tirert proportion to ignition resistance since a different balance of chemical and physical processes is at play. Only a small amount of work has heen dnne on propagation as yet; this is summarized in Appendix 2. Further work is planned in this area. Still another important area, hardly touched upon at present, is the propensity of smolder in insulation applications to transition into flaming; this remains for future examination.

\footnotetext{
* A thinner layer means a quicker test but the extrapolation to real conditions is greater.
} 


\section{REFERENCES}

1. Center for Energy Policy and Research, New York Institute of Technology 01d Westbury, Long Island; study reported in the New York Times, November $10,1977$.

2. J. Zicherman and F. Fisher, "Fire Protection Problems Associated with Cellulose Based Insulation Products", Society of Fire Prevention Engineers Technology Report 78-7, Boston Mass., 1978.

3. L. Issen, Center for Fire Research, National Bureau of Standards, personal communication.

4. D. Yarborough, K. Yoo and P. Koneou, "Recessed Light Fixture Test Facility", Oak Ridge National Laboratory Report ORNL/SUB-7504/3, July, 1979.

5. P. Bowes and S. Townshend, "Ignition of Combustible Dusts on Hot Surfaces", Brit. Journal of Applied Physics, 13, 1962, p. 105.

6. P. Thomas and P. Bowes, "Thermal Ignition in a Slab with One Face at a Constant High Temperature", Trans. Farad Soc., 57, Part II, November 1962, p. 2007.

7. R. Tye, "Heat Transmission in Cellulosic Fiber Insulation Materials", J. of Tcsting and Evaluation, 2, No. 3, 1974, p. 176.

8. W. Ames, Nonlinear Partial Differential Equations in Engineering, Academic Press, New Yurk, 1965, p. 378.

9. T. Ohlemiller and F. Rogers, "Smoldering Combustion Studies of Rigid Cellular Plastics", Princeton University, Department of Mechanical and Aerospace Engineering Report No. 1432, May, 1979. 

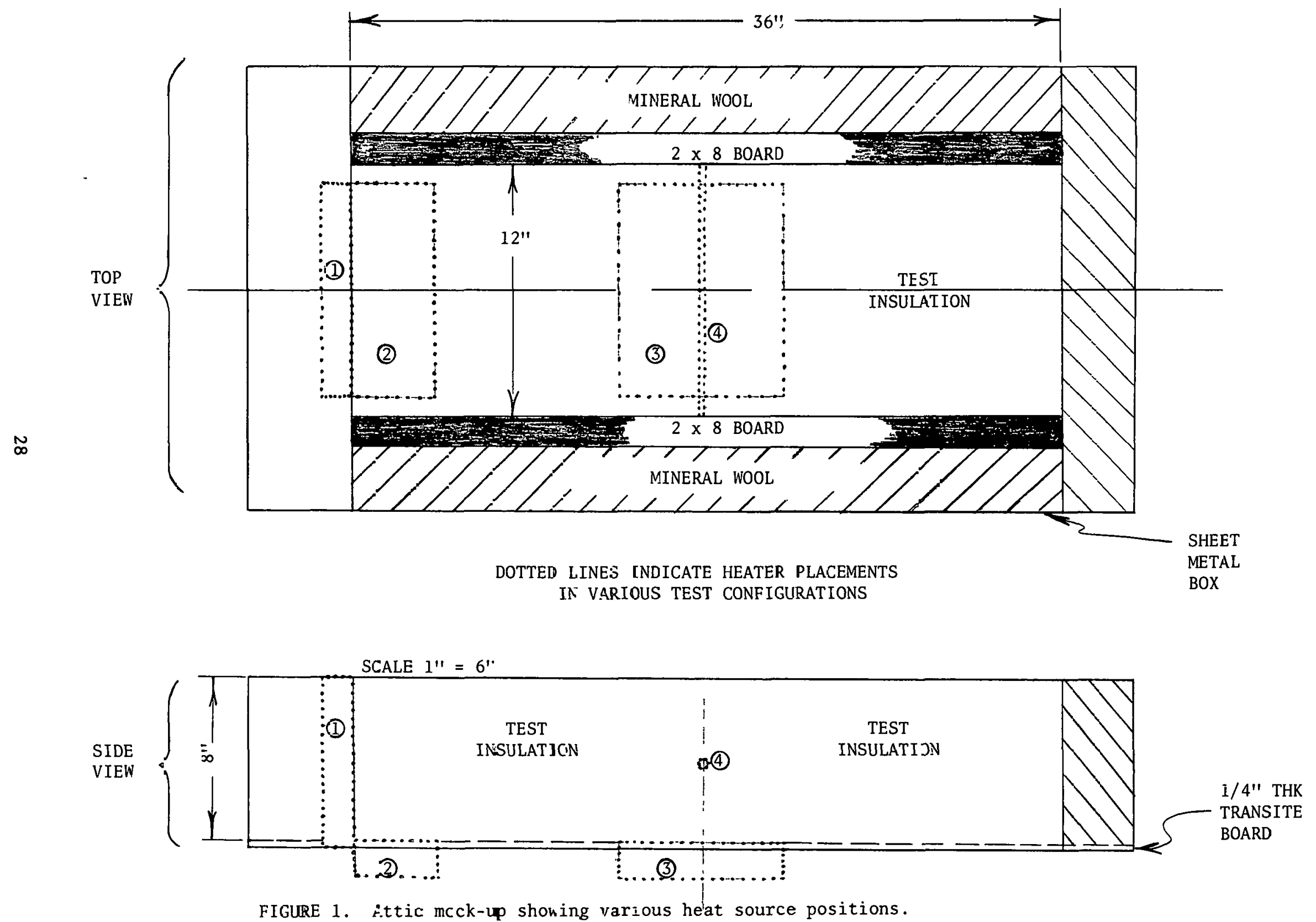
TABLE II

SUMMARY OF SMOLDER IGNITION TEST RESULTS FOR A SINGLE COMMERICAL CELLULOSIC INSULATION

\begin{tabular}{|c|c|c|c|c|c|c|c|c|c|}
\hline \# & CONFIGURATION & $\begin{array}{l}\text { INSULATION } \\
\text { MATERIAL }\end{array}$ & $\begin{array}{l}\text { BULK DENSITY } \\
\rho_{\mathrm{B}}\left(1 \mathrm{~b} / \mathrm{ft}^{3}\right)\end{array}$ & DEPTH (in) & $\begin{array}{l}\text { HEAT SOURCE } \\
\text { TEMPERATURE } \\
\mathrm{T}_{\mathrm{p}}\left({ }^{\circ} \mathrm{C}\right)\end{array}$ & $\begin{array}{l}\text { SMOLDER } \\
(?)\end{array}$ & $\begin{array}{l}\text { TIME TO } \\
\text { MATCH T } p\end{array}$ & $\begin{array}{l}(\text { TIME) TO } \\
5^{\circ}>\mathrm{T}_{\mathrm{p}}\end{array}$ & COMMENT \\
\hline 1 & $\begin{array}{l}\text { VERT ICAL } \\
\text { PLATE }\end{array}$ & $\begin{array}{l}\text { COMMERICAL } \\
\text { BLEND }\end{array}$ & $\leq 2.6$ & 8 & Variea & YES & & & $\begin{array}{l}\text { UNMILLED MAT'L } \\
\text { NO MINERAL WOOL }\end{array}$ \\
\hline 2 & 11 & $"$ & 2.6 & 8 & $\begin{array}{l}205 \\
250\end{array}$ & NO & & & $\begin{array}{l}\text { PLATE TEMP. CHK; } \\
\text { BED } T(x, y) \text { MEAS 'D }\end{array}$ \\
\hline 3 & $"$ & UNPETARDED & 2.6 & 8 & 251 & NO & $\begin{array}{l}\mathrm{TC} 120 * * \\
<\mathrm{T}_{\mathrm{p}}\end{array}$ & - & $\begin{array}{l}\text { SOME T }(x, y) \\
\text { MEAS ' } D\end{array}$ \\
\hline 4 & $"$ & $"$ & 2.6 & 8 & 261 & YES & $1 \mathrm{~h} 55 \mathrm{~m}$ & $40 \mathrm{~m}$ & $\begin{array}{l}\text { SMOL. CONSUMED ALL } \\
\text { BED, SCORCHED WOOD }\end{array}$ \\
\hline 5 & $"$ & $\begin{array}{l}\text { COMMERCIAL } \\
\text { BLEND }\end{array}$ & 2.73 & $71 / 2$ & 282 & YES & $1 \mathrm{~h} 40 \mathrm{~m}$ & $24 \mathrm{~m}$ & $\begin{array}{l}\text { SMOL. CONSUMED ALL } \\
\text { OF BED: < SCORCHED } \\
\text { WOOD }\end{array}$ \\
\hline 6 & $"$ & $"$ & 2.73 & $71 / 2$ & $\begin{array}{l}272- \\
273\end{array}$ & NO & $\begin{array}{l}\mathrm{TC} 13^{\circ} \\
<\mathrm{T}_{\mathrm{p}}\end{array}$ & & $2 \times 8$ PLANKS NEW \\
\hline 7 & $"$ & $"$ & $\leqslant 2.73$ & $\leq 8$ & 272 & NO & $\mathrm{TCl}=\mathrm{T}_{\mathrm{p}}$ & & $\begin{array}{l}\text { TOTAL EXPOS } 12 \mathrm{~h} \\
20 \mathrm{~min} ; 43 \mathrm{~g} \text { MORE } \\
\text { FUEL ON TOP }\end{array}$ \\
\hline 8 & $" 1$ & $"$ & $\leq 2.73$ & $8-\leq 1 / 4^{\prime \prime}$ & $\begin{array}{l}276- \\
277\end{array}$ & YES & $2 \mathrm{~h} 0 \mathrm{~m}$ & $50 \mathrm{~m}$ & $\begin{array}{l}\text { ADDN'L } 4 \mathrm{~g} \text { FUEL } \\
\text { ON TOP }\end{array}$ \\
\hline 9 & $" 1$ & $"$ & $\therefore 2.76$ & $\geq 8$ & 277 & YES & $<2 h$ & & $\begin{array}{l}\text { AGAIN ANOTHER } 4 \mathrm{~g} \\
\text { MORE FUEL ON TOP }\end{array}$ \\
\hline 10 & $"$ & $" 1$ & $\geq 2.73$ & $\leq 8$ & 271 & No & $\underset{\mathrm{p}}{\mathrm{TC} 12^{\circ}}$ & & $\begin{array}{l}\text { TOTAL EXPOS. } 22 \mathrm{~h} \\
46 \mathrm{~m}\end{array}$ \\
\hline
\end{tabular}

** TCl and TC2 are thermocouples $\sim 1 / 4^{\prime \prime}$ from heat source. TC3 is thermocouple $\simeq 11 / 2 "$ from heat source. 
TABLE II (continued)

\begin{tabular}{|c|c|c|c|c|c|c|c|c|c|}
\hline$\#$ & CONFI GURATION & $\begin{array}{l}\text { INSULATION } \\
\text { MATERIAL }\end{array}$ & $\begin{array}{l}\text { BJLK DENSITY } \\
P_{B}\left(1 b / f \tau^{3}\right)\end{array}$ & DEPTH (in) & $\begin{array}{c}\text { HEAT SOURCE } \\
\text { TEMPERATURE } \\
T_{p}\left({ }^{\circ} \mathrm{C}\right)\end{array}$ & $\begin{array}{l}\text { SMOLDER } \\
(?)\end{array}$ & $\begin{array}{l}\text { TIME TO } \\
\text { MATCH T }\end{array}$ & $\begin{array}{c}(\mathrm{TIME}) \mathrm{TO} \\
5^{\circ}>\mathrm{T}_{\mathrm{p}}\end{array}$ & COMMENT \\
\hline 11 & $\begin{array}{l}\text { VERT LCA.L } \\
\text { PLATE }\end{array}$ & $\begin{array}{c}\text { COMMERCIAL } \\
\text { BLENE }\end{array}$ & 3.30 & 8 & $\begin{array}{l}271^{-} \\
272\end{array}$ & YES & $2 \mathrm{~h} 1 \mathrm{C} \mathrm{m}$ & $55 \mathrm{~m}$ & $\begin{array}{l}\text { ANOTHER } 50 \mathrm{~m} \text { TO } \\
\text { TOTAL RUN AWAY }\end{array}$ \\
\hline $12^{*}$ & ' & $"$ & 3.30 & 8 & 266 & NO & $T C 1=T_{p}$ & & $\begin{array}{l}\text { TOTAL EXPOS. } \\
1 \mathrm{~h} 45 \mathrm{~m}\end{array}$ \\
\hline $13^{*}$ & $\cdot$ & $"$ & $\sim 3.39$ & $7-7 / 8$ & 271 & NO & $\underset{>\mathrm{T}_{\mathrm{F}}^{\mathrm{TCl}}}{\mathrm{T}^{\circ}}$ & & $\begin{array}{l}\text { TOTAL EXPOS = } \\
8 \mathrm{~h} 0 \mathrm{~m}\end{array}$ \\
\hline $14^{*}$ & $"$ & $"$ & 3.30 & 8 & $\begin{array}{l}274- \\
275\end{array}$ & YES & $1 \mathrm{~h} 55 \mathrm{~m}$ & $127 \mathrm{~m}$ & $\begin{array}{l}12 \mathrm{~m} \text { LATER TC } 3 \\
\text { TOOK OFF }\end{array}$ \\
\hline $15^{*}$ & י & $"$ & 3.30 & 8 & 275 & YES & $\operatorname{lh} 55 \mathrm{~m}$ & $85 \mathrm{~m}$ & $\begin{array}{l}23 \mathrm{~m} \text { LATER TC } 3 \\
\text { TOOK OFF }\end{array}$ \\
\hline 16 & 1 & $"$ & 3.30 & 8 & $\geq 271$ & NO & $\begin{array}{l}\mathrm{TC} 1 \leq- \\
20>-\mathrm{p}\end{array}$ & & $\begin{array}{l}\text { TOTAL EXPOS. = } \\
221 / 2 \mathrm{~h}\end{array}$ \\
\hline $17^{\star}$ & $"$ & $"$ & 2.76 & $\leq 8$ & $\geq 275$ & No & $\left.{ }^{\mathrm{TC} 1} \mathrm{~T}_{\mathrm{p}}\right]^{\circ}$ & & TOTAL EXPOS. $=6 \mathrm{~h}$ \\
\hline 18 & $"$ & $"$ & & 8 & 276 & NO & $\begin{array}{c}\mathrm{TCl}^{-\infty} \mathrm{\tau}^{-\infty} \\
>\mathrm{T}_{\mathrm{F}}\end{array}$ & & $\begin{array}{l}\text { TOTAL EXPOS. = } \\
6 \mathrm{~h} 35 \mathrm{~m}\end{array}$ \\
\hline
\end{tabular}

* Gas Samples Obtained. 


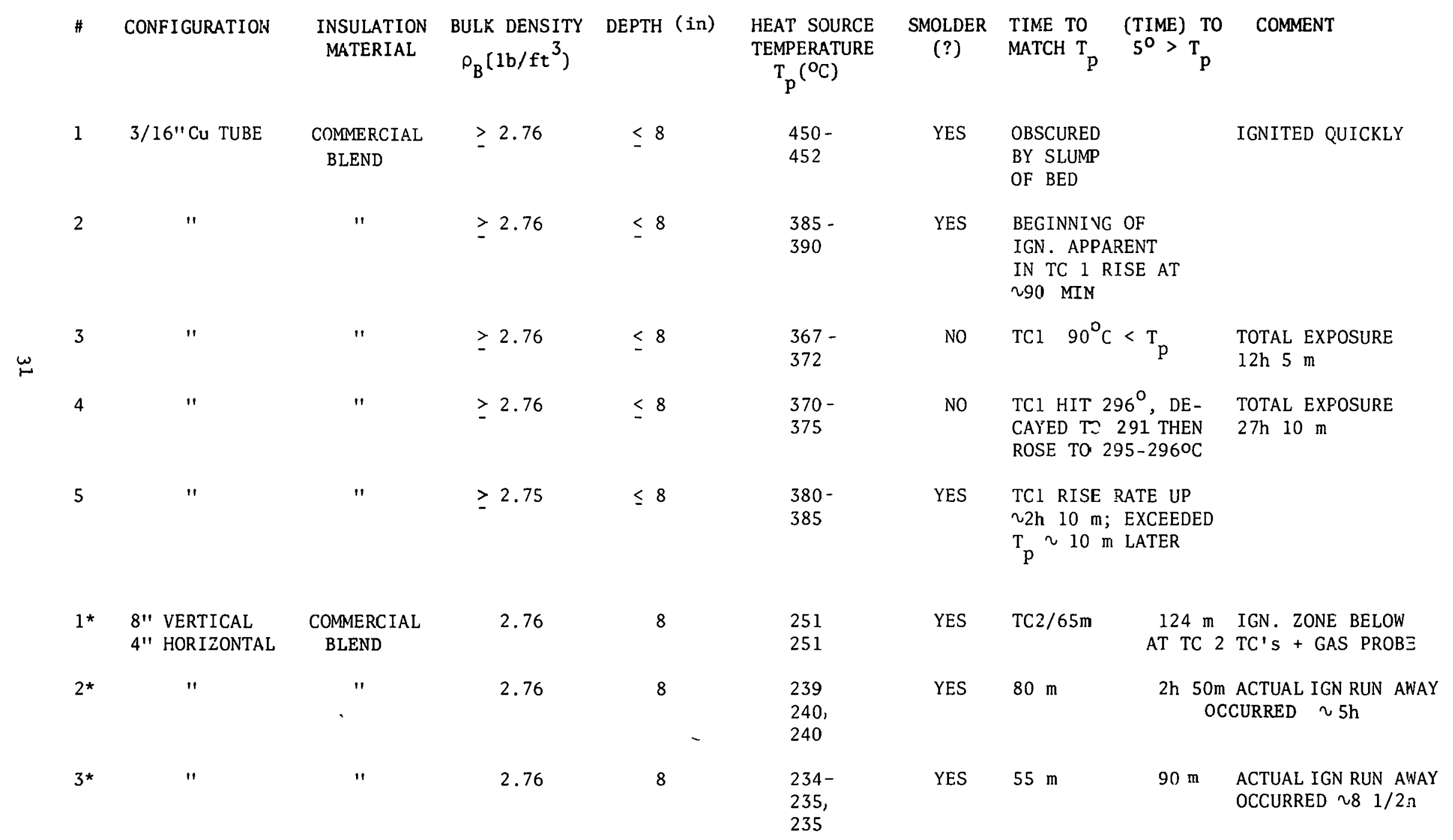

* GAS SAMPLES OBTAINED 
\# CONFIGURATION

$\begin{array}{cc}\begin{array}{c}\text { INSSULATION } \\ \text { MATERIAL }\end{array} & \text { BJLK DENSITY DEPTH (in) } \\ & { }_{B}\left(1 \mathrm{~b} / \mathrm{ft}^{3}\right)\end{array}$

HEAT SOURCE TEMPERATURE

$\mathrm{T}_{\mathrm{p}}\left({ }^{\circ} \mathrm{C}\right)$

4* 8" VERTICAL 4" HOR-ZCNTAL

COFMERCIAL BLEND
2.76

$"$

2.76

8

2.76

8

8

11

$18 \times 10$ HORIZ. UNDER 8" LAYER

2

3

4

5
"

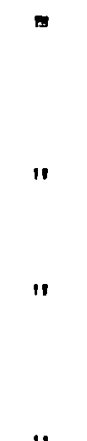

r
2.76

2.76

2.76

2.76

$>2.76$ $\begin{array}{clcc}\text { SMOLDER } & \text { TIME TO } & \text { (TIME) TO } & \text { COMMENT } \\ \text { (?) } & \text { MATCH T } & 5^{\circ}>T_{p} & \end{array}$

NO $85 \mathrm{~m}$

TC3 HIT $224^{\circ} \mathrm{C}$ AT $3 \mathrm{~h} 55 \mathrm{~m}$ AND IT HELD IT TO END AT $23 \mathrm{~h} 10 \mathrm{~m}$

NO $\quad 85 \mathrm{~m}$
TC3 HIT $241^{\circ} \mathrm{C}$ AT $7 \mathrm{~h} 55 \mathrm{~m}$ DOWN TO $235^{\circ} \mathrm{C}$ AT $23 \mathrm{~h} 11 \mathrm{~m}$

YES $\quad 90 \mathrm{~m}$

$2 \mathrm{~h} 20 \mathrm{~m}$ ACTUAL IGN RUN AWAY OCCURRED $\sim 61 / 2 \mathrm{~h}$

NO $3 \mathrm{~h} 25 \mathrm{~m}$

TC2 $1{ }^{\circ} \mathrm{C}$ HOTTER THAN PLATE DOWN TO 10 LESS AFTER $23 \mathrm{~h}$ $45 \mathrm{~m}$

YES $\quad$ 105 $\mathrm{m} \quad$ TC 3 AT

SLOW TAKE OFF THEN FAST OVER NEXT $11 / 2 \mathrm{~h}$

YES $>165 \mathrm{~m}$ TC3 AT SLOW RUN AWAY $7 \mathrm{~h} 15 \mathrm{~m}$ OVER NEXT $1 / 2 \mathrm{~h}$

No

$\leq 120 \mathrm{~m} \quad \mathrm{TC} 1 \rightarrow 253 ; \mathrm{TC} 3 \rightarrow 252^{\circ} \mathrm{C}$ BUT DROPPED TO $246^{\circ} \mathrm{C}$ BY $22 \mathrm{~h} 22 \mathrm{~m}$

NO

$195 \mathrm{~m}$
$\mathrm{TCl} \rightarrow 251^{\circ} \mathrm{C} ; \mathrm{TC} 3 \rightarrow 249^{\circ} \mathrm{C}$ DOWN TO $245^{\circ} \mathrm{C}$ BY $22 \mathrm{~h} 26 \mathrm{~m}$ 
TABLE II (continued)

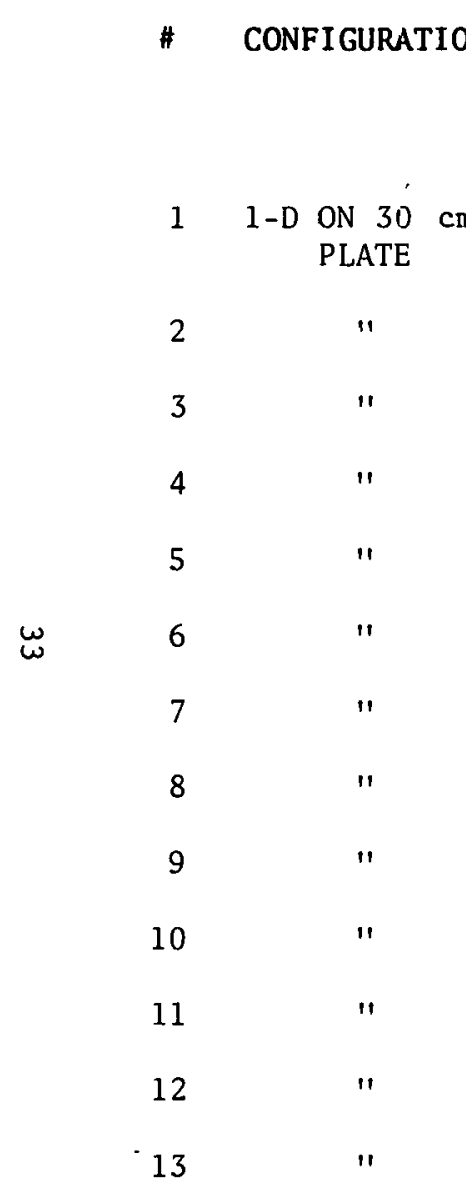

INSULATION BULK DENSITY DEPTH (in)
MATERIAL $\rho_{B}\left(1 b / \mathrm{ft}^{3}\right)$

COMMERCIAL
BLEND

2.79

2.79

2.79

2.79

2.79

2.79

2.79

2.79

2.79

2.79

2.79

2.79

2.79
HEAT SOURCE TEMPERATURE $\mathrm{T}_{\mathrm{p}}\left({ }^{\mathrm{O}} \mathrm{C}\right)$

$5 \mathrm{~cm}$

300

$5 \mathrm{~cm}$

$5 \mathrm{~cm}$

$5 \mathrm{~cm}$

$5 \mathrm{~cm}$

$5 \mathrm{~cm}$

$5 \mathrm{~cm}$

$7 \mathrm{~cm}$

$7 \mathrm{~cm}$

$7 \mathrm{~cm}$

$7 \mathrm{~cm}$

$7 \mathrm{~cm}$

$4 \mathrm{~cm}$
SMOLDER TIME TO (TIME) TO COMMENT (?) MATCH $T_{p} \quad 5^{\circ}>T_{p}$

PEAK TC TEMP $=297^{\circ} \mathrm{C}$

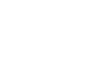


BORDERLINE (MINIMUM) IGNITION TEMPERATURES FOR A COMMERCIAL CELLULOSIC INSULATION IN VARIOUS CONFIGURATIONS

\begin{tabular}{|c|c|c|}
\hline $\begin{array}{l}\text { HEAT } \\
\text { SOURCE }\end{array}$ & $\begin{array}{l}\text { INSULATION BULK } \\
\text { DENSITY }\left(1 \mathrm{~b} / \mathrm{ft}^{3}\right)\end{array}$ & $\begin{array}{l}\text { BORDERLINE IGNITION } \\
\text { TEMPERATURE }\left({ }^{\circ} \mathrm{C}\right)\end{array}$ \\
\hline$\# 1$; vertical plate & $2.6 ;$ unretarded $^{2}$ & ca. 255 \\
\hline$\# 1$; vertical plate & 2.73 & $\gtrsim 277$ \\
\hline$\# 1$; vortical plato & 3.3 & $272-274$ \\
\hline$\# 4 ; 3 / 16$ in. tube & 2.76 & $380-385^{3}$ \\
\hline$\# 1+\# 2 ; 90^{\circ}$ corner & 2.76 & 235 \\
\hline $\begin{array}{l}\# 3 ; 8 " \times 10^{\prime \prime} \text { plate } \\
\text { on floor }\end{array}$ & 2.76 & 255 \\
\hline 1-D flat plate, $5 \mathrm{~cm}$ & 2.76 & 300 \\
\hline 1-D flat plate, $7 \mathrm{~cm}$ & 2.76 & $285=286$ \\
\hline
\end{tabular}

1 Heat source numbers refer to $\bar{F}$ igure 1.

2 This is the only condition run with unretarded insulation in this test series; see' also Appendix 2.

3 This source oscillated over this range with a perind of a few minutes because of an unavoidably large power to thermal mass ratio. 


\title{
APPENDIX I
}

\author{
CELLULOSIC INSULATION MATERIAL. \\ I. OVERALL DEGRADATION KINETICS AND THERMOCHEMISTRY* \\ F. E. Rogers and T. J. Ohlemiller \\ Mechanical and Aerospace Engineering Department \\ Princeton University, Princeton, NJ 08544
}

ABSTRACT

Kinetic studies on the thermal and oxidative decomposition of untreated cellulosic insulation have been carried out with thermal analytical techniques (TGA and DSC). In dry nitrogen the weight loss proceeds in one overall, diffusion-controlled step with the activation parameters: $A=1.1 x^{\prime} 10^{13} m n^{-1}$ and $E=39 \mathrm{kcal} / \mathrm{mol}$. In air the decomposition proceeds in two overall steps, the first of which consumes ca $65 \%$ of the starting material in a diffusion-controlled process and has the activation parameters $A=7 \times 10^{14} \mathrm{~min}^{-1}, E=41.5 \mathrm{kcal} / \mathrm{mol}$. TGA experiments have shown the first oxidative step to be 0.43 order in oxygen mass fraction in the range of $Y_{O X}=0.0147$ to 0.21 . The second oxidation step follows a 3-D diffusion controlled mechanism and has the activation parameters: $A=4 \times 10^{10} \mathrm{~min}^{-1}$, and $E=39 \mathrm{kcal} / \mathrm{mol}$. Heats of thermal and oxidative decomposition have been determined with the differential scanning calorimeter and some aspects of the mechanisms of these reactions are presented. It is proposed that the heat of pyrolysis is largely expla1ned by the introduction of ring strain in the initial pyrolysis product, levoglucosan.

\section{INTRODUCTION}

Cellulosic materials have attracted considerable attention recently for their roles both in energy production and conservation. In the former case, cellulosics are a potentially incxhaustible source of synthetic fuel. vi.a pyrolytic conversion to gaseous and/or liquid fuels [Antal et al, 1979]. In

\footnotetext{
*Work supported by the National Bureau of Standards (Grant 4-9026) and by the Department of Energy (ORNL/SUB-7686).
} 
the latter case, the efficacy and favorable cost of shredded cellulosic materials, principally waste paper, has made their use as insulation attractive for commercial and residential buildings [Anon, 1977]. This dual use has prompted renewed interest in the pyrolytic (inert atmosphere) and oxidative behavior of cellulosics, a knowledge of which is required for safe and effective use in both application areas.

In a previous publication we reviewed the relevant literature on pure cellulose pyrolysis and presented the experimental results of a kinctic otudy on the pyrolysis of Whatman filter paper in steam and nitrogen. Impurities in cellulose are known to have a profound effect on its decomposition mechanism and kinetics. Here we examined milled (homogenized) waste paper (. $99 \%$ newsprint)--a material common to municipal waste and lonse-fill, insulation. We have focused on several aspects. First, we have compared the pyrolysis kinetics in nitrogen of this homogenized waste paper with those derived previously for Whatman filter paper [Antal et al, 19791. Sinne the same experimental procedures were used for both Whatman paper and waste paper, the results are free of those procedural variables that make comparison of data Irom difterent sources difficult, if possible at all. Second, we have derived kinetics of the oxidation and used them in a model to predict the ignition temperature for smoldering combustion (Appendix II). Fina11y, we have proposed an oxidation mechanism which may provide some insights into the smoldering combustion process in cellulosic insulation.

It is well known that oxygen enhances the decomposition of cellulosic materials [Shafizadeh, 1968]. The kinetics of the decomposition of cellulosics in nitrogen have recently been reviewed [Antal et al, 1979] so we herein present only a brief survey of the decomposition kinetics in air. For paper varying in composition from $100 \%$ rag to $100 \%$ sulfite, a low temperature (60 - 
$120^{\circ} \mathrm{C}$ ) study reported first order kinetics and a relatively constant activation energy in the range $19.1-19.9 \mathrm{kcal} / \mathrm{mol}$; the $100 \%$ sulfite paper was about 12 times more reactive than the $100 \% \mathrm{rag}$ paper at $150^{\circ} \mathrm{C}$ [Stamm, 1956]. The oxidative decomposition of $\alpha$-cellulose cylinders described by a first order rate law, gave $E=14$ to $22 \mathrm{kcal} / \mathrm{mol}$ and $A=10^{4}$ to $10^{7} \mathrm{sec}^{-1}$; the cylinder interior giving the lower activation energy [Murty et al, 1966]. From work on the self-ignition of sawdust heated in a uniform temperature field of an electric furnace, first order kinetics were reported with $E=26.1 \mathrm{kcal} / \mathrm{mol}$ and $A\left(225^{\circ} \mathrm{C}\right)=4.45 \times 10^{7} \mathrm{sec}^{-1}$ [Kinbara et al, 1960]. In self-heating experiments on cotton linters in air, Gross and Robertson [1958] adopted first order kinetics with $E=34.5 \mathrm{kcal} / \mathrm{mol}$ and $\mathrm{A}\left(225^{\circ} \mathrm{C}\right)=1 \times 10^{10} \mathrm{sec}^{-1}$. In recent isothermal studies on cotton linters [Shafizadeh et al, 1979], the decomposition was reported faster in air below $300^{\circ} \mathrm{C}$ and "essentially the same in both air and nitrogen" above $300^{\circ} \mathrm{C}$. However, in the TG experiments in the same reference the maximum rate of weight loss occurred at $345^{\circ} \mathrm{C}$ in air and $360^{\circ}$ in nitrogen, showing a small but significant bias in favor of oxidative decomposition. First order plots of the linear portion of the isothermal curves (excluding the initial induction periods) gave the following kinetic results; air, $E=17 \mathrm{kcal} / \mathrm{mol}, \mathrm{A}=1.8 \times 10^{3} \mathrm{sec}^{-1} ;$ nitrogen, $E=37 \mathrm{kcal} / \mathrm{mol}$, $A=4.3 \times 10^{10} \mathrm{sec}^{-1}$. Since the first portion of the decomposition is ignored, these kinetics are not expected to give a good description of the TG and DSC curves in air or nitrogen. Our objective was to derive a formal kinetic description of the decomposition of homogenized waste paper in air and nitrogen that would fit the experimental TG curves at two heating rates. These kinetics will be more suitable for a model of smoldering combustion which itself has heating rates comparable to those of thermal analysis experiments. 
II. EXPERIMENTAL DETAILS

A. Experimental Materials.

Commercial cellulosic insulation is an excellent source of "homogenized" waste paper. Its manufacture is simple, requiring only shredding and milling to convert the waste paper (ca $99 \%$ newsprint) to a low density, fibrous, fluffy material and the addition of chemicals to provide flame retardancy. Attempts are made to exclude slick magazine stock from the raw materials because retardant chemicals tend not to adhere. Otherwise, the milled product probably represents a good cross section of available paper refuse. The sample of cellulosic material used in these experiments was prepared in the usual manner except that the retardant chemicals were not added. This untreated material served as a reference point for our work on the effect of additives on smoldering (Appendix II). In order to further ensure uniformity, the cellulnaic insulation was roll-milled an additional two hours in steel cans fitted with a mixture of stainless steel ball bearings and Tefion rods. (When chemical additives were required for Appendix II of this studv. thev were milled in at this step.)

\section{B. Thermal Analysis.}

Since the samples were well dispersed and homogenized, we anticipated no sampling problems. The thermal analysis (TGA and DSC) was carried out with the Dupont 990 Thermal Analyzer System using techniques described elsewhere [Antal et al, 1979, Rogers et al, 1979]. Several points which bear on the accuracy of derived kinetic data deserve restatement. The nominal instrument heating rates were found to be lower than the experimentally measured heating rates. At heating rates greater than $10^{\circ} / \mathrm{min}$, the DTG curves generated by this instrument 
are inaccurate, being displaced to higher temperatures. Because of thermal gradients along the length of the TGA furnace, the temperature the sample thermocouple records depends upon how much the quartz tube penetrates the furnace. This distance is controlled by a retaining ring. We found a $1^{\circ} \mathrm{C}$ temperature change per millimeter shift of this ring. This distance was set so that the melting points of aluminum, tin and zinc fell within the accuracy of the type $K$ thermocouple used in the Dupont system.

For all the experiments reported here, the sample size was $2.7 \pm 0.1 \mathrm{mg}$ and the sample thermocouple occupied the same relative position, about $2 \mathrm{~mm}$ away from the cellulose. To facilitate purging in inert atmosphere experiments, a Teflon stopcock was attached to the end of the bell jar which covers the counterbalance part of the beam. A one-hour nitrogen purge at 50 ml/min was generally adequate. All samples were dried to constant weight at $110^{\circ} \mathrm{C}$ before starting the temperature program.

III. RESULTS AND DISCUSSION

\section{A. Kinet1c Procedures}

The derivation of kinetic data from thermal analytical curves obtained under nonisothermal conditions has received considerable attention, and several comprehensive reviews are available [Sestak et al, 1973, Wendlandt, 1974, Baker, 1978]. The details of the kinetic method we used in this work appear elsewhere [Rogers et al, 1979], and we will summarize here only the essential elements of the procedure. First, from the shape of the DTG and TG curves a choice is made of a suitable heterogeneous reaction mechanism from the sixteen that are available in the literature. These sixteen expressions are based on the equalion 


$$
\mathrm{da} / \mathrm{dt}=\mathrm{kf}(\mathrm{a}) \quad \mathrm{a}=\text { fraction reacted } \mathrm{k}=\operatorname{Aexp}[-\mathrm{E} / \mathrm{RT}]
$$

and various choices for the function, $f(a)$. In the most common kinetic treatment $f(a)$ equals $(1-a)^{n}$ with $n=1 / 2,2 / 3$ or 1 . These functions represent only three of the sixteen possible expressions. The second element is the calculation of the apparent kinetic parameters, A and E, for this rate law. The third element is the testing of the kinetic description against the experimental data at several heating rates. Since some of the choices for $f(a)$ may give a rate equation which is analytically integrated only with difficulty, several approximate solutions have been proposed (for a comparison of these approximations, see Rogers et al, 1979). Rearranging Equation (1) after adapting it for the linear heating process of TGA experiments gives

$$
\int[1 / f(a)] d a=(A / \beta) \int \exp (-E / R T) d T ; \quad \beta=\text { heating rate }
$$

Solutions for the left hand integral, which are called $g(a)$, with any of the sixteen $f(a)$ functions are available [Rogers et al, 1979]. The right hand integral has no analytical solution; of the three approximations in the literature we have found that of Gorbachev [1975] somewhat more accurate. The final expression linking the fraction reacted with the temperature during linear heating is then

$$
B(a)=\left[A H^{\prime} I^{2} \exp \left(-E^{\prime} / K^{\prime} I^{\prime}\right)\right] / \beta\left(E^{\prime}+2 K^{\prime} I^{\prime}\right)
$$

where $g(a)$ is any one of the tabulated solutions for the sixteen $f(a)$ functions. Since some of the $g(a)$ functions are complex, a graphical relationship between $g(a)$ and $(a)$ is used for such cases in order to obtain conversion values to compare with the experimental TG curve.

This general approach to kinetic analysis is valid when the TG curve has the appearance of and is treated as if one overall reaction was taking place. If the decomposition process and the changes brought in the TG curve by changes in heating rate suggest coupled competitive, independent or consecutive 
reactions, then an additional step is required. We have given expressions for two-step TG curves exhibiting these three reaction modes and discuss their application elsewhere [Rogers, 1979].

\section{B. Decomposition in Nitrogen}

Figure 1 shows the experimental TGA curves for the thermal degradation of homogenized waste paper in nitrogen at 1 and $5^{\circ} \mathrm{C} / \mathrm{min}$. The degradation proceeds in one overall reaction leaving a $24 \%$ residue compared to a $13 \%$ residue for Whatman filter paper. The shape of the TG and DTG curves [10] implies a rate equation of the form

$$
a^{n}=\left[A R T^{2} \exp (-E / R T)\right] / \beta(E+2 R T)
$$

where $\mathrm{n}=1 / 4,1 / 3,1 / 2,1,3 / 2$ or 2 as an appropriate description of each curve alone. However, only the rate law with $\mathrm{n}=2$, i.e., a parabolic law for 1-D diffusion, will furnish kinetic parameters which fit both curves. This arises because each of the six rate laws given above requires a different $E$ value in order to fit a single curve, but only the $a^{2}$ law gives an $E$ which predicts the temperature shift of the TGA curve with changes in heating rate. Generally, it is impossible to arrive at a unique set of kinetic parameters based on a single TGA curve. For example, the $5^{\circ} \mathrm{C} / \mathrm{min}$ curve of Fig. 1 can be fit very well by a zero order law ( $n=1$ in Eqn. 4) with $A=9.5 \times 10^{5} \min ^{-1}$ and $E=19.5 \mathrm{kcal} / \mathrm{mol}$ but the same kinetics will miss the curve at $1{ }^{\circ} \mathrm{C} / \mathrm{min}$ by about $20^{\circ} \mathrm{C}$. The kinetics which give a very good fit to both TGA curves are $A=1.1 \times 10^{13} \mathrm{~min}^{-1}$ and $E=39 \mathrm{kcal} / \mathrm{mol}$ and the complete rate laws for the thermal degradation of homogenized waste paper and Whatman filter paper in nitrogen [Antal et al, 1979] are

Eilter Paper: $\quad d(a) / d t=3.64 \times 10^{11}(1-a)^{0.464} \exp [-36600 / R T] \mathrm{min}^{-1}$ Homogenized Waste Paper: $\mathrm{d}(\mathrm{a}) / \mathrm{dt}=1.1 \times 10^{13}(1 / 2 \mathrm{a}) \exp \left[-3 y \cup u \cup / \mathrm{Kl}^{\prime}\right] \mathrm{min}^{-1}$ 
Since the kinetics for the filter paper and waste paper were determined in the same laboratory on the same equipment, experimental details are equivalent and comparison is valid. While the activation energies are similar, the overall rate laws differ. Filter paper, a loose array of fibers, degrades according to a random nucleation law with $\mathrm{n} \cong 0.5$ while the waste paper, a highly impure and originally compacted array of fibers, degrades according to a one dimensional diffusion process. From a comparison of the TGA curves in this and the previous study [Antal, 1979], it is apparent that the wood-based waste paper with its unknown impurities has a significantly lower degradation temperature than the pure cellulose filter paper. The extent of the catalysis by the complex (and probably variable) impurities of homogenized waste paper is seen in a comparison of half-lives $\left(t_{1 / 2}\right)$. These values, calculated from the equation $t_{1 / 2}=g(a) / k$ are given below (Table 1$)$ :

TABLE I

HALF-LIVES (min.)

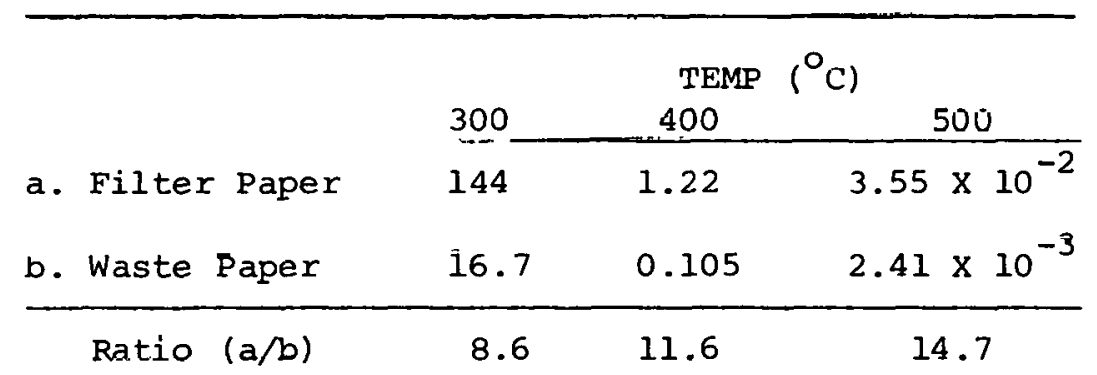

These data show that the structural and chemical differences that separate filter paper and homogenized waste paper bring about a significant 9-15 fold difference in half-l1fe favoring faster degradation in the latter.

The above, simple and accurate, formal kinetic description of the pyrolysis $\left(\mathrm{N}_{2}\right)$ of waste paper should be useful in engineering design of reactors for the conversion of municipal waste paper to fuel and in the formulation of 
combustion models.

Figure 2 shows the DSC curve for the degradation of homogenized waste paper in nitrogen at $5 \% / \mathrm{min}$. In contrast to the smoothness of the TG weight loss curve, the DSC curve shows an inflection at $315^{\circ} \mathrm{C}$ indicating the composite nature of the overall process, less apparent in the TGA. Using the TGA kinetics, a heat of pyrolysis of $+80.4 \mathrm{cal} / \mathrm{g}$ (see below) and the following expression for the rate of heat absorption,

$$
(d q / d t)=m Q A(1 / 2 a) \exp [-E / R T](\mathrm{ca} / / \mathrm{sec})
$$

we calculated the DSC curve also shown in Fig. 2. The agreement between the calculation and experiment is very good in the early stages and less so in the latter stage of heat absorption, reflecting the composite nature of the real degradation process. The subtleties of the degradation reaction which are masked in the simple one-step description of the TG curve are magnified in the DSC curve. (A better description of the DSC curve would require at least a consecutive series of two reactions).

In general, the choice between kinetics derived from TGA or DSC depends on the ultimate application. In smoldering ignition (Appendix II) the heat flow process is paramount hence a kinetic description biased in favor of DSC curves is more appropriate* For waste-to-fuel conversion the TGA kinetics which give an adequate description of the heat flow and a better description of gasification are an appropriate starting point. Of course, if all the thermochemical and mechanistic details of the degradation were known, a choice would not be necessary, however, the complexity of this description may make it unsuitable for tractable computer models.

*The Dupont sample pan design (aluminum, approx. $6 \mathrm{~mm}$ diam. $\mathrm{x} 2 \mathrm{~mm}$ deep; cover on top with few pinholes) couple., with the low temperature range $\left(<500^{\circ}\right)$ lead one to conclude that the DSC measures essentially only condensed phase heat eflects; theee are most relevant to smoldering. 


\section{Decomposition in Air}

The decomposition of homogenized waste paper in air at 1 and $5^{\circ} \mathrm{C} / \mathrm{min}$ is shown in Fig. 3. The oxidation takes place in two overall reactions with the first reaction consuming about $65 \%$ by weight of the starting material. At $1^{\circ} \mathrm{C} / \mathrm{min}$, the first reaction takes place at ca $280^{\circ} \mathrm{C}$ and the second reaction at ca $360^{\circ} \mathrm{C}$. The DSC curve at $5^{\circ} \mathrm{C} / \mathrm{min}$ in air is also shown. Two exothermic reactions of approximately equal area are shown; the first peaking at $320^{\circ} \mathrm{C}$ and the second at $440^{\circ} \mathrm{C}$.

As with the decomposition in nitrogen, a one-dimensional diffusion rate law for the first reaction is suggested by the TG, DTG curves and the temperature displacement between the two TG curves, i.e.,

$$
\mathrm{da} / \mathrm{dT}=\mathrm{k} / \boldsymbol{\beta} 2 \mathrm{a} ; \quad \mathrm{a}=\text { fraction reacted } \quad \beta=1 \text { inear heating rate }
$$

The approximation of the integrated form of Equation (5) is, therefore, the same as Equation (3) with $\mathrm{n}=2$

$$
a_{1}^{2}=\left[A_{1} R T^{2} \exp \left(-E_{1} / R T\right)\right] / \beta\left(E_{1}+2 R T\right)
$$

The second reaction is best fit with a 3-D diffusion law of the form

$$
\mathrm{da} / \mathrm{d}^{\prime} \mathrm{I}^{\prime}=3 \mathrm{k} / 2 \beta\left(\left(1-\mathrm{a}_{2}\right)^{-1 / 3}-1\right)
$$

and the approximation of the integrated form is

$$
\left(1-2 a^{2} / 3\right)-\left(1-a_{2}\right)^{2 / 3}=\left[A_{2} R^{2} \exp (-E / R T)\right] / \beta(E+2 R T) \text {. }
$$

The kinetic parameters for each reaction are given below (Table II)

TABLE II

OXIDATION KINETIC PARAMETERS

\begin{tabular}{ccccc}
\hline Reaction & Model & $g(a)$ & $E(k c a l / m o l)$ & $A\left(m i n^{-1}\right)$ \\
\hline 1. & 1-D Diffusion & $a^{2}$ & 41.5 & $7 \times 10^{14}$ \\
2. & 3-D Diffusion & $(1-2 a / 3)-(1-a)^{2 / 3}$ & 39 & $4 \times 10^{10}$
\end{tabular}

Figure 3 shows that the curves derived from these kinetics give good fits to 
the experimental oxidation data at 1 and $5 \%$ min.

If we assume that our formal mechanism reflects the actual controlling mechanism, then the rate of weight loss in air (first reaction) and nitrogen are both governed by $1-D$ diffusion of the products out of the fibers. This type of rate law is most frequently associated with the oxidation of metals where the rate of oxidation has an inverse dependence on the thickness of an oxide layer. Here the fibers are seen under a microscope to be flat thin strips, probably flattened versions of the hollow cylindrical tubes that comprise the cell walls of the original wood. The fiber strips are thin compared to their width and length, so diffusion of a product out of the strip will be essentially 1-D. When the strips are extensively degraded so that they contain, in effect, numerous holes of diameter comparable to the strip thickness, the outward diffusion of products will be 3-D in character. This is a possible explanation for the changes in mechanism between the first and second stages of oxidation. Proof of actual mechanism would require much more direct evidence, of course. Regardless of the underlying mechanism, the kinetic data given here constitute a very useful description of the gasification rates of this impure cellulosic material, useful for assessing some of its smolder characteristics (Appendix II).

Comparison of the TGA and DSC curves at $5 \% / \mathrm{min}$ (Fig. 3) shows that the abrupt change in the rate of weight loss at the end of the first reaction is not entirely reflected in the DSC curve which exhibits a more gradual transition between the first and second reaction. Since the dynamics of the heat flow process are more important in smoldering combustion, we derived an alternate set of kinetics based on a fit to the DSC curves. Using the same activation energy and second order kinetics to account for the symmetry around the DSC peaks we derived the following kinetics: (Table III) 
TABLE III

DSC Oxidation Kinetic Parameters

\begin{tabular}{ccccccc} 
Reaction & A(min $)$ & $\underline{E(\mathrm{kcal} / \mathrm{mol})}$ & $\underline{Q}(\mathrm{cal} / \mathrm{g})$ & $\underline{\mathrm{n}}$ & $\underline{\text { m }}$ \\
1 & $6 \times 10^{14}$ & 41.5 & 1000 & 2 & $\mathrm{~m}_{0}$ \\
2 & $3 \times 10^{11}$ & 39.3 & 6000 & 2 & $0.25 \mathrm{~m}_{0}$ \\
\hline
\end{tabular}

These kinetics and the rate law

$$
\mathrm{dq} / \mathrm{dt}=\mathrm{mQA}(1-\mathrm{a})^{2} \exp [-\mathrm{E} / \mathrm{RT}]
$$

where $m_{n}=$ dry weight of cellulosic insulation give the fit shown in Fig. 3 . The agreement between theory and experiment is satisfactory overall except at the beginning of the first reaction which is important in explaining the smolder ignition process. The second order description does not have the somewhat sharp inflection $\left(280^{\circ} \mathrm{C}\right)$ that the experimental curve shows. For this reason, the DSC kinetics are expected to predict a smolder ignition temperature somewhat lower than the kinetics obtained from the TGA kinetics. The DSC kinetics will be used in a model of the overall smolder process similar to that recently developed [Ohlemiller et al, 1979].

\section{Application of Kinetics to Decomposition at High Heating Rates}

Because in some conditions, smoldering and waste paper-to-fuel conversions can involve significantly higher heating rates than 1 or $5 \% / \mathrm{min}$, we tested these oxidation and pyrolysis $\left(\mathrm{N}_{2}\right)$ kinetics further at higher heating rates. While the use of thermogravimetric procedures at high heating rates is generally not recommended, we nevertheless ran decomposition experiments in air and nitrogen at nominal heating rates (instrument setting) of $100^{\circ} \mathrm{C} / \mathrm{min}$. In air, two experiments duplicated each other within $5^{\circ} \mathrm{C}$; similar results were obtained in nitrogen. Figure 4 shows the TG curve for each atmosphere. The exothermic oxidation reaction gives rise to an increasing tendency toward 
thermal runaway in the sample as the reaction proceeds so that an initial heating rate of ca $190^{\circ} / \mathrm{min}$ increased to ca $325^{\circ} / \mathrm{min}$ at the end of the reaction. The non-linearity of the heating rate makes equation (3) inappropriate as a basis for fitting the TG curve in air. However, the increase in heating rate during the course of the oxidation reaction was found to be hyperbolic in nature (i.e., $1 / T=a-q t$ instead of $T=a+b t$ for a linear heating rate). Gorbachev [1975] has given an equation suitable for hyperbolic heating which is similar to cquation (3)

$$
g(a)=[A \operatorname{Rexp}(-E / R T)] / q E
$$

where $\mathrm{q}$ is the coefficient in the temperature equation above. Analysis of the temperature-time portion of a two pen TGA plot (i.e., weight loss vs $t$ and $T$ vs t) gave the following equation:

$$
1 / T=1.925 \times 10^{-3}-5.587 \times 10^{-4} t
$$

This equation fits the temperature range $246-403^{\circ} \mathrm{C}$ which includes all but a few percent of the weight-loss curve. The onset of hyperbolic heating was taken at the temperature $\left(246.28^{\circ} \mathrm{C}\right)$ where $1 \%$ weight loss occurred. Figure 4 shows the calculated TGA curves using equation (6) and the kinetics for the first reaction, $A=7 \times 10^{14} \min ^{-1}, E=41.5 \mathrm{kcal} / \mathrm{mol}$ and $q=5.587 \times 10^{-1}\left({ }^{\circ} \mathrm{K}-\mathrm{min}\right)^{-1}$. Two theoretical curves are given; one which shows excellent agreement takes $65 \%$ conversion as the limjt for the application of these kinetics and the other which uses the first reaction kinetics for the entire decomposition. This latter curve underestimates the experimental $\mathrm{TGA}$ curve by about $10-20^{\circ} \mathrm{C}$ which is surprisingly good in view of the procedural problems inherent in the partial thermal runaway of such high heating rate experiments.

It is interesting to note that the thermal decomposition in air even up to nominal heating rates of $50 \%$ min has the appearance of Fig. 3 . The first reaction consumes ca $65 \%$ of the fuel and a slower char oxidation step consumes 
the remainder. Figure 4 shows that at a nominal heating rate of $100 \%$ min this second stage does not appear. It is probable that at $100^{\circ} \mathrm{C} / \mathrm{min}$ nominal heating rate the char is consumed very rapidly in a true ignition-type process (complete thermal runaway). The temperature time curves have a rather abrupt upward bump in them at this point (end of 1st reaction stage) that strongly suggests this behavior.

The decomposition of the homogenized waste paper in nitrogen is also shown in Fig. 4. The endothermic nature of the reaction causes the initial heating rate of $165^{\circ} / \mathrm{min}$ to decrease to $135^{\circ} / \mathrm{min}$ by the end of the reaction. The amount of reaction residue (ca $24 \%$ ) is about the same as found in the lower heating rate experiments of Fig. 1. Since the change in heating rate is not so drastic as in the oxidation experiments we used an average heating rate of $145 \pm 10^{\circ} / \mathrm{min}$ with $\mathrm{A}=1.1 \times 10^{14} \mathrm{~min}^{-1}, E=49 \mathrm{kcal} / \mathrm{mol}$ to obtain the theoretical curve shown in Fig. 4. The somewhat loose coupling between the thermocouple and the sample causes the falloff in heating rate to be underestimated and the theoretical curve is shifted to higher temperature by $10-15^{\circ} \mathrm{C}$. However, in spite of the procedural problems, the fit is surprisingly good considering that the parabolic rate law and the above kinetic parameters provide an excellent fit to the experimental data at a heating rate of $10 / \mathrm{min}$.

T'he agreement between experimental and theoretical TGA curves over rather large heating rate ranges of 1 to $145^{\circ} \mathrm{C} / \mathrm{min}$ in nitrogen and 1 to ca $300^{\circ} \mathrm{C} / \mathrm{min}$ air, confirms the broad usefulness of our kinetic description in explaining the decomposition of homogenized waste paper in air and nitrogen.

E. Effect of Uxygen Concentration on Degradation Rate

In air the rate of degradation of the homogenized waste paper is 
determined principally by oxidative pyrolysis, but inert pyrolysis makes a small though significant contribution to the first stage of weight loss. If the two modes of degradation are competitive in nature (with no other interactions), then the overall degradation in air is given by

$$
\mathrm{da} / \mathrm{dt}=\mathrm{k}_{\mathrm{obs}} / 2 \mathrm{a}
$$

and $k_{o b s}=k_{o x}\left(Y_{o x}{ }^{m}+k_{p y r}\right.$

where $k_{o x}$ and $k_{\text {pyr }}$ are the rate constants for the oxidative and inert pyrolysis components respectively and $Y_{o x}$ is the mass fraction of oxygen. In order to separate out the oxygen dependence of the overall rate of degradation we made additional TG runs in nitrogen containing $1.47,3.99,8.69$ and 12.80 mole \% oxygen. From these four curves and the TG data in air and nitrogen, we derived the kinetic parameters which provide a good fit for all TG curves, i.e., $k_{\text {obs }}\left(\min ^{-1}\right)=1.67 \times 10^{15}\left(Y_{\text {ox }}\right)^{0.43} \operatorname{EXP}[-41,900 / R T]+$ $1.1 \times 10^{13} \operatorname{EXP}[-39,000 / \mathrm{RT}]$

When $\mathrm{Y}_{\mathrm{ox}}=0, \mathrm{k}_{\text {obs }}=\mathrm{k}_{\text {pyr }}$ and the kinetics are those reported above for degradation in nitrogen. In air, $Y_{o x}=0.21$, this competitive model predicts about $15 \%$ weight loss via pyrolysis. The 0.43 power dependence on the oxygen concentration also explains the significant effect a small amount of oxygen has on the rate of degradation.

The foregoing kinetic analysis was based on one batch of homogenized waste paper. A second batch differed slightly in TG and smolder experiments (Appendix II) and could be fit with the same activation energies, however $A_{\text {pyr }}=7 \times 10^{12}$ (vs. $1.1 \times 10^{13} \min ^{-1}$ ) and $A_{\text {obs }}=2.9 \times 10^{14}$ (vs. $7 \times 10^{14} \mathrm{~min}^{-1}$ ).

\section{F. Heat of Oxidation}

Figure 3 shows the DSC curve for the oxidation of this homogenized waste paper at a heating rate of $5^{\circ} \mathrm{C} / \mathrm{min}$. While the peaks are of approximately equal 
size, the weight loss associated with the first peak is much greater than the second. This trend reflects a shift toward the increased production of more energetic species $\left(\mathrm{CO}, \mathrm{CO}_{2}\right)$ as the char becomes more carbonaceous. We have calculated the heat of oxidation as a function of conversion; the results appear below (Table IV):

TABLE IV

CUMULATIVE HEAT OF OXIDATION OF WASTE PAPER

\begin{tabular}{cc}
\hline Reacted & $\Delta \mathrm{H}(\mathrm{cal} / \mathrm{g}$ reacted $)$ \\
60 & -707 \\
75 & -1198 \\
100 & -2279
\end{tabular}

The first entry is also lower because inert pyrolysis is competing somewhat with oxidation during the initial stage of decomposition.

Since the TGA and DSC experiments were run on samples of equal size at the same heating rate, the DTG and DSC curves are related in the following way (assuming an equal number of overall reactions, i.e, two here, is found by each method): DTG: $d w / d t=k f(w)$ DSC: $\quad \mathrm{dq} / \mathrm{dt}=\alpha \mathrm{Qkf}(\mathrm{w}) ; \quad \alpha=\mathrm{DSC}$ cell constant $\approx 1$ Dividing the calibrated deflection of the DSC curve from the base line by the similar DTG value at a particular temperature gives $Q$

$$
\mathrm{dq} / \mathrm{dw}=\mathrm{Q}(\mathrm{cal} / \mathrm{g})
$$

This procedure gives about -600 and $-5200 \mathrm{cal} / \mathrm{g}$ of reactant (i.e., cellulose or char) as the heat for the first and second reaction respectively. These heats and the kinelius of Table II are potentially useful for modeling smolder propagation in cellulosic insulation. 


\section{G. Mechanism of Oxidation}

For matcrialo suoh as waste paper that are predominantly cellulose, depolymerization to levoglucosan tars is the prevalent decomposition mechanism in nitrogen [Antal et al, 1979]. In air, a different mechanism prevails which does not involve the formation of levoglucosan. A knowledge of this oxidative mechanism may ultimately provide the focal point for the ultimate control of smolder ignition and propagation (Appendix II). We propose the following oxidatively-assisted depolymerization mechanism for the predominant cellulose component of the material:

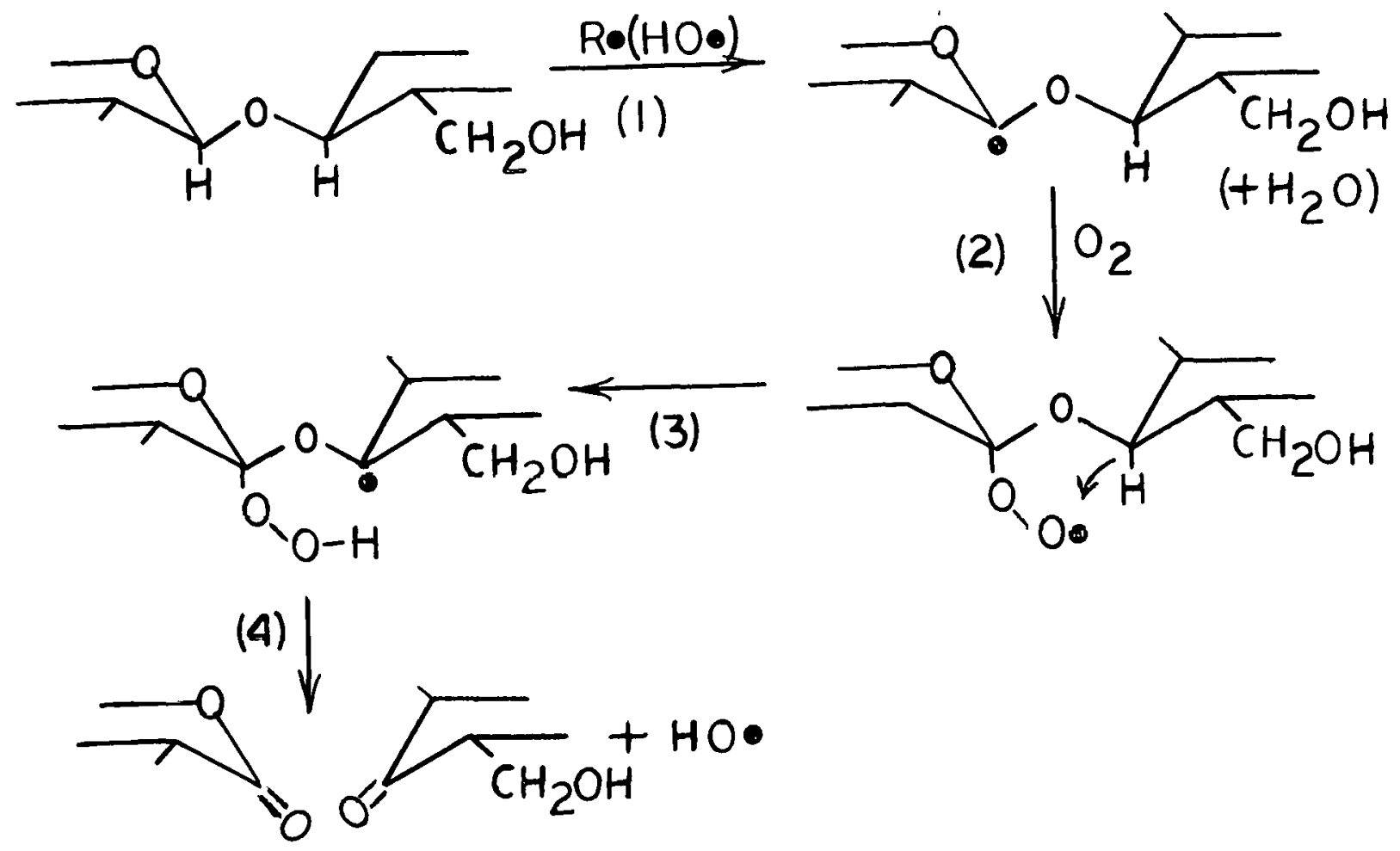

The rings are joined by glycoside linkages between $C-1$ and $C-4$ of the next ring. Because of activation by two adjacent oxygen atoms, $\mathrm{C}-1$ is the most reasonable site for hydrogen abstraction (step 1). The addition of oxygen gives the peroxy radical (step 2) which, via a six-center hydrogen transfer. 
reaction, produces the hydroperoxide (step 3). This, in turn, subsequently undergoes a concerted cleavage to yield a lactone, a carbonyl segment and the chain carrying HO radical. Lactone and carbonyl compounds are known to be important in the initial stages of cellulose oxidation and this simple concerted six-center mechanism explains their appearance. According to step (4), the scissions of a glycosidic bond and the hydroperoxide group are coordinated and this step leads to one lactone and ketone function. Shafizadeh and Bradbury [1979] have shown that cleavages of the glycosidic and hydroperoxide groups are indeed comparable in rate at $170^{\circ} \mathrm{C}$, i.e., $7.5 \times 10^{-7}$

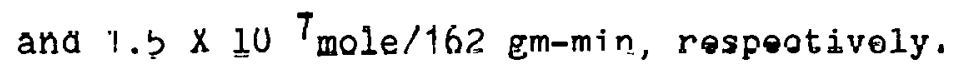

Pursuing the decomposition further with the lactone moiety, we propose an additional, simple step which explains the formation of aldehyde and carboxyl groups.

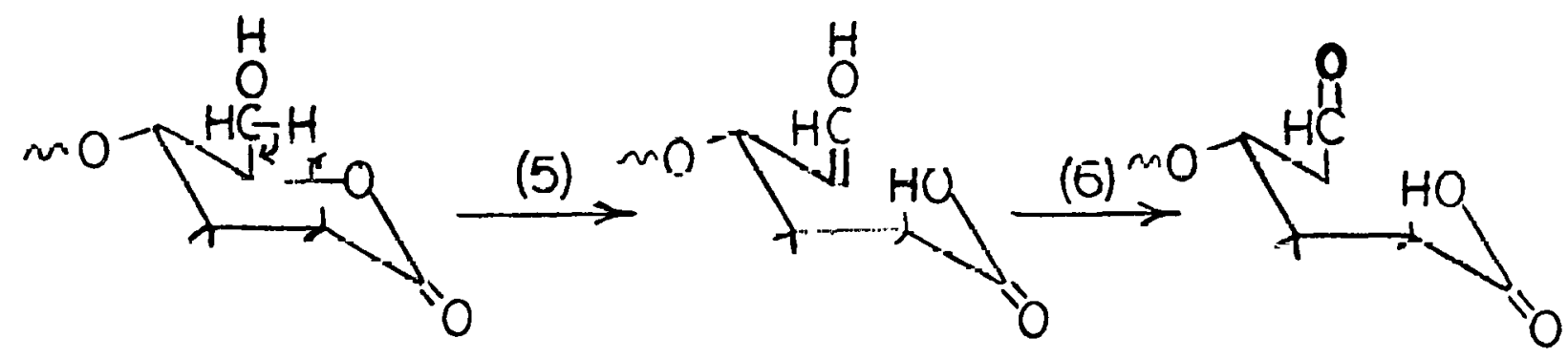

In these additional steps, the lactone, via internal rearrangement (step 5), gives a carboxylic acid and an enol which quickly converts to the aldehyde (step 6). In the overall scheme, every glycosidic bond that breaks, forms one lactone and one ketone; each lactone, in turn, yields one carboxylic acid and one aldehyde group. Therefore, according to this scheme the sum of lactone plus carboxylic acid groups formed should approximately equal the number of ketone groups. During 30 hours in air at $190^{\circ} \mathrm{C}$, cellulose yields 5.4 mmole of ketone/162 $\mathrm{g}$ and 6.4 mmole of lactone plus carboxylic acid groups/162 g 
[Shafizadeh et al, 1979]. Furthermore, from the initial rates of bond scission at $190^{\circ} \mathrm{C}$ in air [Shafizadeh et al, 1979], one can calculate an expected yield of $8.8 \mathrm{mmole} / 162 \mathrm{~g}$ for ketone or lactone plus carboxylic acid. The reasonable agreement between the mechanistic predictions and the experimental results of Shafizadeh give further support to the reaction sequence proposed above. Since steps $1-4$ are expected to be exothermic, they may be important in the early stage of smoldering combustion. The heat evolved in steps 1-4 may be estimated by analogy with the oxidation of ethyl ether.

$$
\mathrm{CH}_{3} \mathrm{CH}_{2} \mathrm{OCH}_{2} \mathrm{CH}_{3}+\mathrm{O}_{2} \rightleftharpoons 2 \mathrm{CH}_{3} \mathrm{CHO}+\mathrm{H}_{2} \mathrm{O}
$$

This reaction also breaks a $\mathrm{C}-\mathrm{O}-\mathrm{C}$ bond and generates 2 carbonyl compounds and water. From available data on heats of formation [Cox et al, 1970], the above reaction (5) liberates $77 \mathrm{kcal} / \mathrm{mol}$ of ether or $475 \mathrm{cal} / \mathrm{g}$ of cellulose in the analogous glycosidic bond breakage of cellulose (unit $M W=162$ ). Smolder ignition inhibition may, therefore, depend on how well this reaction sequence can be controlled. Perhaps smolder retardants act on or can be made to act on the chain carrying $\mathrm{OH}$ radical.

\section{H. Heat of Pyrolysis}

The heat of pyrolysis of pure cellulose has previously been reported by Tang and Neil [1964] at $+88 \mathrm{cal} / \mathrm{g}$. Using differential scanning calorimetry, we also determined the heat of pyrolysis of the homogenized waste paper. At a heating rate of $5 \%$ min the DSC curve peaks at $345^{\circ} \mathrm{C}$, leaves a $20.4 \%$ residue and the integrated area gives $+80.4 \mathrm{cal} / \mathrm{g}$ of dry sample as the heat of pyrolysis. This value is sufficiently close to that previously reported $(+88 \mathrm{cal} / \mathrm{g})$ as to indicate a minor role for the impurities on the energetics of pyrolysis.

The pyrolysis reaction is largely one of depolymerization and yields 
levoglucosan as the most important initial product. This depolymerization reaction is predominant above $275^{\circ} \mathrm{C}$ and appears to be the only significant one in the temperature range of $325^{\circ}$ to $375^{\circ} \mathrm{C}$ which corresponds to the surface temperature during flaming combustion [Parker, 1973]. We may gain an insight into the thermochemistry of the depolymerization by considering the reverse reaction--the formation of cellulose from levoglucosan. This latter transformation takes place without the loss of any chemical groups; in fact, an equal number of $\mathrm{C}-\mathrm{O}$ and $\mathrm{O}-\mathrm{H}$ bonds are broken and made in the reaction. Therefore, to a first approximation, differences in bond energies will not. explain the energetics of depolymerization.

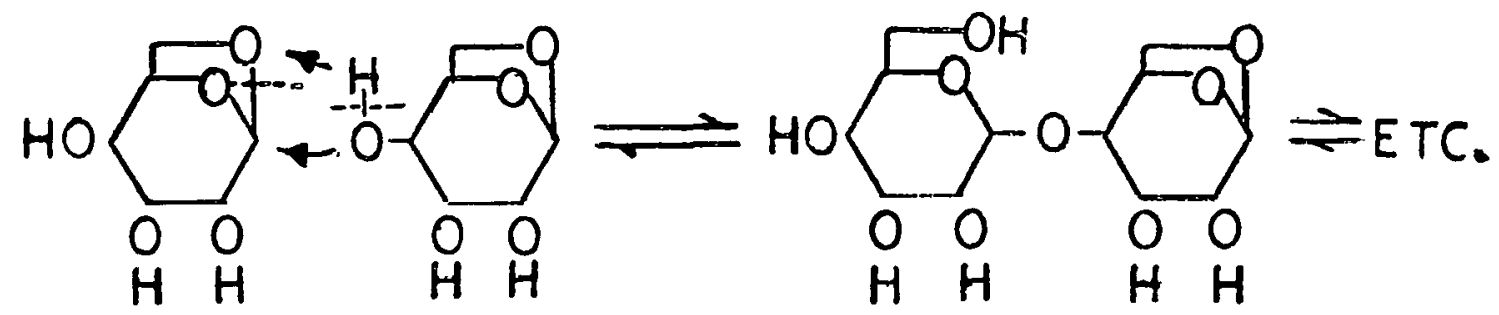

Furthermore, if we assume that levoglucosan and çellulose exhibit. the same amount of hydrogen bonding (they both have three OH grouns) then this fartor can be eliminated as a driving force in the reaction. The one but not necessarily only factor that remains to explain the energetics of the levoglucosan-sel.1ulnse transformation is the relief of ring strain in the levoglucnsan itself. Structurally, the levoglucosan ring system is similar to a bicyclo (3.2.1.) octane
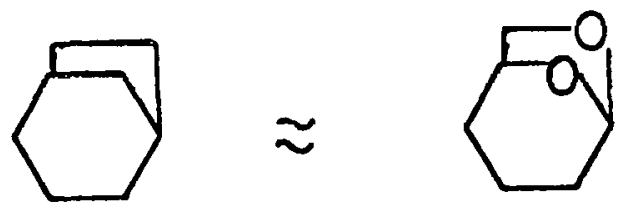

with two melhylene groups replaced by oxygen atoms. The substitution of 0 for $\mathrm{CH}_{2}$ is not expected to change the strain energy significantly [Benson, 1967] so that levoglucosan approximates the bicyclic hydrocarbon with about $12 \mathrm{kcal} / \mathrm{mol}$ 
of strain [Muller et al, 1975]. On a similar basis the strain energy of a pyranose ring in cellulose has about $1 \mathrm{kcal} / \mathrm{mol}$ of strain. Therefore, the levoglucosan-cellulose transformation is accompanied by a relief of $11 \mathrm{kcal} / \mathrm{mol}$ of strain or about $-68 \mathrm{cal} / \mathrm{g}$ levoglucosan $(M W=162)$. The reverse reaction--the formation of levoglucosan from cellulose--must be endothermic by this amount $(+68 \mathrm{cal} / \mathrm{g})$; this compares very well with the experimentally determined heat of pyrolysis $(+80.4 \mathrm{cal} / \mathrm{g})$. The heat of the pyrolysis process as a depolymerization sequence is adequately, though not completely, explained by one factor--the introduction of appreciable strain in the product. 


\section{References}

1. M. J. Antal, H. L. Friedman and F. E. Rogers, to appear in Combust. Sci. Technol.

2. Survey of Cellulosic Insulation Materials, Energy Research and Development Administration, ERDA 77-23, January 1977.

3. F. Shafizadeh, Advan. Carbohyd., Chem 23, 419, (1968).

4. A. J. Stamm, Ind. Eng. Chem, 48, 413 (1956).

5. K. A. Murty and P. L. Blackshear, Jr., Pyrodynamies, 4, 285, (1966).

6. T. Kinbara and K. Akita, Combusl. \& Flame, 4, 173 (1960).

7. D. Gross and A. F. Robertson, J. Res. Natl. Bur. Std., 61, 413 (1958).

8. F. Shafizadeh and A. G. W. Bradbury, J. Polym. Sci.

9. (a) V. Seslak, V. Satava, W. W. Wendlandt, Ihermochim. Acta, I, 333

(1973); (b) W. W. Wendlandt, "Thermal Methods of Analysis", Wiley-Interscience, N. Y. 2nd Edition, 1974; (c) R. R. Baker, Thermochim. Acta, 23, 201 (1978).

10. F. E. Rogoro and T. J. Ohlcmillcr, to appear in J. Macromolecular 3oi.

11. I'. J. Unlemiller, J. Bellan and F. Rogers, Combust.

Flame 36:197-215 (1979).

12. V. M. Gorbachev, J. Thermal Anal., $\underline{8}, 348$ (1975).

13. (a) J. D. Cox and G. Pilcher, "Thermochemistry of Organic and Organometallic Compounds", Academic Press, N. Y., 1970.

14. W. K. Tang and W. K. Neil, J. Polymer. Sci, 6C, 65(1964).

15. W. J. Parker, "S1multaneous Unzlpping Model t'or the Decomposition of Cellulose and the Effect of Flame Retardants," in Fire Prevention and Control-- Major Societal Problem, University of Utah Polymer Conf. Series, June 1973.

16. S. W. Benson, "Thermochemical Kinetics, 2nd Ed.", Wiley Interscience; $N$. 
Y., 1976, p. 273-4, 276.

17. P. Muller and J. C. Perlberger, J. Am. Chem. Soc., 27, 6862(1975). 


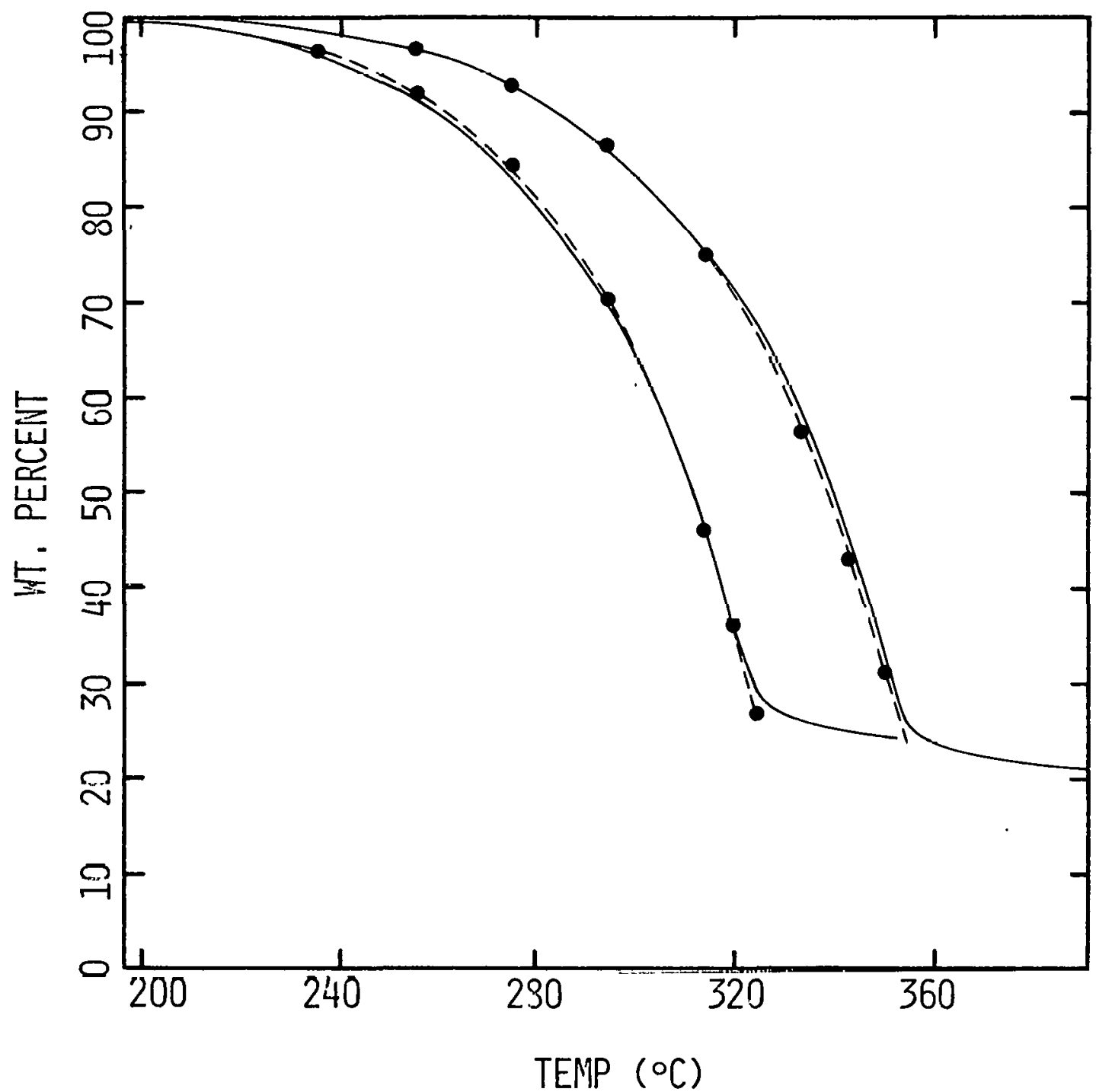

Fig. 1 Comparisun of experimental (- $\longrightarrow$ and theoretical (---0--) ThA rurres for the thormal dooompooition of liomoyenized wasle paper in nitrogen at nominal heating rates of 1 and $5^{\circ} \mathrm{C} / \mathrm{min}$ using rate law and kinetic parameters given in text. 


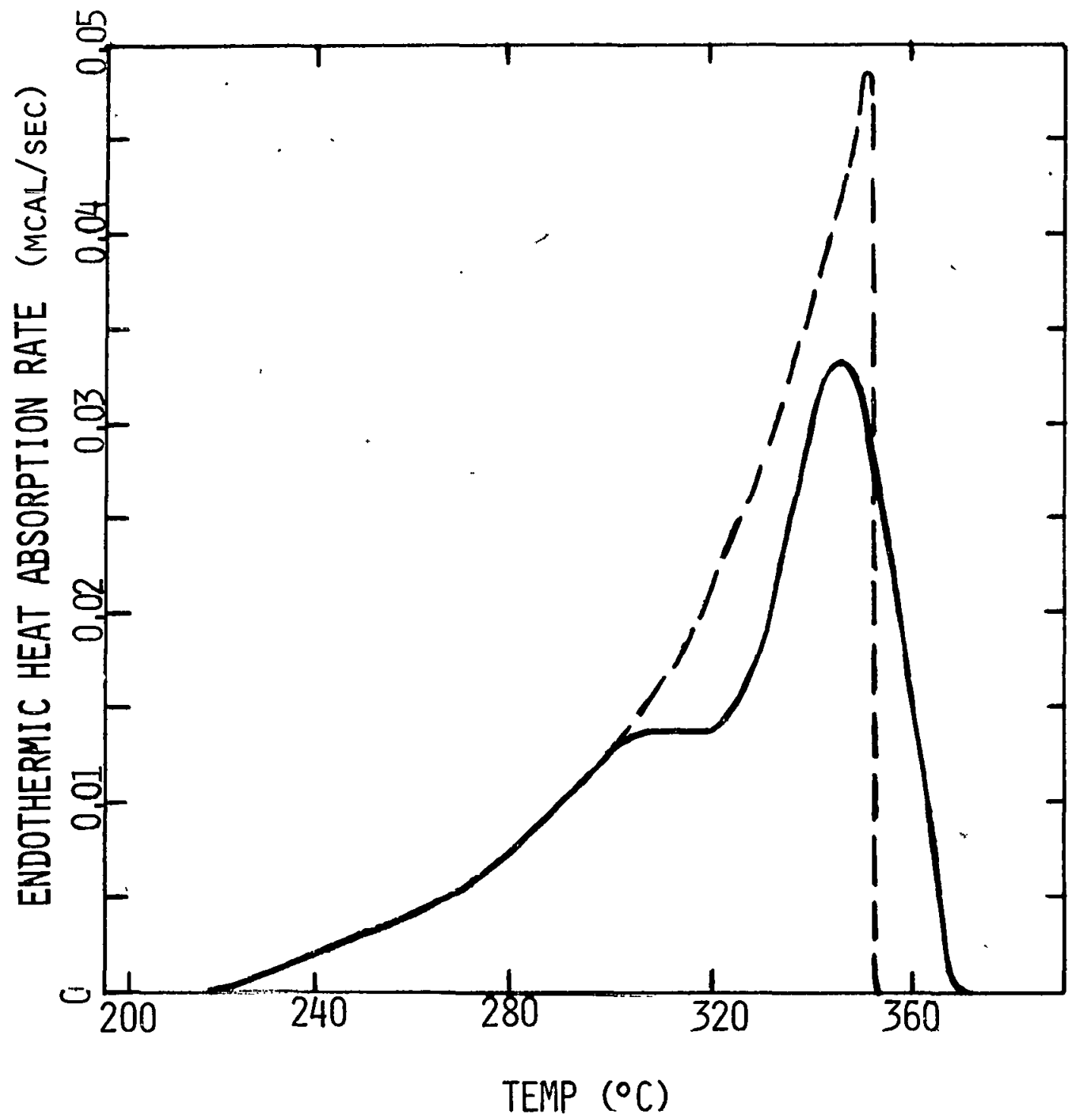

Fig. 2 Comparison of experimental and (--) and theoretical (--) DSC curves for the endothermic degradation of homogenized waste paper in nitrogen at a heating rate of $5^{\circ} \mathrm{C} / \mathrm{min}$. Same kinetic parameters as used in Figure 1. 


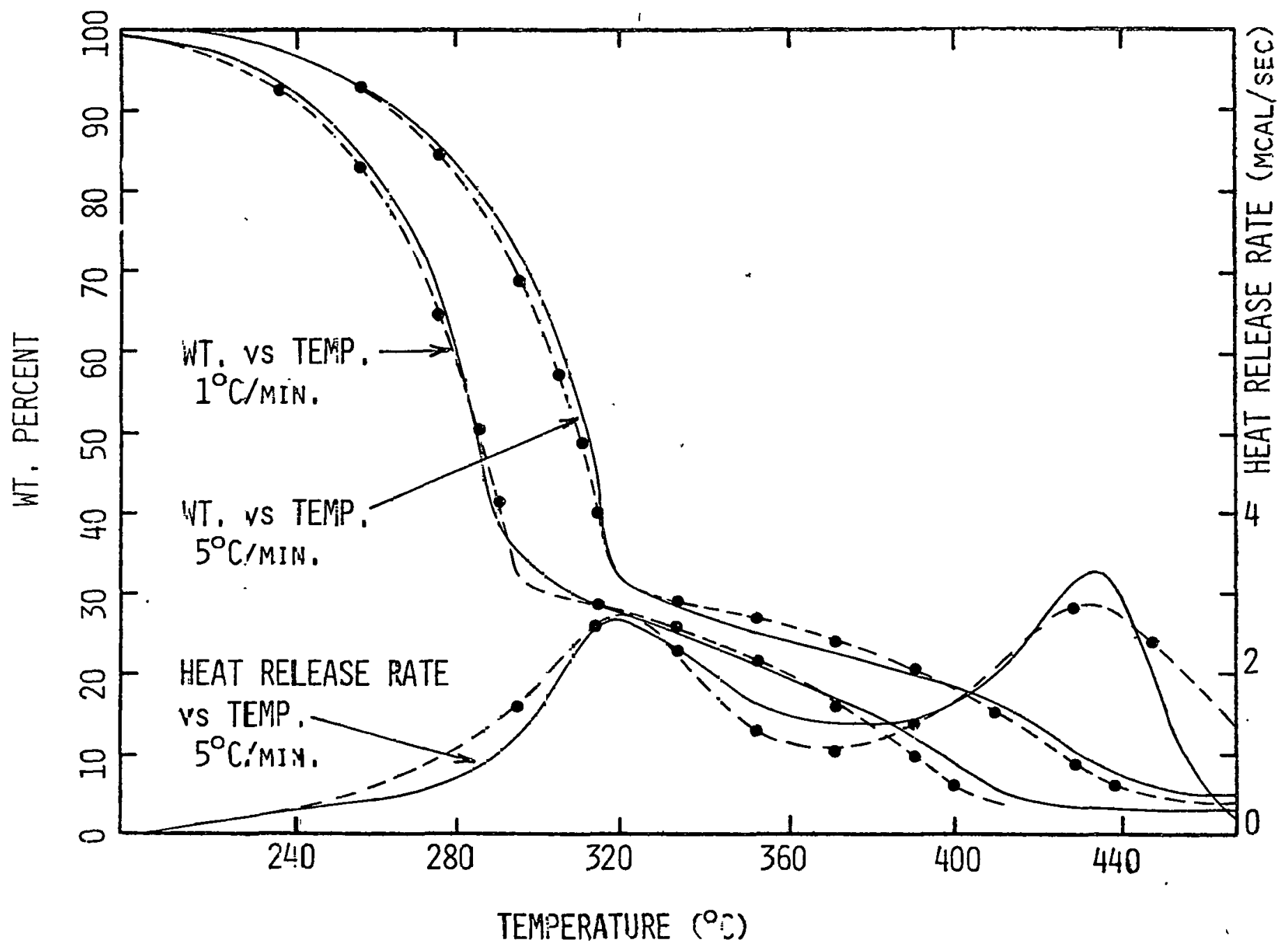

Fig. 3 Comparison of experimental ( $\longrightarrow$ ) and theoretical (--.--) TGA curves for the dezomposition of homoger.ized waste paper in air at nominal heating rates of 1 and $5^{\circ} \mathrm{C} / \mathrm{min}$ using kiretic parameters given in table II. Also shown are the exserimental ( $\longrightarrow$ ) anc theoretical (-.--) DSC curves at a heating rate of $5^{\circ} \mathrm{c}$ mim using second order kinetic parameters given in table III. 


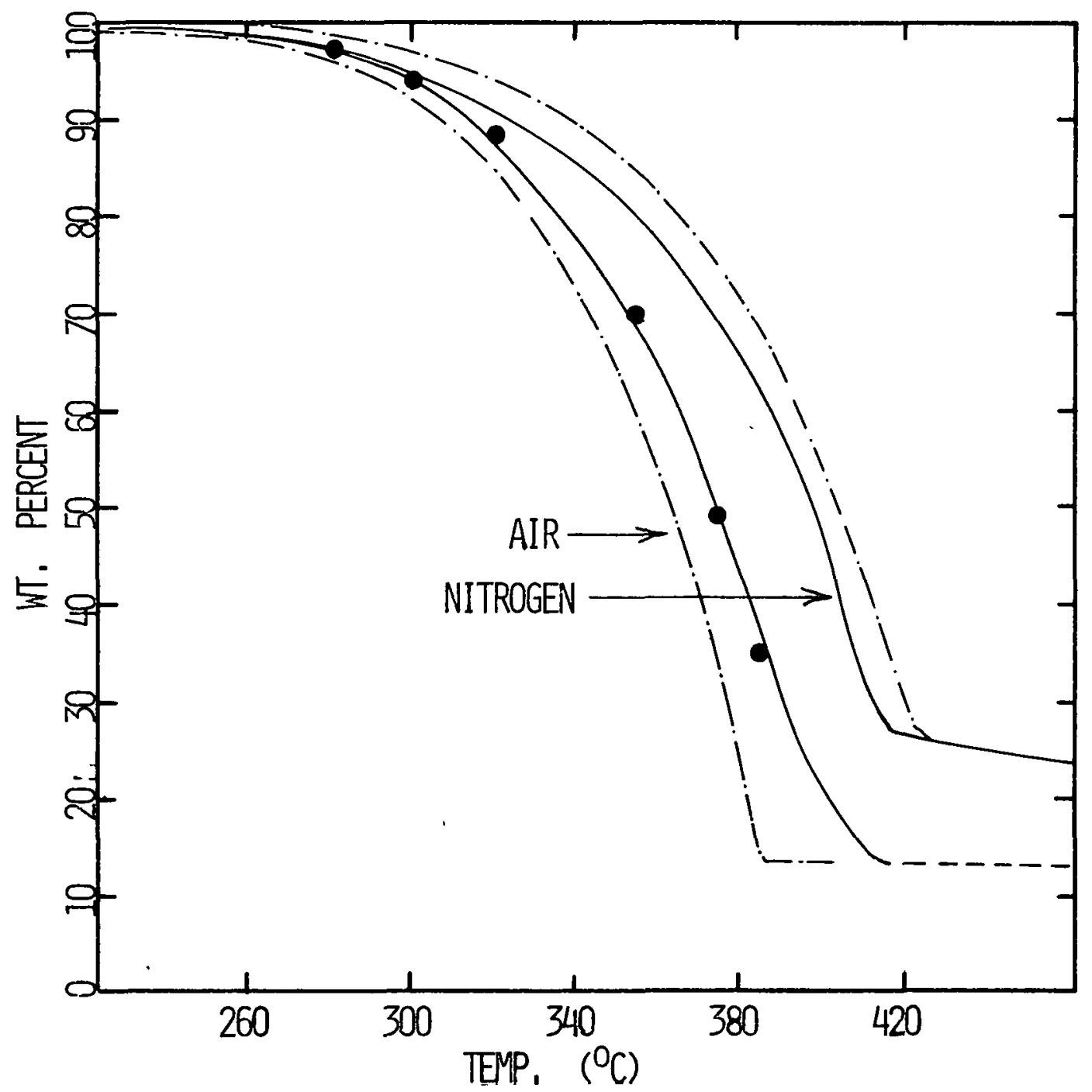

Fig. 4 Comparison of experimental and theoretical (-. - TGA curves for the degradation of homogenized waste paper in air and nitrogen at high heating rates (nominal $100^{\circ} \mathrm{C} / \mathrm{min}$; see text). The filled circles are the fit using the first reaction oxidation kinetics (table II) limited to $65 \%$ weight loss. (The dashed line on the left is for the same oxidation kinetics for the entire reaction.) The dashed line accompanying the TG curve in nitrogen is the fit using kinetics from section 1 II $-B$. 


\section{THIS PAGE \\ WAS INTENTIONALLY \\ LEFT BLANK}


Appendix II

CELLULOSIC INSULATION MATERIAL

II. EFFECT OF ADDITIVES ON SOME SMOLDER CHARACTERISTICS

\author{
T. J. Ohlemiller and F. E. Rogers \\ Princeton University \\ Princeton, New Jersey
}

\title{
ABSTRACT
}

Minimum temperatures for the initiation of sinolder in cellulosic insulation materials were measured by the method of Bowes and Townshend ( $1-D$ heat flow through a layer on a hot surface). The minimun temperature decreases rather rapidly with layer thickness; a range of about $320^{\circ} \mathrm{C}$ to $220^{\circ} \mathrm{C}$ is indicated for layers from 3 to 30 an thick. Additives (boric acid, elemental sulfur, conmercial retardant blend) have a substantially lesser effect; boric acid, the most effective, raises the ignition temperature only about $20^{\circ} \mathrm{C}$. Thennal analytical kinetics (DSC)-are used, in conjunction with the Bowes and Townshend ignition model, to successfully predict ignition temperatures and to demonstrate that the first overall stage of oxidation of the material is responsible for its ignition characteristics. It is demonstrated that solid reactant consumption, neglected in the model, somewhat distorts the ignition data; oxygen consumption effects are minimal. Boric acid is also the most influential additive on snolder propagation; it doubles the minimum thickness for continued propagation (from $31 / 2$ to $5 \mathrm{~cm}$ ). Additive effects on propagation are detemined by their influence on both overall stages of insulation oxidation.

Work supported primarily by the National Bureau of Standards (Grant 4-9026) and also by the Department of Energy (ORNL/SUB 7686). 
INTRODUCTION

The milled waste-paper products discussed in Appendix I form the basis of a thermal insulation industry. The fibrous nature of the milled product coupled with its low bulk density make it a good barrier to both convective and conductive heat flows. Furthennore, it is low in cost with the result that it may well give the most insulation efficiency for the dollar in the retrofit market for homes (New York Inst. of Tech., 1977). It is readily installed on attic floors with a mechanical blower to yield an insulating hed of fibrous particles up to 25 or $30 \mathrm{am}$ deep with low bulk density $\left(0.04-0.05 \mathrm{grams} / \mathrm{an}^{3}\right)$ and a large surface area/unit volume $\left(\sim 900 \mathrm{~cm}^{2} / \mathrm{cm}^{3}\right)$. These physical factors, while making this a good insulation, when coupled with the exothermic oxidation characteristics of the cellulosic material (Appendix I), yield a system that is vulnerable to smoldering combustion; in some circumstances this smoldering can progress to flaming. Recommended installation practices would preclude exposure of the insulation to any of the usual sources of heat to be found in attics (recessed light fixtures, furnace vents, etc.). However, these recommendations are apparently not always tollowed; there have been several residential fires where this type of Insulation was implicated (Zicherman and Fisher, 1978).

Nearly all commercial cellulosic insulation products are treated with various proprietary blends of chemicals, milled in, to improve fire retardance. Borax and boric acid appear to be among the most common additives (ERDA, 1977); borax is apparently added to improve flaming resistance and boric acid to improve snolder resistance. A 20-258 add-on by weight is fairly typical (ERDA, 1977); apparently it is difficult to retain much higher particulated retardant loadings in the fibrous mass. The flame retardants appear rather effective in the insulations the authors are familiar with. Smolder resistance is another question and it is this question we address here. 
It is desireable to test smolder tendency of these insulation materials in circumstances that bear a reasonable resemblance to those encountered in usage. Improperly installed insulation material will most frequently be in danger of being ignited by hot surfaces such as recessed light fixtures, furnace vents, chimneys, overheated electrical conductors, junction boxes, etc. Heat flow considerations imply that large flat areas will yield lower ignition temperatures than snall convex hot objects ${ }^{+}$; thus one would expect that a recessed light fixture need be less hot to ignite a given layer of insulation than an immersed electrical wire. The light fixture in this sense provides the greater hazara (probably also on a frequency of occurrence basis) .

A very simple geometry that has the advantage of resembling this real hazard situation is a flat hot plate with a uniformly-thick layer of insulation on top. Furthennore, if one employs this flat plate heat source in such a way that the heat flow is essentially one dimensional and the ignition temperature sought is the minimum, an analysis of the problem is already available (Thomas and Bowes, 1961; Bowes and Townshend, 1962). The one-dimensional heat flow criterion can be adequately met if the width of the plate is at least 4 to 5 times the thickness of the fuel layer. One seeks the minimum ignition temperature by performing a sequence of go/no-go tests at successively higher plate temperature levels. The minimum is that plate temperature which just yields ignition after long exposure (comparable to the themal relaxation time of the fuel layer). Below this ininimum a pseudo-steady-state is reached in which some reaction occurs in the fuel closest to the hot plate but it is unable to bootstrap itself to a runaway ignition condition.

\footnotetext{
tpreliminary work done for NBS supports this; further supportive studies of geometry effects are being performed for DOE.
} 
Thomas and Bowes (1951) and Bowes and Townshend (1952) present an approximate analysis of this ignition situation based on thermal ignition theory originally developed for pre-mixed fuels and oxidizers; the present system looks "pre-mixed" by virtue of the large air-filled void volume and the relatively high permeability of the fuel bed. They first note that ignition as defined above is the upper limit on the pseudo steady-state non-ignition situation. If reactant consunption is small, it can be ignored in a first approximation and one is treating a true steady-state to find the highest plate temperature at which that steady state can exist. There are twp reactants; oxygen is replenished by diffusion and buoyant flow; fuel depletion is snall if its reaction heat is large. We will discuss depletion further below. The exact problem solved in the above references is thus,

$$
\begin{aligned}
& d^{2} \theta / d z^{2}=-\delta e^{\theta} \\
& \theta=0 \quad \text { at } z=0 \\
& -d \theta / d z=\alpha\left(\theta-\theta_{0}\right) \text { at } z=2
\end{aligned}
$$

$$
\text { where } \begin{aligned}
\delta & =\left(Q \mathrm{Er}^{2} / \lambda \mathrm{RT}_{\mathrm{p}}{ }^{2}\right) & \exp \left(-\mathrm{E} / \mathrm{RT}_{\mathrm{p}}\right) \\
\theta & =\left(\mathrm{E} / \mathrm{RT}_{\mathrm{p}}{ }^{2}\right)\left(\mathrm{T}-\mathrm{T}_{\mathrm{F}}\right) & \\
\alpha & =(\mathrm{hr} / \lambda) & \mathrm{Z}=(\mathrm{x} / \mathrm{r})
\end{aligned}
$$

Symbols are explained in the Nomenclature table. Equations (1) and (2) describe the steady flow of heat from the hot plate and the reaction zone near the plate through the layer to ambient via a convective loss from the cooler exterior surface of the layer. There is a maximum value of the parameter $\delta$ in eqn. (1) for which a steady-state $\theta\left(z ; \delta, \alpha, \theta_{0}\right)$ exists. A graphical relation between $\delta_{\text {MAX }}$ and $\alpha, \theta_{0}$ is presented in the above references. Note that $\delta_{\text {MAX }}$ is a function of the dimensional layer thickness and the ambient temperature.

The real virtue of this model is that it provides a simple approximate 
description of what is actually a very complex unsteady process. If the model is reasonably accurate, it allows one to extrapolate limited data on minimun ignition temperatures to different layer thicknesses and ambient temperatures (provided that the basic assumptions continue to apply). The model was generally successful in correlating data for layers $(0.3$ to 2.5 an) of assorted organic particles (Bowes and Townshend, 1952). The authors caution against using such data to make a unique ranking of smolder ignition tendency since the ranking may vary with layer thickness. We will examine the use of this model for cellulosic loose-fill insulation material and attempt to ascertain its limitations in this context.

We are interested in the effects of additives not only on snolder ignition but also on snolder propagation. The spread of smolder through a horizontal layer of porous fuel (such as insulation laid in an attic) is a complex multi-dimensional process that is only beginning to be examined. Since the balance of thermal and chemical processes is different during propagation than during ignition, we might anticipate at least quantitative differences in the effects of additives on the fuel in these differing circumstances. We have selected as a measure the minimum layer thickness needed to sustain smolder propagation. As layer thickness decreases, the surface to volume ratio increases until losses swamp heat generation and extinction occurs. The thickness at which extinction just occurs is a measure of the heat generation strength of the overall smolder zone; we can ascertain indirectly, then, how additives affect this measure of smolder strength. Unfortunately, there is no quantitative model of this smolder limit, at present, with which to correlate or extrapolate the results. For now we can only discuss the results qualitatively. 
SMOLDER IGNITION

Experimental Details.

The apparatus is a slightly nodified, 30 an square aluminun alloy hot plate. The inodification is the addition of a peripheral shelf and screen-wire "cage"; the latter simply provides support to the periphery of the fuel layer; the former holds a 2 in. thick $\times 4$ in. wide layer of fiberglass batt insulation. The fiberglass layer insulates the fuel periphery, blocks convective hot air currents from the underside of the hot plat.e and defines, to some extent, a reference plane for buoyant plune flow above the heated fuel layer. The plate itself shows negligible temperature variation over most of its surface.

Plate temperature is controlled to better than $\pm 1^{\circ} \mathrm{C}$ by a constant temperature controller (once the set point is reached). Measurement and control thermocouple junctions (30 gage wire) are held firmly against the top center of the plate by a small brass screw/washer roinhination. Two to three additional thermocouples (.010 in, or $0.020 \mathrm{in.}$ sheath dia,) extend from the plate perıphery (trom two or three different sides) parallel to the plate and about $5 \mathrm{~mm}$ above it. Their junctions are arrayed within about one inch of the plate center. The function of these off-plate thennocouples is merely to monitor the temperature of the fuel near the plate surface. They are not used to define ignition but they help in ascertaining how near the minimun temperature borderline a given test was.

Tests are conducted in go/no-go fashion. That is, a layer of the desired thickness is formed on the plate while it is cold (this requires careful distribution of the pre-weighed fuel to minimize bulk density fluctuations) . 
The controller is set to the desired temperature level and turned on; the plate typically requires about $20 \mathrm{~min}$. to reach the set temperature after which it will hold it indefinitely. Exposures have been continued for as much as seven hours but, invariably, if ignition is going to occur for the layer thicknesses tested $(3$ to $7 \mathrm{~cm})$, it occurs within about two hours of the start of the test. Ignition is made apparent by the subsequent smoldering of the fuel and its conversion to a shrunken black replica of the original layer. Ignition is inevitably localized (judging by first penetration of sinolder through the top of the layer) despite the plate temperature unifonnity; the locus is not consistently on one part of the plate.

If ignition does not occur, a new layer is put on the plate after it has cooled and the next test is run at a higher constant temperature. The behavior of the off-plate thermocouples in the first test provides a guideline for the plate temperature setting in the next test: if the off-plate thermocouples came within 2 or $3^{\circ} \mathrm{C}$ of the plate, the new plate temperature should be only about $5^{\circ} \mathrm{C}$ higher and this will probably be above the minimum ignition borderline; if the off-plate thermocouples all fall more than 2 or $3^{\circ} \mathrm{C}$ below the plate temperature, the new value may be raised $10^{\circ} \mathrm{C}$ or more depending on the exact result.

The fuel layer thickness range examined here $(3$ to $7 \mathrm{~cm}$ ) is 1 imited by two considerations. At 2 an thickness, ignition is an ill-defined phenomenon, occurring before the final plate temperature is reached. Beyond 7 an layer thickness, the 1-D heat flow criterion is increasingly violated causing a possible distortion of the results and a deviation from the assumptions of the model of Bowes, et al. While the range of thickness allowed is rather narrow, it is sufficient for present purposes. 
The base insulation material was supplied by a commercial manufacturer; it was prepared from newsprint by the usual shred milling operation but the manufacturer added no fire retardants. In our laboratory this material was roll-milled for two hours in two gallon steel cans (with internal vanes to promote tumbling) containing about a dozen $1 / 2$ in. dia. steel balls and two $1 / 2$ in. $x 8$ in. Teflon rods. This roll-milling served two purposes; it fluffed the insulation so that bulk-densities approaching those in usual practice could be achieved (it was not feasible to form the experimental layers by a mechanical blower, the usual installation method for attics); the roll-milling also served to blend in retardants when these were being added. The boric acid used was reagent grade material ground to a particle size of less than 75 microns. The sulfur was "flower" type used in the as-received powder form.

The base value of the bulk density for the unretarded fuel layers was $0.034 \mathrm{~g} / \mathrm{cm}^{3}\left(2.1 \mathrm{lb} / \mathrm{ft}^{3}\right)$. When retardants were added, the bulk density was increased in direct proportion so that the amount of fuel present was constant. Exceptions to these cases will be noted.

In addition to the tests in which sample preparation included the above-mentioned roll-milling procedures, some tests were done prior to this with mechanical fluffing of the insulation during layer formation. Additives were inserted by thorough hand-mixing prior to this or by solution spray-on. The results were generally quite similar to those for roll-milling; they will be quoted below where pertinent. 
Ignition Results and Discussion.

Minimum ignition border. First, to illustrate the nature of the go/no-go test results and how they define a minimun ignition temperature border, we present test data for a commercial insulation material. Figure $l$ is for a commercial blend $^{+}$(containing 20-258 of a proprietary retardant mix) at a bulk density of $0.036 \mathrm{~g} / \mathrm{cm}^{3}\left(2.25 \mathrm{lb} / \mathrm{ft}^{3}\right)$; this material was mechanically fluffed during layer formation. The results were obtained on two different hot plates: layers 5 an and below were tested on an 18 on square hot plate; the 7 cm layers were tested on the 30 an square hot plate. Since both plates had excellent temperature uniformity and were controlled similarly, it is reasonable to look at the results as a unit. In Fig. 1 an open circle means that a test conducted at that combination of layer thickness and temperature did not yield smolder ignition; a dark circle means the combination did ignite (and consune the whole sample). The line shown is thus the approximate minimun ignition temperature borderline as a function of layer thickness. The exact position of the border for any layer thickness is uncertain within a few ${ }^{\circ} \mathrm{C}$ because of the 1 imited number of tests and the $5^{\circ} \mathrm{C}$ intervals used. The line is shown dashed below 3 an layer thickness because, as was indicated, the ignition process is ill-defined for lesser thicknesses. Disregarding this, we note that there is still a substantial decrease in minimum ignition temperature as layer thickness increases. This trend is consistent with the data of Bowes and Townshend (1962) for other organic inaterials and is qualitatively consistent with the above model. The major reason for the downward trend is quite simple: increasing the layer thickness increasingly insulates the material adjacent to the hot surface

this material is from a different manufacturer than that of the other materials used here. However, preliminary data on the commercial blend of our principal material supplier indicates its ignition behavior is quantitatively similar. 
in which the runaway reaction will occur; if its rate of heat loss is lessened, a lower temperature is sufficient to generate heat that matches then exceeds this rate of loss, thus causing ignition.

It is interesting to note that the ignition temperatures for this commercially-retarded material are not very high in an absolute sense even at these small layer thicknesses. Furthennore, they appear to decrease rapidly with increasing thickness; layers up to 25-30 an may be found in residential insulation practice. We will return to this question of extrapolating to thicker layers below.

Additives effect on minimum ignition border. Figure $2(a),(b)$ and (c) show the effects of boric acid and sulfur additives on the minimun ignition temperature curves of an unretarded material; all of the samples were prepared by the roll-milling process described above and were tested on the 30 an hot plate. Figure 2 shows the actual test points and their outcome (snolder/no snolder) for each composition. Relative comparisons are nore readily apparent on the left side of Fiq. 3 where only the borderline points are plotted. The number of tests per composition in Fig. 2 is signiticantly lower than in fig. 1 but sufficient to establish that the differences in ignition temperatures of the approximate magnitude shown there are real.

Figure 2(a) might be regarded as the base case composition. However, we have noted some variability in the ignition characteristics of unretardea material obtained from the same manufacturer at two different times. All data in Fig. 2 are based on our second batch of material which contains a significant fraction of small but easily recognizable shreds of newsprint. our first batch of this material was clearly milled inore thoroughly and contained no detectable newsprint shreds. The first batch also had a significantly lower 
ash content. (1 $1 / 2.8$ by wyt. vs. 38). This first batch had somewhat lower minimun ignition temperatures $\left(10^{\circ} \mathrm{C}\right.$ less at 3 an; $5^{\circ} \mathrm{C}$ at $\left.7 \mathrm{cn}\right)$.

Extensive testing was also done with this first batch of I iterial using the same techniques except, as noted, hand mixing of retardants was usted instead of roll-inilling. Those results confirm the same trends as are seen in Fig. 2. With first batch material, 108 boric acid hand-mixed-in gave an approximate $20^{\circ} \mathrm{C}$ increase in ignition temperature (all thicknesses); the same level of boric acid sprayed on in water solution gave an additional $5^{\circ} \mathrm{C}$ increase in ignition temperature (tested only at $5 \mathrm{~cm}$ thickness). Comparing these results with Fig. 2(b) indicates that the $20 \%$ add-on used there achieved no more increase than the $10 \%$ add-on. Some caution is necessary since the base materials were different but the results do suggest diminishing returns from increasing amounts of boric acid. It should be noted that $10 \%$ addition of this particular retardant is more in line with commercial practice than is $20 \%$ addition.

Elenental sulfur was also tested in our first batch naterial at a lower level of add-on than in Fig. 2(c). At $10 \%$ add-on it showed no significant effect (tested at 5 an thickness only). Fig. 2(c) indicates a possible slight lowering of the ignition temperature at a $20 \%$ add-on of sulfur. Sulfur is known to be effective in suppressing cellulosic fabric smolder; it is also effective in suppressing insulation smolder ignition when the heat source is a cigarette (McCarter, 1978). It is apparently ineffective in the more severe (and, we feel, more realistic) circumstances of the present test. Since it is a fairly volatile material, there could be some subtle, geometry-dependent thermophysical effects at play here, influencing the actual concentration of sulfur vapors in the incipient reaction zone. 
Context for judging additive effect. Boric acid seems to be one of the best available snolder retardants for cellulosic insulation (especially when economic considerations are also introduced). However, its effect here on snolder ignition is snall, at best, when viewed in absolute terns. The appropriate context for judging the impact of this 20 or $25^{\circ} \mathrm{C}$ increase in snolder ignition temperature is much more complex, however. viewed nationally as a statistical problem, the frequency of snolder ignitions in cellulose-insulated houses per year is the result of the nverlap of two distribution curves. The first distribution qives, versus temperature, the number of houses per year where the insulation is anywhere exposed to a given temperature. The work of Yarborough, et al (1979) with various commercial recessed light fixtures insulated to varying degrees implies that this first distribution is tailing off to relatively small numbers by $250^{\circ} \mathrm{C}$ (at least for this type of heat source). The second distribution gives, versus temperature, the hypothetical number of houses where exposure anywhere of the insulation to a given temperature will result in snolder occurrence. Unfortunately, we have little information on the shape or mean value of this latter distribution; the present data seem to imply the maximum may not be much greater than $300^{\circ} \mathrm{C}$ while the lower end of the distribution tails off perhaps around $250^{\circ} \mathrm{C}$. If these estimates are correct, the two distributions overlap only slightly; in such a context the $20^{\circ} \mathrm{C}$ increase in minimun ignition temperature brought about by boric acid addition could have a large effect on frequency of insulation-inftiated fires. Unfortunately, this question cannot be settled without further information. The present work can shed some light on the probable nature of second distribution curve only. 
Extrapolating to other conditions. The data in Fig. $2(a),(b)$, and (c) are for a linited range of layer thicknesses and one ambient temperature (nominal room temp., $20-25^{\circ} \mathrm{C}$ ). Other conditions are of interest and the model of Bowes and Townshend provides a possible basis for extrapolating the present results to them. Bowes and Townshend (1962) give an iterative procedure for deducing effective kinetic parameters from data such as that in Fig. 2; the results are shown in Table I.

TABLE I

APPARENT KINETIC PARAMETERS DEDUCED FROM HOT PLATE TESTS

\begin{tabular}{|c|c|c|c|}
\hline & Material & $\begin{array}{l}\text { Activation Energy } \\
\text { (cal/mole) }\end{array}$ & $\begin{array}{l}\text { Pre-Exponential, } \\
Q \cdot f\left(\mathrm{cal} / \mathrm{cm}^{3} \mathrm{sec}\right)\end{array}$ \\
\hline 1) & Unretarded Insulation & 27,000 & $3.0 \cdot 10^{8}$ \\
\hline 2) & Above $+20 \%$ Boric Acid & 31,500 & $8.8 \cdot 10^{9}$ \\
\hline 3) & $\# 1+20 \%$ sulfur & 25,000 & $6.1 .10^{7}$ \\
\hline
\end{tabular}

Note that only the product $Q \cdot f$ can be deduced (and only the product is needed in the theory). Once these parameters are available, one can turn around and use them, together with the theory, to predict minimun ignition temperatures for other conditions. The lines in Fig. 3 comprise such a prediction for the effects of layer depth and ambient temperature. Note that the model predicts that ignition temperature varies only modestly $\left(\sim 10^{\circ} \mathrm{C}\right)$ over the widest realistic range of ambient temperature; on the other hand, layer thickness has a more substantial effect. This prediction is qualitatively in agreenent with the results of Yarborough, et al (1979) for the effects of the same variables on peak temperatures in insulated 1ight fixtures. Ignition depends essentially on the balance of heat generation and heat losses and both of the above variables affect the heat loss rate. However, using the steady-state inert temperature profile (Carslaw \& Jaeger, 1959) as a first approximation to that 
obtained here prior to ignition, one can show that the heat loss rate is typically an order of magnitude more sensitive to changes in layer thickness than to changes in ambient temperature. Of course, the heat generation rate, with its exponential temperature dependence, is much more sensitive to factors affecting temperature near the plate and can balance out a very large change in heat loss rate with a modest change in plate temperature.

Use of thermal analysis kinetics. The results in Fig. 3 show that the model described above can successfully correlate the data but further scrutiny of it is needed. Recall from Appendix I that we have available a kinetir. Hessrintinn nf the temperature-dependent weight loss and heat release from this material in air. These processes occur in two successive overall steps and this immediately raises the question as to which of these overall reactions is responsible for the ignition process. It also raises the question of how the predictions of these kinetics compare with those derived above from the experiments. We address these questions first by retaining the Bowes and Townshend assumption of negligible reactant consunption; afterwards we will attempt to assess the impact of finite consumption.

Recall from Appendix I that we have two somewhat different kinetic descriptions of the oxidative weight loss and heat generation in the unretarded insulation material. 'The DSC-based kinetics, while they fit the experimental data of Appendix I somewhat less well then the TGA results, are most relevant here since ignition behavior is responsive to heat evolution rather than weight 1oss. Use of these DSC kinetics for the first and second overall reaction stages as inputs for the Bowes and Tomshend model gives the two solid curves marked $a=0$ in Fig. 4. The dashed curve is based on ignition experiments with the unretarded insulation and is extrapolated (as in Fig. 3) using the kinetics inferred from the data by the method of Bowes and Townshend. Clearly 
the predicted ignition borderline based on the first overall reaction is much more in agreement with the experimental results than is the borderline for the second overall reaction. This should be so for any insulation depth of interest in residential usage. One can show, using the DSC kinetics, that, at the experimental ignition temperatures of Fig. 3, the first overall reaction is generating about 50 times more heat than is the second reaction. It should be noted that the prediction of minimum ignition temperatures for the second overall reaction stage assumes that the entire layer is made up of the solid product of the first reaction at the same bulk density as the initial value and same thennal conductivity; in practice these would tend to change in such a way as to increase the ignition temperature of such a layer somewinat.

If we were to use the TGA-based kinetics here instead, the conclusion would be the same; in fact, the borderline for the second reaction would inove further upward away from the experimental line while the border for first reaction hardly moves.

An important implication of this result is that smolder ignition retardants should be aimed at the first overall reaction stage. Unfortunately, boric acid has its greatest effect on the second reaction stage (see below) . The product of the first reaction stage (which is the reactant for the second stage) is a black, somewhat-shrunken replica of the original fibrous mass; it is this product which we call char. As we will see below this char does contribute to smolder propagation.

Boric acid impact on DSC. The use of the DSC results to predict ignition behavior of unretarded material is generally successful. It is of interest to see what the DSC implies about the effect of a retardant on smolder behavior. Figure 5 shows the influence of boric acid addition on both the TG and DSC 
curves of cellulosic insulation. Again, the DSC curve for the first overall reaction stage is most relevant to ignitability. The $10 \%$ boric acid add-on shifts the first reaction portion of the curve upward about $15^{\circ} \mathrm{C}$. Figure 2 shows an upward shift of about $20^{\circ} \mathrm{C}$ for $20 \%$ boric acid add-on. There is thus a reasonably good correspondence between the effect on the DSC curve and the effect on ignitability. This suggests that the DSC could be used to rapidly scan candidate ignition retardant materials (assuming good care in blending the small samples used). As we will see below, the DSC is harder to correlate with retardant effects on propagation.

Reactant Depletion Effects. Returning to Fig. 4, we note that while the DSC-based prediction for the first reaction (with no reactant consumption) is in reasonable quantitative agreement with the actual experimental minimum ignition temperatures, the slopes of the two curves are distinctly different; this leads to significant differences in extrapolated values for large layer thicknesses. Exact quantitative agreement is not be expected. The heat transfer parameters, thermal conductivity and outer surface heat transfer coefficient, are obtained from the literature and cannot fit the present situation exactly. Fortunately, the model above tells us that the ignition border line is not very sensitive to these values; for example, a $20 \%$ change in thermal conductivity shifts the ignition line in a nearly parallel fashion by only 2 or $3^{\circ} \mathrm{C}$.

There is something more important contributing to the slope disagreement in Fig. 4, i.e., reactant depletion effects that are ignored in the above model. The real experiments are, of course, transient in nature. The layer of fuel is formed on the plate and the plate is then heated to some temperature and held there. Both reactants, oxygen and fuel, are being consumed before 
actual ignition.

Using the DSC results of Appendix I, we can make an approximate calculation of first reactant depletion prior to ignition (Table II). The calculations have been made at an approximate mean of experimental and thermal-analysis-predicted ignition temperatures for the layer thicknesses shown. Once the fixed plate temperature is reached, the fraction of the fuel at the hot surface which has reacted, as a function of time, is given by

$$
a=\left(k t+\left(1 /\left(1-a_{0}\right)\right)-1\right) /\left(k t+\left(1 /\left(1-a_{0}\right)\right)\right)
$$

where

$$
k=1.2 \cdot 10^{13} \exp (-41,500 / \mathrm{RT}), \sec ^{-1}
$$

and

$$
\begin{aligned}
& a_{0}=G /(1+G) \\
& G=(E / \beta)\left(R T_{p}{ }^{2} \exp \left(-E / R T_{p}\right)\right) /\left(E+2 R T_{p}\right)
\end{aligned}
$$

This first expression follows from constant temperature integration of the DSC rate law of Appendix I; the kinetic parameters in the rate constant are for the first overall oxidative degradation reaction. It is important to note that the above equation holds strictly only for the fuel in contact with the plate; however, only the first few millineters of the layer depth (Bowes and Townshend, 1962) actually react during the early ignition process. Thus, the above equation exaggerates the reactant consunption of the "ignition zone" somewhat, but it is useful for estimating these effects. The quantity $a_{0}$ in the above equations is the fraction that has reacted when the plate just reaches its set value (i.e., the amount reacted during heat-up). We estimate this by noting that, to a first approximation, the plate heats up 1 inearly at about $10^{\circ} \mathrm{C} / \mathrm{min}$; we have thus used the Gorbachev approximation of Appendix I (Eqn. 3) and the DSC rate law to derive the above expression for $a_{0}$. 
TABLE II

\section{SOIID REACTAKT DEPLETION PPICF TO IGNITION CALCULATED USELG DSE KINETICS}

\begin{tabular}{|c|c|c|c|c|c|c|}
\hline $\begin{array}{l}\text { Layer Depth } \\
\text { (cm) }\end{array}$ & $\begin{array}{c}\text { Theru:al } \\
\text { Relaxat:on Time } \\
t^{*}(\sec )\end{array}$ & $\begin{array}{l}\text { Ignition Temp- } \\
\text { erature } T_{p}\left({ }^{0} \mathrm{C}\right)^{*}\end{array}$ & $\begin{array}{c}\text { Frac. Reacted } \\
\text { When } \mathrm{T}_{\mathrm{p}} \\
\text { Feached, }{ }_{\mathrm{a}}\end{array}$ & $\begin{array}{l}\text { Reaction Rate } \\
\text { Constant, } s e e^{-1}\end{array}$ & $\begin{array}{c}\text { Frac. Reacted } \\
\text { at } t^{*}\end{array}$ & $\begin{array}{l}\text { Reaction Rate } \\
\text { Decreased by } 2 \\
\text { Factor }(1-a)\end{array}$ \\
\hline 3 & $4.9 \cdot 10^{2}$ & 501 & $1.6 .10^{-1}$ & $2.1 .10^{-5}$ & 0.55 & 0.20 \\
\hline 7 & $2.7 .10^{3}$ & 271 & $2.1 \times 10^{-2}$ & $2.5 .10^{-4}$ & 0.41 & 0.35 \\
\hline 15 & $1.2 .10^{1}$ & $\approx 45$ & $1.8 .10^{-3}$ & $3.7 .10^{-5}$ & 0.31 & 0.48 \\
\hline 30 & $4 \cdot 9 \cdot 10^{7}$ & $=25$ & $3.3 \cdot 10^{-4}$ & $7.3 .10^{-E}$ & 0.26 & 0.55 \\
\hline
\end{tabular}

* Approximate average of expt'1 extrap. value and DSC-predicted value. 
There are several points of interest in Table II. The times shown in the second column are the themal relaxation times for the respective layer thicknesses. From the inert transient heat conduction solution (Carslaw \& Jaeger, 1959), one can show that the temperature gradient at the hot surface is within a few percent of its steady state value when

$$
t=\left(0.40 \ell^{2} / \alpha\right), \sec
$$

Here $\alpha$ is thennal diffusivity and $\ell$ is layer thickness (CGS units). This is the value reported for $t^{*}$; note that it is strongly dependent on layer thickness, covering a range of two orders of magnitude in Table II. Since the real test is transient in nature, $t^{*}$ is a measure of how long it should take to achieve ignition when the plate temperature is at or near the minimum ignition value. Before $t^{*}$ the heat losses from the reaction zone are increased by transient thennal wave effects; after $t^{*}$ the losses are constant but the heat generation rate continues to decline via fuel consumption.

Table II indicates that there is much more time available for reactant consumption with thick layers, but this time factor is more than offset by the lower ignition temperatures. The net result is that reactant consumption affects thin layers more than thick layers of fuel (see last two columns of Table II). Thus, in Fig. 4 the observed ignition border will tend to have a steeper slope than any of the constant-fraction-depletion lines $(a=0.15, a=0.45)$ and to cross them. Note that the value of $a$ in Fig. 4 applies implicitly to the entire layer while the value in Table II is for the hottest region at the surface only; this is why lower values of a are used in Fig. 4. This varying depletion effect is the reason for much of the difference between the experimental and thermal-analysis-based curves in Fig. 4. It is not the total explanation since the extrapolated experimental curve passes outside the band of predicted ignition temperatures. This may be due to 
some ambiguity in the experimental slope caused by the $5^{\circ} \mathrm{C}$ spacing of successive go/no-go tests.

Note in Table II that we estimate more than 508 consunption of the hottest part of the fuel in the 3 an case and, more importantly, substantial consumption during plate heatup. Since heat-up is much shorter than total equilibration time, substantial amounts of heat released during this period may not be lost from the systen. This is probably what causes a diffuse sort of ignition during heat-up in thinner layer cases (e.g., 2 an).

The other reactant subject to consumption prior to ignition is oxygen. Here we have some direct measurements as shown in Fig. 6. Samples (1/2 to 1 cc) from immediately above the center region of the plate were slowly withdrawn into a syringe and analyzed by gas chromatography. This was done in three successive tests and the data all fell on the oxygen curve shown. For reference, the temperature history of the plate and the near-plate fuel layer are included. It is apparent that there is significant $(\sim 20-25 \%)$ oxygen depletion prior to the sample temperature running away but, since this has a less than linear effect on the reaction rate, tnis would retard iguitiun only a few degrees centigrade. Extensive oxygen depletion is occurring only as the sample temperature goes well above the plate temperature.

Oxygen is replenished in the ignition zone by convection and by diffusion; we can estimate the contributions of these two sources to the reaction zone. Looking first at diffusion in the absence of convection, we can estimate the depletion in $\mathrm{O}_{2}$ concentration at the hot plate surface necessary to supply the reaction zone, i.e.,

$$
\overline{\rho D}\left(Y_{O X A}-Y_{O X S}\right) / l=\dot{S}_{O 2}\left(g O_{2} / \mathrm{cm}^{2} \text { sec }\right)
$$

where 


$$
\dot{\mathrm{S}}_{\mathrm{O} 2} \simeq \mathrm{n}_{\mathrm{O} 2} \mathrm{X}_{\mathrm{RZ}} \rho_{\mathrm{FB}}(1-\mathrm{a})^{2} \mathrm{Y}_{\mathrm{OXS}} \operatorname{Aexp}\left(-\mathrm{E} / \mathrm{RT}_{\mathrm{p}}\right)
$$

The two critical factors in this last expression are $\mathrm{n}_{02}$, the grams of $\mathrm{O}_{2}$ per gram of fuel reacted, and $x_{\mathrm{RZ}}$, the effective reaction zone thickness. For $\mathrm{n}_{\mathrm{O} 2}$, we have a measured value of 0.03 , deternined in separate $1-D$ smolder propagation experiments. For $\mathrm{X}_{\mathrm{RZ}}$, "we use the estimate that it is twice the depth of the slight temperature peak near the hot surface (Bowes and Townshend, 1962); temperature is nearly constant over this depth

$$
\mathrm{x}_{\mathrm{RX}}=.028 \ell(\text { (UII) }
$$

Then these results can be combined to estimate the $\mathrm{O}_{2}$ level near the hot plate surface, Y YXS, as a function of insulation layer depth; the results in Table III use the same temperatures and reacted fuel fractions as in Table II. The last column in Table III indicates that, regardless of layer depth, diffusion should be able to match the pre-ignition reaction with negligible depletion. This is supported by separate experiments we have performed on 20 cn fuel layers that showed $\mathrm{O}_{2}$ depletion comparable to that in Fig. 6 for a 7 an layer. Diffusion is supplemented by a convective inflow of air. We can only estimate its order of magnitude in view of the probable complexity of the flow. A balance of buoyancy and flow drag leads to

$$
\begin{aligned}
\dot{M}_{02} & \simeq .231\left(g_{R} \rho^{2 / a_{D}}\right)\left(\mu_{R} / \mu\right)\left(\bar{T}-T_{R} / \bar{T}\right) \\
& \simeq 5.10^{-6}\left(g / \mathrm{cm}^{2} \mathrm{sec}\right)
\end{aligned}
$$

Here $a_{D}$ is a measured "drag constant" for the insulation. This flux of $\mathrm{O}_{2}$ is larger than $\dot{\mathrm{S}}_{\mathrm{O} 2}$ in Table III so that we once again conclude $\mathrm{O}_{2}$ depletion should be small. In view of the experimental results in Fig. 6 the calculations here appear somewhat optimistic; recall, however, that we are calculating based on a non-igniting steady-state while Fig. 6 applies to an igniting transient situation. In any event, the neglect of $\mathrm{O}_{2}$ depletion for any case of interest in the present attic insulation context appears justified. 
OXYGEN DEPLETION AND FLUX AT IGNITION CALCULATED USING DSC KINETICS

\begin{tabular}{|c|c|c|c|c|}
\hline Layer & $\begin{array}{l}\text { Thickness, } \\
(\mathrm{cm})\end{array}$ & $\begin{array}{c}\text { Ignition Temp. } \\
\mathrm{T}_{\mathrm{p}}{ }^{*}\left(\mathrm{O}_{\mathrm{C}}\right) \\
\end{array}$ & $\begin{array}{l}\text { Oxygen Mass } \\
\text { Frac. at Hot } \\
\text { Surface, Y OXS } \\
\end{array}$ & $\begin{array}{c}\text { Oxyqen Mass } \\
\text { Flux to Reac. } \\
\text { Zone }\left(\mathrm{g} / \mathrm{cm}^{2} \mathrm{sec}\right)\end{array}$ \\
\hline & 3 & 301 & .23 & $3.1 .10^{-7}$ \\
\hline & 7 & 271 & .23 & $1.7 .10^{-7}$ \\
\hline & 15 & 245 & .23 & $7.1 .10^{-8}$ \\
\hline & 30 & 225 & .23 & $3.2 .10^{-8}$ \\
\hline
\end{tabular}

*Approximate average of expt'l extrap. value and DSC-predicted value. 
TWO-DIMENSIONAL SIMOLDER PROPAGATION

Experimental Details

The apparatus for these tests was again quite simple. A rectangular screen wire basket (20 an wide, 40 an long, 25 an deep) was insulated on the outside bottom and sides with $21 / 2$ an of ceramic fiber insulation. The outside of thesé planes was covered with 24 gage sheet metal to block air influx. The ends of the basket were covered with 5 an layers of highly permeable fiberglass batt insulation.

Cellulosic insulation of the desired composition was weighed out and formed into a layer of the desired thickness covering the bottom of the basket by careful hand distribution. Three thennocouples (35 gage chromel/alumel) were included in the layer at mid-depth and at 10 an intervals; these were inserted laterally, parallel to the bottom surface of the layer. The temperature-time records of the thennocouples and their known spacing permitted calculation of the average snolder velocity between each pair. Smolder was initiated uniformly at one end of the layer by an appropriately-shaped, electric heater cable. Smolder propagated into the layer, away from the heater, in accord with its own self-induced buoyant flow of air.

Snolder propagation in this situation bears a strong resemblance to that encountered in layers of insulation placed between the wooden joists of an attic. The present situation is somewhat more adiabatic due to the replacenent of the lateral joists and underlying plasterboard with ceranic fiber insulation. The length of the bed used here is about four times the snolder wave length (for thin insulation layers) so that end effects are not greatly influencing the zone, midway along the bed, where peak temperatures and smolder velocities are measured. Of main interest here is the minimun bed depth below 
which the snolder wave, though fully ignited, is unable to continue propagating to the opposite end of the bed due to heat losses. This minimun depth is ascertained in successive experiments of a go/no-go nature, using layers of increasing depth. We have also compared smolder propagation characteristics at greater bed depths.

Results and Discussion

This 2-D,buoyantly-driven smolder wave is complex in structure. It appears that it propaqates as coupled, sequential near co-current and near counter-current zones with the former leading (more detailed studies of the wave structure are in progress). It is probable that the co-current portion involves the first overall oxidation stage of the insulation and the counter-current portion the second overall oxidation stage. With both stages involved in propagation, rather than just the first, as in ignition, we can expect different quantitative effects of the same fuel additives.

The results of our examination of the impact of additives on smolder propagation are summarızed in Table IV. Note that, as with the ignition experiments, the bulk density was adjusted to keep the amount of fuel per unit volume constant.

The minimum layer depth that just gives continuing propagation (end to and though not necessarily full width) is shown in the middle column. This value is some measure of the total heat generation rate in the wave. Heat losses per unit volume of the bed increase inversely with the bed depth. At the minimum depth, losses just overcome heat generation. The unretarded material is able to endure the greatest losses. With the assumption of equal wave structures (roughly true), the doubling of the minimum depth when 208 boric acid is added, implies this retardant about halves the overall rate of heat generation. The 
TABLE IV

EFFECTS OF ADDITIVES ON SMOLDER PROPAGATION IN CELLULOSIC INSULATION

\begin{tabular}{|c|c|c|c|c|c|}
\hline & MATERIALS & $\begin{array}{c}\text { BULK } \\
\text { DENSITY }\left(\mathrm{g} / \mathrm{cm}^{3}\right)\end{array}$ & $\begin{array}{l}\text { MINIMUM LAYER DEPTH FOR } \\
\text { CONTINUING PROPAGATION } \\
(\mathrm{cm})\end{array}$ & $\begin{array}{l}\text { SMOLDER VELOCITY } \\
(\mathrm{cm} / \mathrm{sec})^{a}\end{array}$ & $\begin{array}{l}\text { PEAK SMOLDER WAVE } \\
\text { TEMPERATURE }\left({ }^{\circ} \mathrm{C}\right)^{\mathrm{a}}\end{array}$ \\
\hline 1) & $\begin{array}{l}\text { MILLED } \\
\text { UNRETARDED } \\
\text { INSULATION }\end{array}$ & $3.8 \cdot 10^{-2}$ & $31 / 2$ & $\left.\begin{array}{l}4.6( \pm 0.4) \times 10^{-3} \\
6.5( \pm 0.6) \times 10^{-3}\end{array}\right\} b$ & $623 \pm 18$ \\
\hline 2) & $\begin{array}{l}\text { ABOVE + } 20 \% \\
\text { BORIC ACID }\end{array}$ & $4.6 \cdot 10^{-2}$ & $61 / 2$ & $2.8( \pm 0.2) \quad 10^{-3}$ & $753 \pm 9$ \\
\hline 3) & $\begin{array}{l}\# 1+20 \% \\
\text { SULFUR }\end{array}$ & $4.6 \cdot 10^{-2}$ & 4 & $\left.4.8( \pm 1.2) \times 10^{-3}\right\} \mathrm{c}$ & $554 \pm 17\} \mathrm{c}$ \\
\hline 4) & $\begin{array}{l}\text { COMMERCIAL } \\
\text { BLEND }\end{array}$ & $4.6 \cdot 10^{-2}$ & NOT MEASURED & $3.4( \pm 0.4) \times 10^{-3}$ & $614 \pm 22$ \\
\hline
\end{tabular}

a For layer depths in range $15-20 \mathrm{~cm}$; \pm range is average deviation for 4 to 8 measurements.

$\mathrm{b}$ Upper numbers for passage between first set of thermocouples; lower for second set.

c Limited data. 
effect on minimun snolder depth is a much more dramatic effect than that which boric acid has on snolder ignition (though, in fact, the impact on rate of heat generation is comparable in both situations). Note that, even with $20 \%$ boric acid, the minimun smolder propagation thickness is small compared to usual attic insulation layers (20-30 an).

It is not apparent from the DSC curves of Fig. 5 that the total available heat $(\mathrm{cal} / \mathrm{s})$ will be reduced a great deal. The boric acid inanages, however, to stop the oxidation process short of completion in the actual smolder wave; the residue weight, corrected for $\mathrm{B}_{2} \mathrm{O}_{3}$ cont.ent, still comprises about $2 / 3$ of the available char. The boric acid succeeds in doing this even though, as the last column shows, the temperature achieved in the wave is substantially higher than that without boric acid. These seemingly incompatible results are presumably a consequence of rate processes. The higher temperature is possible, despite lower heat release rates, because the layer remains much thicker cutting heat loss rates. At some point prior to complete combustion, however, the loss rate exceeds the heat generation rate and the consumption of char ceases. All this is a consequence of the retarding of the rate of char oxidation (second overall stage) by the boric acid residue.

At the same time, Table IV indicates that the boric acid containing material has roughly half the smolder velocity of the unretarded material. The temperature structure of the 2-D smolder wave (to be reported in detail elsewhere) implies that it is largely the first overall oxidation stage that determines the propagation rate. In view of this and the comparatively small effect (in Fig. 5) of boric acid on the first oxidation stage, it is surprising to see such a large change in smolder velocity. This is a point that requires further investigation. 
Table IV shows that sulfur has only a sinall effect on the minimun depth for continued smolder propagation or on snolder velocity. This latter observation is in contrast to measurements reported by Earl (1979) for the effect of sulfur on snolder propagation in cotton batting; there a 10 s sulfur addition produced a halving of smolder velocity. Our observation of decreased peak temperature is in agreement with Earl; this presumably reflects an impact of sulfur on the kinetics of char oxidation. It should be noted, however, that sulfur, unlike boric acid, does not stop the char oxidation prior to completion; the smolder residue with sulfur present is the same $5-6 \%$ by weight of the original as it is with no retardants present.

A possible source of the disagreement with regard to sulfur effects on smolder velocity lies in transient effects. In the case of the unretarded material in Table IV, there is an indication that the snolder wave was accelerating. In the case of the sulfur addition, our limited data point to a possibly decreasing velocity with time. The sources of such effects are not clear at present and deserve further investigation.

Finally, we note that the commercial blend of retardants yields behavior intermediate between the unretarded case and the $20 \%$ boric acid case. This is to be expected since boric acid is probably about half of the retardant blend and the principal ingredient with an impact on smolder characteristics. .

As additional information is obtained on the structure of this $2-D$ smolder propagation wave, the factors controlling propagation should be clearer. A more quantitative rationalization of the above results should then be possible. This will aid the development of improved snolder suppression methous. 
CONCLUS IONS

The results here support the applicability and usefulness of the Bowes and Townshend model of snolder initiation. The ignition situation which this inodel describes bears a sufficient resemblance to the real hazard situation of insulation usage around recessed light fixtures in attics that one can expect the results to carry over qualitatively and, in some cases, semi-quantitatively. The results here coupled with the model predictions indicate that, in order of importance, the factors influencing smolder ignition temperature are:

1) Heat source and insulation layer geometry. In the present 1-D case this reduces to layer thickness only but it can become more complex. Figure 4 indicates that the range of realistic layer thicknesses can produce $100^{\circ} \mathrm{C}$ variation in minimum ignition temperature.

2) Present smolder retardants. Figure 3 indicates that these cause variations of only about $20^{\circ} \mathrm{C}$ in minimun ignitıon temperature. This small variation could be of disproportionately large significance if it raises the ignition temperature of most insulation installations above the maximum probable heat sunitie Lenperaluite.

3) Other themophysical parameters (insulation density, thennal conductivity, cool surface heat transfer coefficient, ambient temperature). The Bowes and Townshend model provides predictions of the impact of these parameters; it is of the order of $10^{\circ} \mathrm{C}$ for realistic ranges of variation.

Thennal analysis can successfully provide kinetic parameters that permit a priori predictions of sinolder ignition temperatures. DSC has the potential of being a valuable screening tool for ignition retardants. 
Smolder spread, inasinuch as it involves both overall oxidation stages of the cellulosic naterial, is differently affected by retardants. Boric acid has a rather large effect but is far from being able to preclude snolder propagation in real applications. Sulfur, in contrast to its undesirable effect on ignition, shows some tendency to weaken propagation. The mechanisms of action of these materials on ignition propagation are far from clear; more work is needed. 


\section{Nomenclature}

a - fraction of solid reactant that is consumed at some time, $t$; here used only for first stage of overall oxidation

$a_{0}$ - fraction reacted when plate temperature is just reached

E - apparent activation energy

E - pre-exponential frequency factor

h - convective heat transfer coefficient, top of fuel layer to anbient

$\ell$ - insulation layer thickness

$Q$ - heat release per unit mass reasted

r - half thickness of insulation layer; $r=\ell / 2$

R - gas constant

$\mathrm{T}$ - temperature

$\mathrm{T}_{\mathrm{p}}$ - plate temperature

$X$ - distance nonnal to hot plate

$\beta$ - constant heating rate

$\lambda$ - thermal conductivity of insulation layer 


\section{References}

1. Bowes, P. C., and Townshend, S. E., (1952), Ignition of Combustible Dusts on Hot Surfaces, British Journal of Appl ied Physics 13, 105.

2. Carslaw, H. S. and Jaeger, J. C., (1959), Conduction of Heat in Solids, Oxford University Press, 126.

3. Earl, W., (1979), Results presented at N3S Annual Conference in Fire Research.

4. Energy Research and Developnent Administration, (1977), Survey of Cellulosic Insulation Materials, ERDA 77-23, January 1977.

5. McCarter, R. J., (1978), National Bureau of Standards, personal communication.

6. New York Institute of Technology, (1977), study results on insulation material quoted in New York Times (November 10, 1977) under title "Choosing Home Insulation".

7. Thomas, P. H. and Bowes, P. C., (1961), Thermal Ignition in a Slab with One Face at a Constant High Temperature, Transactions of the Faraday Society, 57, Part II, 2007.

8. Yarborough, D. W., Yoo, K. T. and Konery, P. B., (1979), Recessed Light Fixture Test Facility, Oak Ridge National Laboratory Report, ORIN/SUB - 7504/3, July, 1979.

9. Zicherman, J. B. and Fisher, F. L., (1978), Fire Protection Problems Associated with Cellulose Based Insulation Products, society of Fire Protection Engineering Technology Report, 78-7, Boston, MA. 


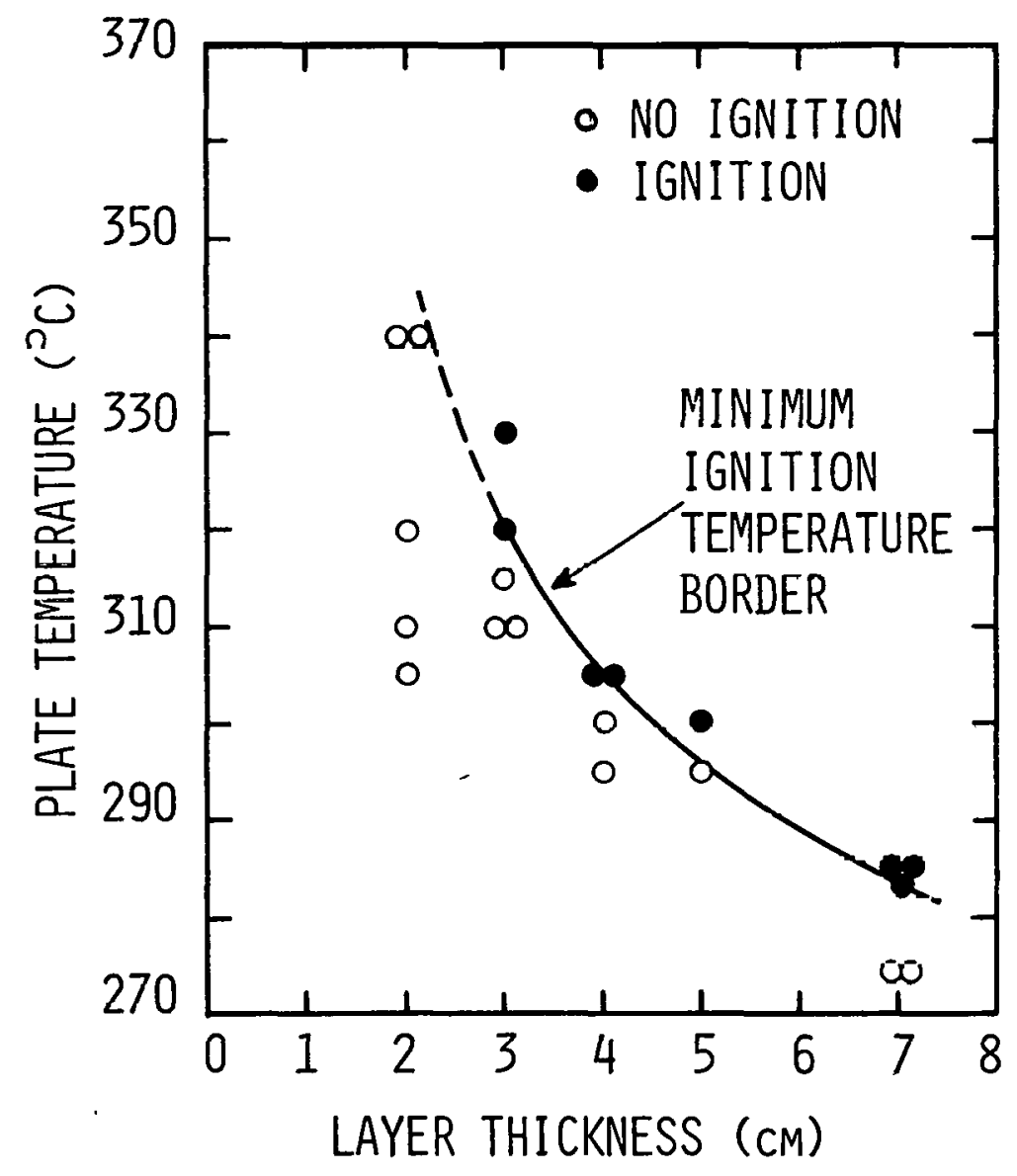

1. Thickness-dependent smolder ignition behavior of a commercial cellulnsic. insulation; bulk density is $2.2 \mathrm{lb} / \mathrm{ft}^{3}$. 


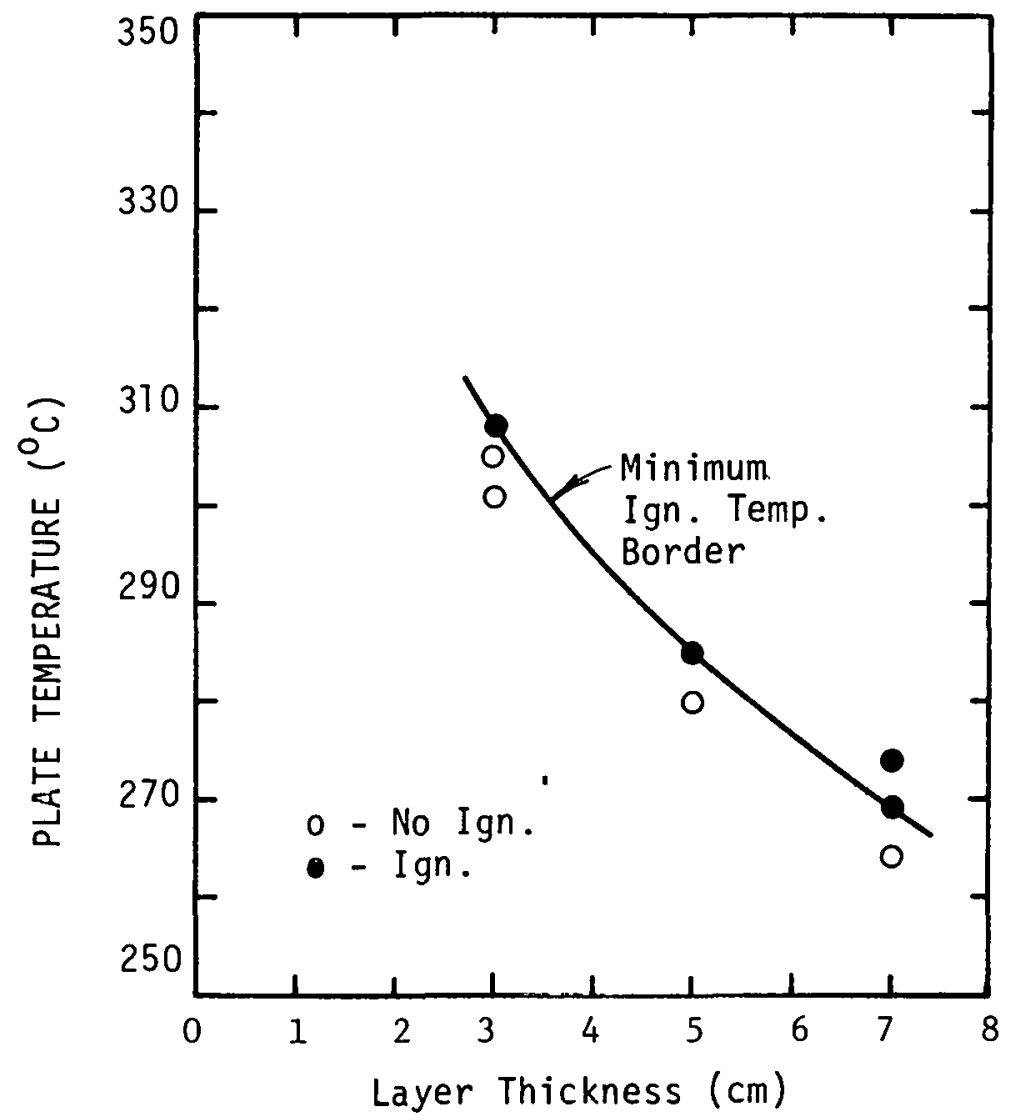

2. Thickness-dependent smolder ignition test results for three insulation compositions:

a.) unretarded $\left(2.4 \mathrm{lb} / \mathrm{ft}^{3}\right)$ 


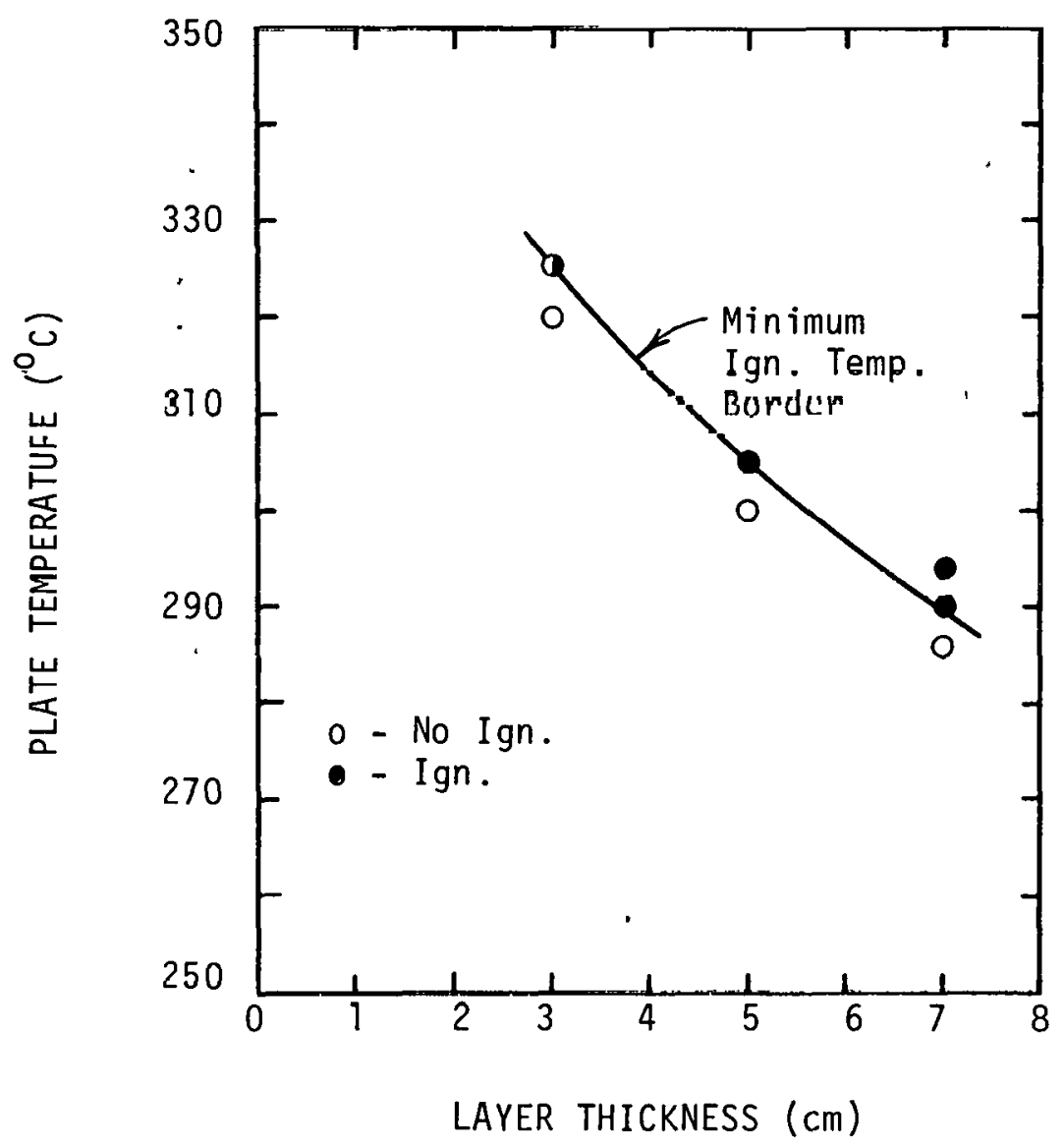

2. Thickness-dependent smolder ignition test results for three insulation compositions:

b.) $20 \%$ boric acid added to unretarded (2.88 $\left.1 \mathrm{~b} / \mathrm{ft}^{3}\right)$ 


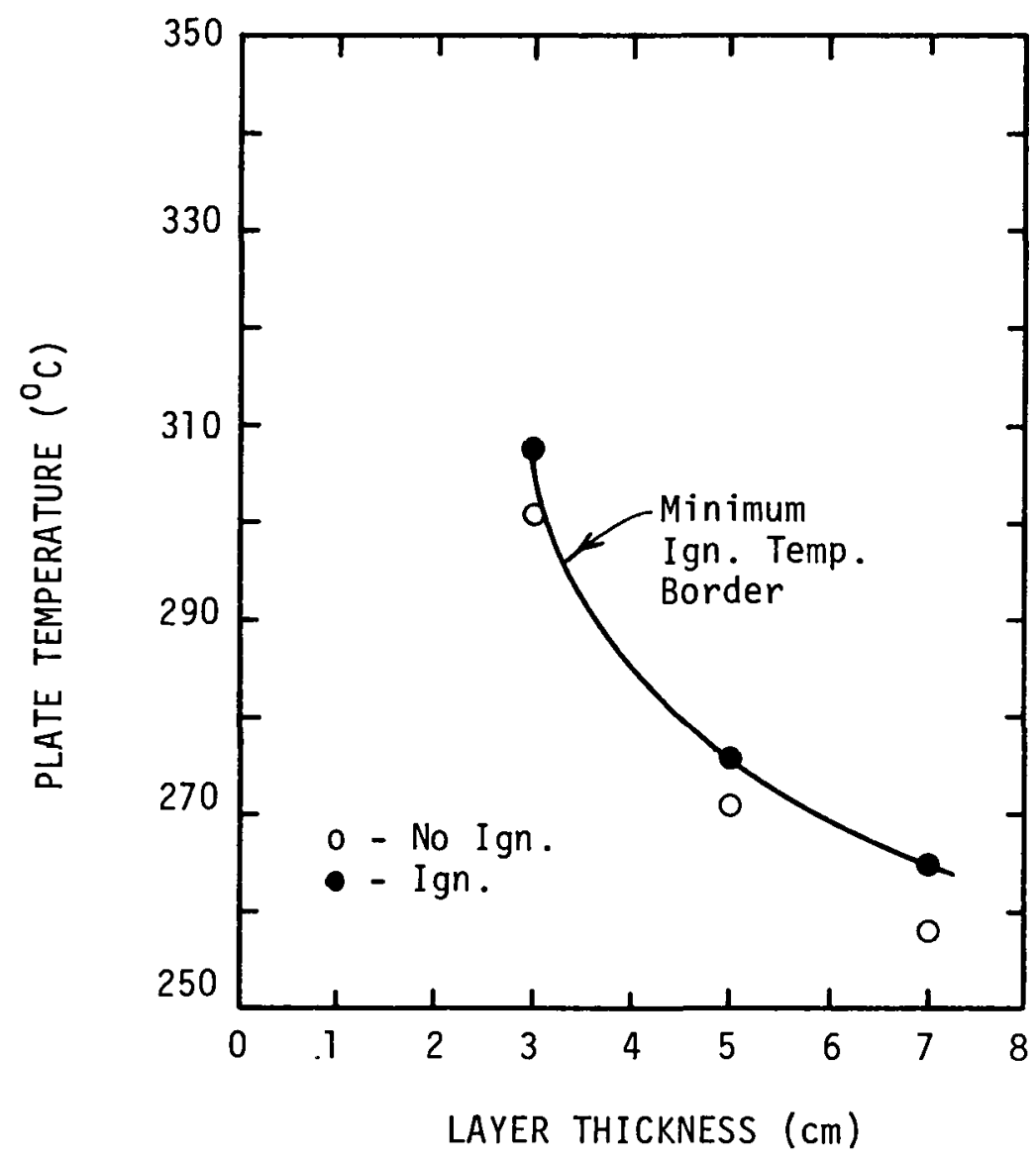

2. Thickness-dependent smolder ignition test results for three insulation compositions:

c.) $20 \%$ suifur added to unretarded $\left(2.88 \mathrm{lb} / \mathrm{ft}^{3}\right)$ 


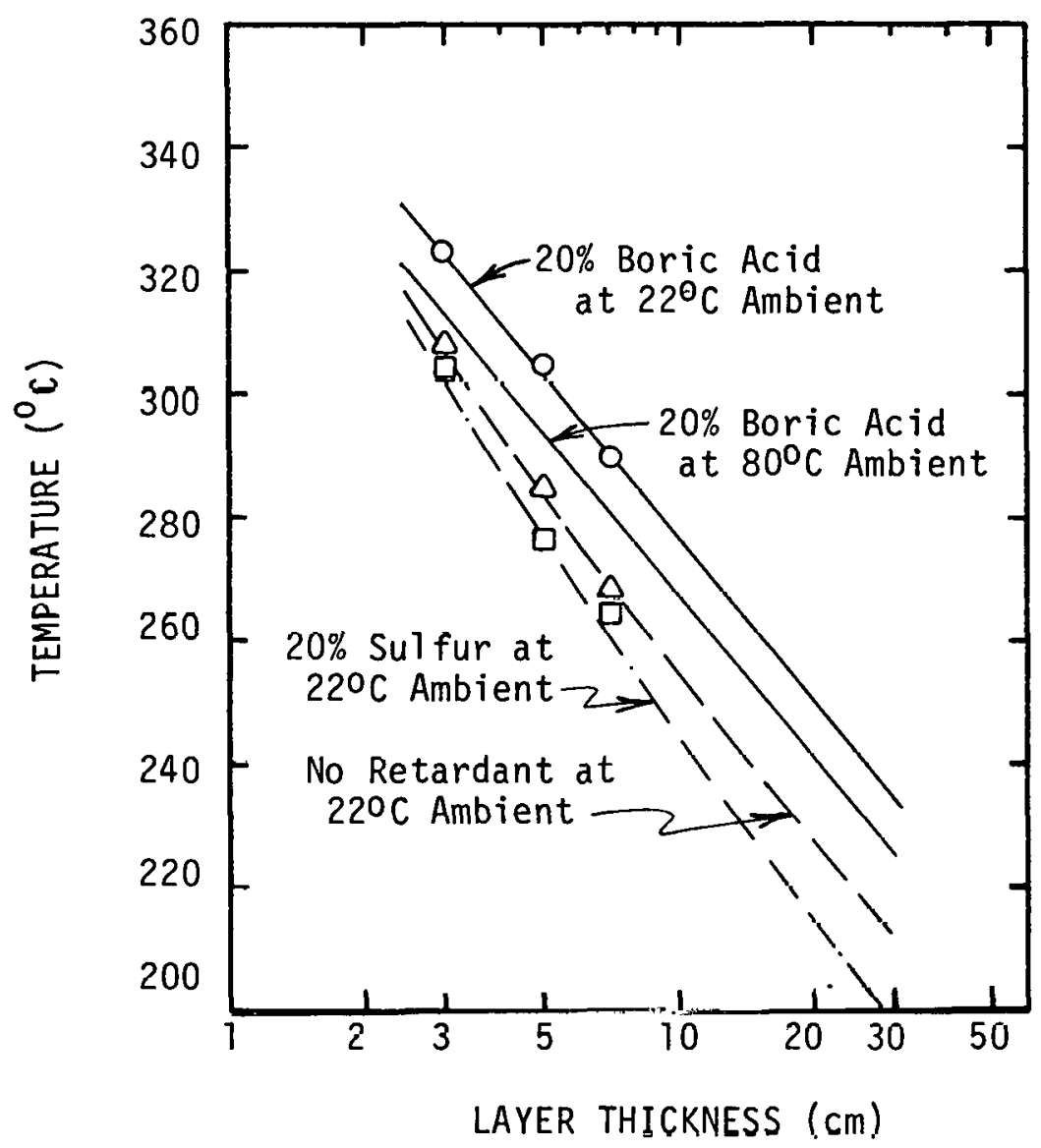

3. Minimum ignition temperature borders for three materials extrapolated to other conditions using Bowes and Townshend model. Symbols are dat,a points along the ignition border; lines are model fit to data and extrapolation. 


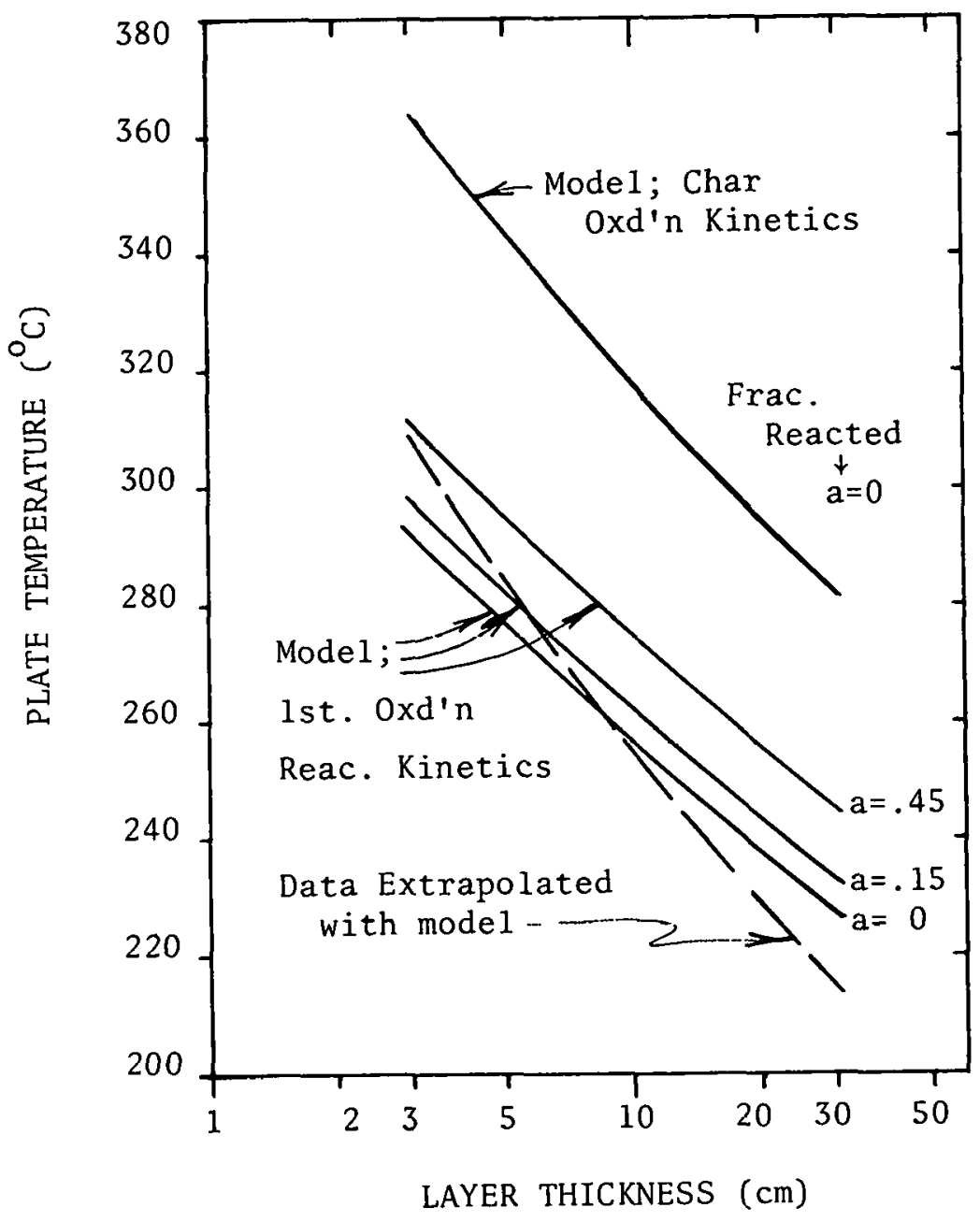

4. Comparison of experimental ignition borderline (+ extrapolation) and model result based on DSC kinetics; a is fraction of material consumed in first oxidation stage. 


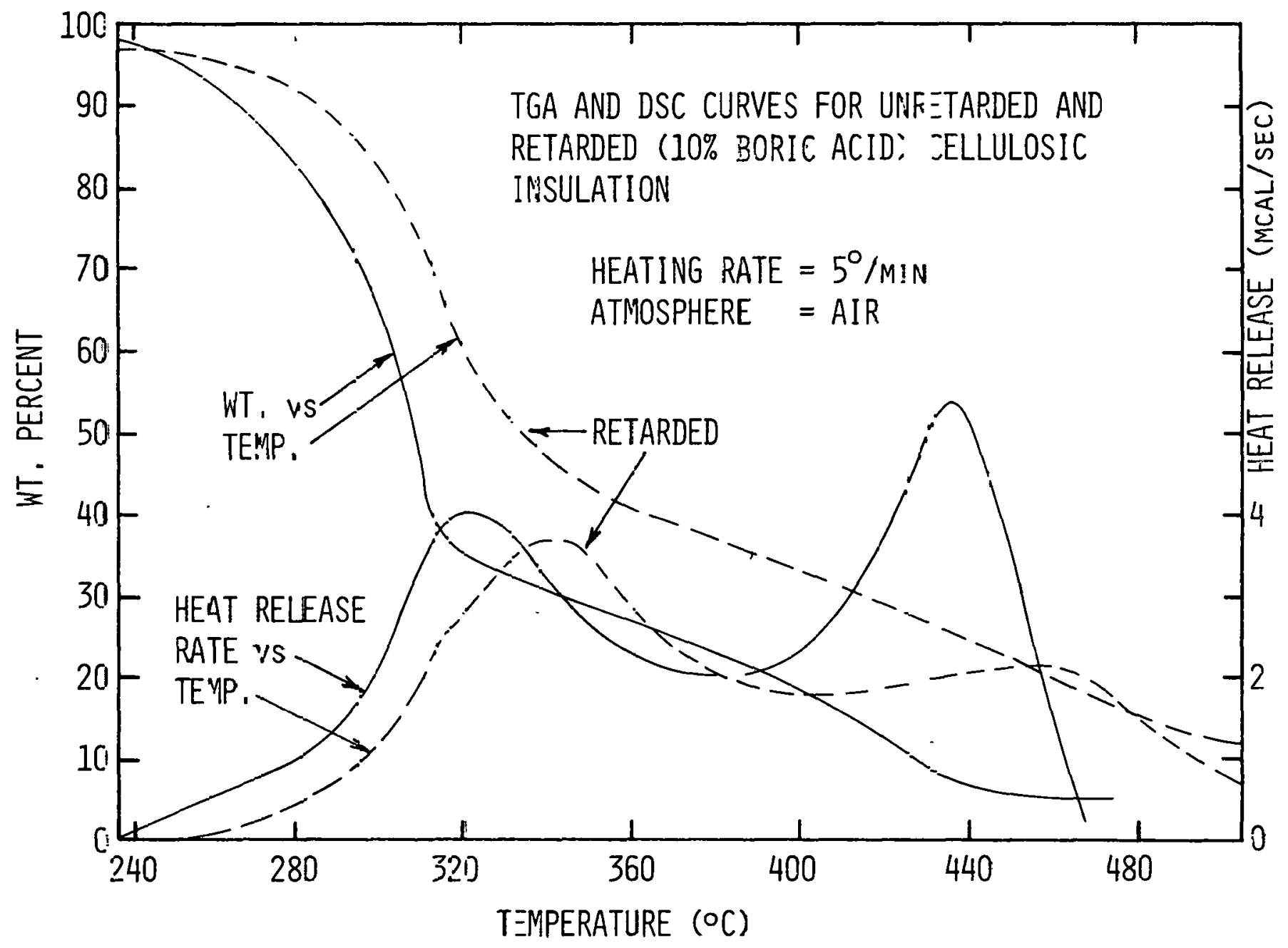

5. Thermogravinetry (TGA) and differential scanning calorimetry (DSC) curves 三or unretarded and boric-azid-retarded insulation materials. 


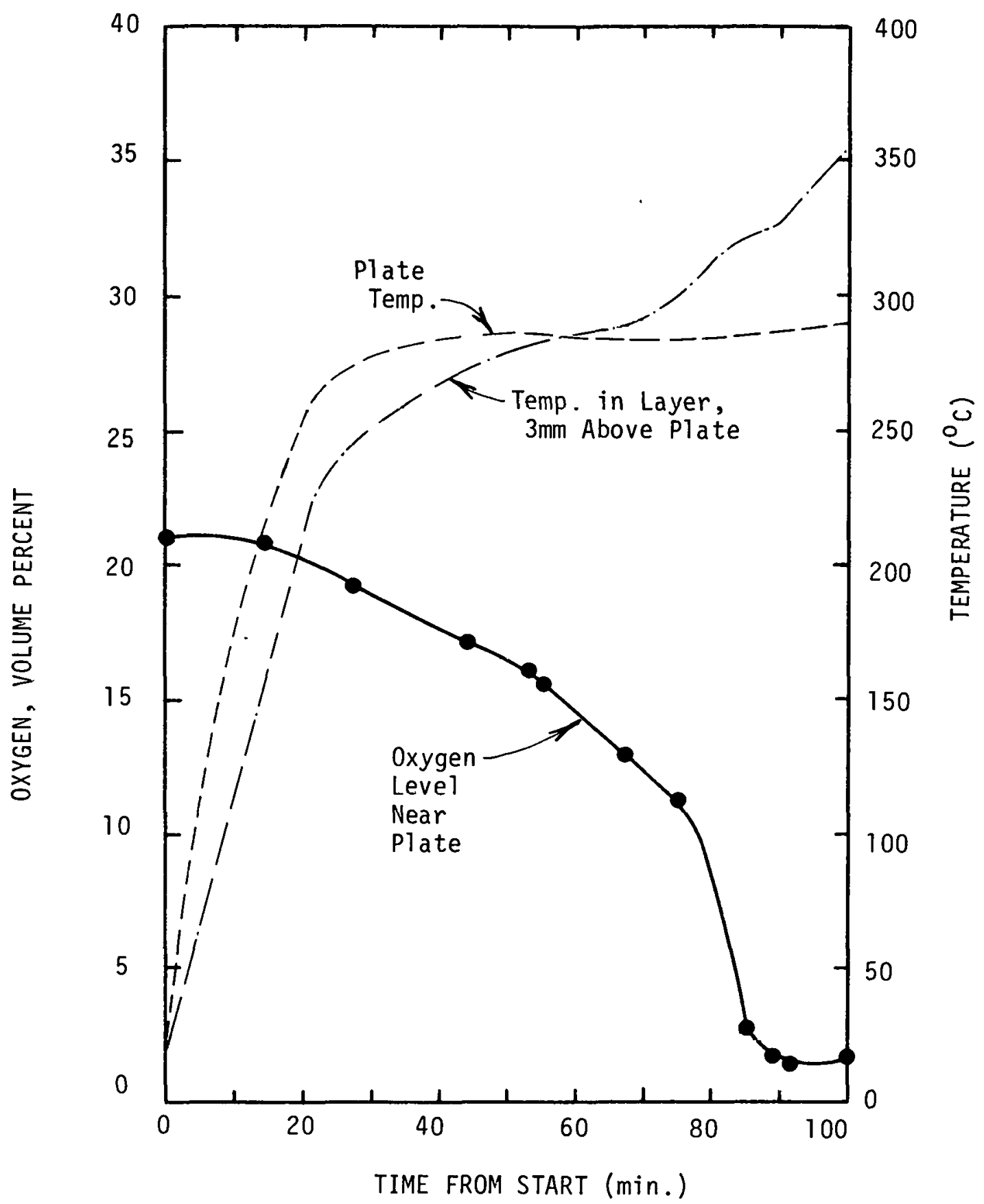

6. Transient behavior, near-plate, of oxygen percentage and temperature during hot plate ignition tests; case when ignition occurs. 


\section{THIS PAGE}

\section{WAS INTENTIONALLY \\ LEFT BLANK}




\section{APPENDIX III}

Pyrolysis Kinetics of a Polyurethane Foam by Thermogravimetry; A General Kinetic Method

$$
\text { F. E. Rogers and T. J. Ohlemiller }
$$

Mechanical and Aerospace Engineering Department Princeton University Princeton, New Jersey 08544

\section{$\underline{\text { ABSTRACT }}$}

Kinetic studies on the decomposition of a flexible polyurethane foam based on tolylene diisocyanate (TDI) and a polyether polyol of propylene oxide ( $P P O$ ) have been carried out with the thermogravimetric technique (TGA). In dry nitrogen the decomposition proceeds in two overall steps. At the end of the first step, which follows a diffusion-control rate law, the cellular structure collapses to a viscid liquid. The viscid liquid decomposes further in accord with a random nucleation rate law. The activation parameters which provide very good fits to the experimental TGA curves at heating rates of 2 and $20^{\circ} / \mathrm{min}$ are $A_{1}=3.4 \times 10^{19} \mathrm{~min}^{-1}, E_{1}=52 \mathrm{kcal} / \mathrm{mol}$, and $A_{2}=6.8 \times 10^{12} \mathrm{~min}^{-1}, E_{2}=39 \mathrm{kcal} / \mathrm{mol}$. A general approach for the derivation of kinetic parameters for such complex reactions is presented. 
Introduction

In connection with a study of the smoldering combustion of polyurethane foams $[1-7]$, it became necessary to develop procedures to evaluate the overall kinetics of the decomposition of these materials. This communication deals with the decomposition kinetics of a particular flexible foam which exhibits a marked smolder tendency .

Commercial flexible polyurethane foams are most often prepared trom tolylene dissocyanate (80:20 mixture of 2,4- and 2,6-isomers), a polyether polyol, water, a blowing agent, catalysts and a surfactant. The principal bonds formed in the polymerization reaction are urethane and urea groups.

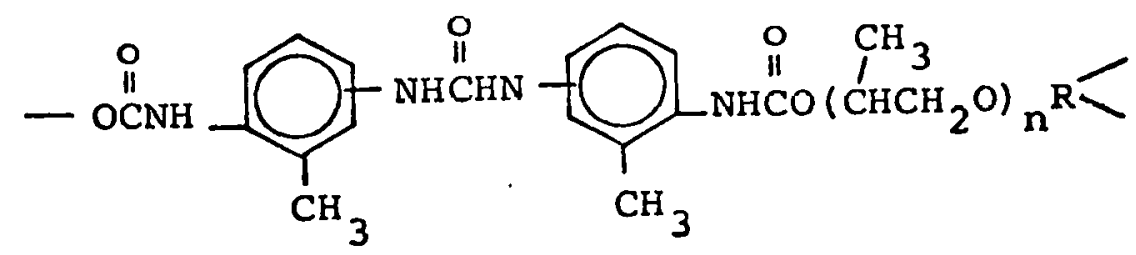

The urea bonds are formed in a hydrolysis-addition reaction sequence between water and two isocyanate groups [8].

Several recent investigations show the product distribution and discuss the mechanistic aspects of the thermal decomposition of polyurethanes [9-10]. I'he urethane is clearly the most thermolabile bond. Woolley found that at low temperatures $\left(200\right.$ to $\left.300^{\circ} \mathrm{C}\right)$ there was a rapid and complete loss of tolylene diisocyanate from a TDI-PPO-polymer as a yellow smoke leaving a polyol residue [10]. A carbon-14 tracer study on the thermal decomposition of a similar foam at $207^{\circ} \mathrm{C}$ shows that some TDI is retained in carbodiimide formation [11]. 
The kinetics of the thermal decomposition of polyurethanes has received less systematic attention. Isothermal studies on the thermal degradation of a linear polyurethane in vacuum at $260-$ $300^{\circ} \mathrm{C}$ indicated a diffusion-controlled, random chain-scission process with an activation energy of $14.1 \mathrm{kcal} /$ mode [12]. Non-isothermal studies on the decomposition of a flexible polyurethane (TDI-PPO) in dry nitrogen show a dependence of the kinetics on molecular weight of the polyol. As the molecular weight of the polyol increases from ca. 300 to 2700, the activation energy and reaction order decrease from $36.2 \mathrm{kcal} / \mathrm{mole}$ and 0.72 to $25.9 \mathrm{kcal} / \mathrm{mole}$ and 0.26 [13]. For model linear polyurethanes from xylylenediisocyanate and dimethylolcyclohexane, the mechanism and kinetics of thermal decomposition have been established. The derived activation energy varied from 20 to $32 \mathrm{kcal} / \mathrm{mole}$ depending on the calculation method and the experimental technique employed [14].

Experimental

Materials: The foam used in this study was prepared from an 80:20 TDI mixture and a trifunctional polyol according to the recipe given in Table $I$.

\section{Apparatus}

For the pyrolysis studies reported here, measurements of weight loss on a mass fraction-remaining basis vs. temperature were obtained using the Dupont 951 Thermogravimetric Analyzer (TGA) as part of the Dupont 990 Thermal Analysis System. In using the Dupont 990 System several operational features were noted which have 
a significant influence on calculated kinetics. First, the nominal heating rates indicated on the instrument generally were lower than the actual experimental heating rates measured during the course of an experiment. Second, although the instrument simultaneously plots the time derivative of the weight loss curve, it was observed to be inaccurate at nominal heating rates exceeding $10^{\circ} \mathrm{C} / \mathrm{min}$. In the present method the DTG curve was used only for diagnostic purposes; however, in other work on the pyrolysis kinetics of cellulose, it assumed a more important role and a computer approach to the calcullation of each DTG curve was developed [15]. Third, strong temperature gradients were observed along the length of the TGA furnace. Since the "sample" thermocouple also senses the local furnace temperature, the penetration distance, within the furnace, of the quartz tube containing the sample pan and sample thermocouple was observed to affect weight loss vs. temperature results. This distance was set so that the melting points of aluminum, tin and zinc fell within the accuracy of the type $K$ thermocouple used in the Dupont system. For experiments reported here, small samples $(1.5-1.8 \mathrm{mg})$ of foam were introduced into the platinum sample pan and the instrument was subsequently purged for one hour using flowing dry nitrogon $(50 \mathrm{ml} / \mathrm{min}$ ) to reduce the concentration of oxygen within the system to below detectable Iimits. The sample was then dried to constant weight at $110^{\circ} \mathrm{C}$ and heated to $650^{\circ} \mathrm{C}$ in the flowing nitrogen at nominal heating rates of $2,5,10$ and $20^{\circ} / \mathrm{min}$. 
Results and Discussion

The TGA curves for the thermal decomposition of the flexible urethane foam in nitrogen at 2 and $20^{\circ} \mathrm{C} / \mathrm{min}$ are shown in Fig. 1. The decomposition takes place in two overall steps and the completion of the first step transforms the cellular structure to a tarry, viscous liquid. In describing this sequence of events, our purpose is to derive those kinetic parameters which provide the best fit to the entire experimental curve at both heating rates. In this way, we are assured of an empirical description of the decomposition process at heating rates comparable to those found in smoldering combustion and thus suitable for mathematical model development $[3,6]$.

\section{A. General Kinetic Method}

The derivation of kinetic data from TGA curves obtained under non-isothermal conditions has received considerable attention and several comprehensive reviews are available [16-18]. In general, the kinetic procedure consists of three parts: the choice of a suitable heterogenous reaction mechanism, the calculation of the apparent kinetic parameters for this rate law and finally the testing of the kinetics description against the experimental data at several heating rates.

At present, there are some sixteen rate laws in existence to explain heterogenous reactions of the type found in polymer degradation $[19-22]$. These rate laws are divided into four groups: 1) diffusion, 2) phase boundary reaction, 3) random nucleation and 4) power laws. All these laws have as their starting point the generalized rate equation:

$$
\frac{d a}{d T}=\frac{k}{B} f(a)
$$


Here $\beta=$ linear heating rate, $a=$ fraction reacted, $k=A e^{-E / R T}$

and $f(a)$ is the particular rate law in question. Also, the integral of $d a / f(a)$ is customarily called $g(a)$ so that

$$
\int \frac{d a}{f(a)}=g(a)=\frac{A}{B} \int e^{-E / R T} d T
$$

The $g(a)$ 's for the sixteen rate laws are given in Table II.

The evaluation of the right hand integral in Eqn. (2) has been more troublesome and several approximate solutions have appeared in the literature $[23-25]$.

$$
\begin{aligned}
\frac{A}{\bar{B} \int e^{-E / K^{\prime}} \cdot d T} & \simeq \frac{A R T^{2} / E}{(1+4 R T / E)^{\frac{3}{2}}} \cdot e^{-E / R T} \quad[\operatorname{Ref} 25] \\
& \simeq \frac{A}{\beta}\left(1-\frac{2 R T}{E}\right) \frac{R T^{2}}{E} \cdot e^{-E / R T} \quad[\operatorname{Ref} 23] \\
& \simeq \frac{A R T^{2}}{B\left(E+\frac{R T}{2 R T}\right)} e^{-E / R T} \quad[\operatorname{Ref} 24]
\end{aligned}
$$

We have compared each approximation with a theoretical curve obtained from a tourth order Runge-Kutta integration routine. Using the following kinetic parameters we derived two numerical curves and compared the three approximate solutions in Table IIJ: $\mathrm{E}=30 \mathrm{kcal} / \mathrm{mole}, \mathrm{A}=4.2 \times 10^{11} \mathrm{~min}^{1}, \mathrm{n}=1$ (random nucleation), $B=b^{n} / \mathrm{min}$ and $E=45 \mathrm{kcal} / \mathrm{mole}, A=6 \times 10^{14} \mathrm{~min}^{-1}, \mathrm{n}=1$, $\beta=5^{\mathrm{o}} / \mathrm{min}$. (These kinetic parameters cover thermal decomposition reactions in the temperature range of $200-400^{\circ} \mathrm{C} .1$ The accuracy of each approximation is within the reproducibility of the TGA curves obtained with the present instrument. Each approximation is of comparable accuracy for the high temperature reaction and the Gorbachev equation [24], which we have adopted, is slightly better for the low temperature reaction. The generalized form of the rate 
law we have adopted is, therefore

$$
g(a)=\frac{A R T^{2}}{\beta(E+2 R T)} \cdot e(-E / R T)
$$

where $g(a)$ is any one of the 16 tabulated functions (Table II).

criado [26] has provided a simple method for an easy and quick analysis of the apparent mechanism of thermal decomposition reactions of solids from DTG curves. This method does not pinpoint which of the 16 rate laws is the most appropriate, but it does simplify the process significantly. The Criado method is based on a series of master curves that depend neither on the kinetic parameters nor on the heating rate, but only on the reaction mechanism. Each master curve is obtained from a plot of the "reduced rate" against (a),' the former term being defined as

$$
\left(\mathrm{T} / \mathrm{T}_{0.5}\right)^{2}(\mathrm{da} / \mathrm{d} \mathrm{t}) /(\mathrm{da} / \mathrm{d} \mathrm{t})_{0.5}
$$

Here the subscript denotes the value at $a=0.5$ and $\left(T / T_{0.5}\right)^{2}$ is close to unity, so the "reduced rate" is approximated by the ratio of the rates or the ratio of the distances of the DTG curve from the base line. The master curves for various mechanisms are close together up to $a=0.5$, then diverge, showing the greatest difference in the vicinity of $a=0.75$. The maxima of these curves also show a shift which has diagnostic utility. In Table IV, we have tabulated the "reduced rate" at $a=0.75$ and 0.80 for each of the 16 mechanisms shown in Table II. Also shown in this Table are the values of a at the "reduced rate" maximum and the expected ratio of apparent activation energies $\left(E_{a}\right)$ for unresolved cases within particular sets of mechanisms. For example, if the "reduced rate" at $a=0.75$ is 1 and 
the maximum occurs at $a=0.63$, then any one of five random nucleation mechanisms with $\mathrm{n}=1 / 4,1 / 3,1 / 2,2 / 3$ or 1 is suggested. However, each of these five rate laws requires different apparent activation energies whose values will be in the ratio shown in the last column. What this means, for example, is that an experimental TGA curve might be equally well fit with either the $R(1)$ or $R(1 / 2)$ law, but the $E_{a}$ of the $R(1 / 2)$ solution will be $1 / 2$ that of the $E_{a}$ for the $R(1)$ solution. This situation is illustrated in Fig. 2 which shows two theoretical TGA surves that are nearly coincidental (maximum difference is $1.5 \%$ ) even though the two sets of kinetic parameters chosen have $E_{a}$ of 15 and $30 \mathrm{kcal} / \mathrm{mole}$. The last column of Table IV further suggests that it is possible to obtain a solution within the experimental reproducihility nf a TGA surve with an $\mathrm{E}_{\mathrm{a}}$ as low as $7.5 \mathrm{kcal} / \mathrm{mole}$. Therefore, unless the DTG curves suggest one of the unambiguous rate laws $(B(1 / 2), D 4$ or $D 2)$, it is impossible to obtain a unique set of kinetic parameters from a single TGA curve. This non-uniqueness of kinetic parameters for a single curve may help explain the great variation of activation energy parameters reported in the literature, especially when $\mathrm{E}_{\mathrm{a}}$ alone or only $E_{a}$ and $A$ are given.

The most suitable set of kinetic parameters may he estahlished by using a second non-isothermal curve or a non-isothermal and an isothermal curve combination [22]. The use of two or more different non-isothermal curves to derive activation energy is called the multiple heating rate method [27] and is based on the assumption that the temperature displacement between two or more curves at a point of equal conversion is a function of the activation energy. Procedural factors (sample size and weight, 
particle size, atmosphere) are also known to affect the temperature shift of TGA curves, especially in reversible reactions which show a greater sensitivity to diffusional factors $[28-29]$. Also, the value of the apparent activation energy will depend on the precision of the measured temperature difference. Thus, a $2^{\circ} \mathrm{C}$ error in a typical temperature shift of $20-30^{\circ} \mathrm{C}$ introduces a $5-10 \%$ error in $\mathrm{E}_{\mathrm{a}}$. At the beginning and end of a reaction the temperature changes very rapidly with conversion so it is better to evaluate the temperature shift in the central portion (ca 90-10\% range) of the decomposition. Using small samples $(2-3 \mathrm{mg})$ and identical experimental procedures, we have found the multiple heating rate method to be a useful diagnostic tool in dexiving a very good formal kinetic description for the irreversible decomposition of cellulose in steam at heating rates of 5 to $150^{\circ} / \mathrm{min}[15]$. In the present work we reduced the sample weight further $(1.7 \pm 0.1 \mathrm{mg})$ and have again employed this method as a diagnostic aid in establishing the proper mechanism.

Unfortunately, the thermal decomposition of a polymeric material seldom proceeds according to a single, well-defined mechanism. More often, the degradative pathway is a series of complex steps made up of competitive, independent and/or consecutive reactions. Furthermore, the reaction steps in these three sequences may proceed by different rate laws. This situation becomes very complex if the steps in the reactions overlap appreciably. General methods for extracting the mechanism and rate parameters for such TGA curves are not available, and one is left with what amounts to trial and error integrations of possible rate schemes in attempting to match the experimental data. There is no guarantee of uniqueness 
in the parameter set that one finds to give a best fit so that conclusions about mechanisms are not justifiable.

In the following, we assume that the various reaction steps are unambiguously separated (ox can be separated by proper choice of heating rate). Then the individual steps can be analyzed as if they comprise an entire TGA curve. Afterwards, one generates the full multi-step TGA curve to check against the experimental curve. Even here restrictions enter in and analytical expressions cannot he. given for all possible cases. Below we give rxpressinns for simplo competitive, independent and consecutive reactions which can be used with Eqn. (3) and a graphic relationship between the $g(a)$ function and (a) to calculate a theoretical curve; this is then compared with the experimental trace.

The simplest competitive reaction case is the following

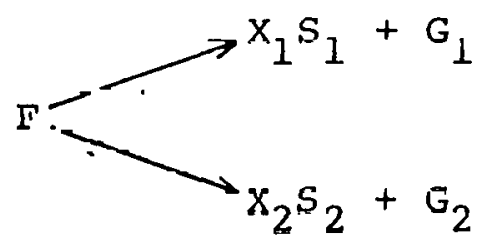

$$
\begin{aligned}
& S=\text { Solid } \\
& G=\text { Gas }
\end{aligned}
$$

where $x_{1(2)}$ is the mass fraction of solid $1(2)$ left ungasified at the end of the reaction. Letting $x=x_{1}+x_{2}$, mass conservation leads to the following expression for the TGA surve

$$
\frac{W_{T}}{W_{O}}=|1-a(1-x)|
$$

Where $W_{T}=$ sample weight at $T, W_{O}=$ original sample weight, and (a) comes from $g(a)=G_{1}+G_{2}$ (when the two reactions follow the same mechanism). $G_{1}$ and $G_{2}$ àre the Goxbachev approximations for reaction ( 1 ) and (2) (Eqn. 3). Here (a) is the fraction of original F consumed by both pathways. 
For two independent reactions of the type:

$$
\begin{aligned}
& A=\delta \mathrm{F} \longrightarrow \mathrm{X}_{1} \mathrm{~S}_{1}+\mathrm{G}_{1} \\
& \mathrm{~B}=(1-\delta) \mathrm{F} \longrightarrow \mathrm{X}_{2} \mathrm{~S}_{2}+\mathrm{G}_{2}
\end{aligned}
$$

Fraction $\delta$ of the fuel behaves as material $A$; the remainder as material B. $x_{I(2)}$ is the mass fraction of solid l(2) left ungasified at the end of the reaction. Mass conservation gives the following equation for the TGA curve of such independent reactions:

$$
\frac{\mathrm{W}_{\mathrm{T}}}{\mathrm{W}_{0}}=\delta\left(1-\mathrm{a}_{1}\left(1-\mathrm{x}_{1}\right)\right)+(1-\delta)\left(1-\mathrm{a}_{2}\left(1-\mathrm{x}_{2}\right)\right)
$$

where $a_{I(2)}$ is the mass fraction of component $1(2)$ reacted. The values of $a_{1(2)}$ are obtained as in the single reaction case since the reactions here do not interact.

For the simple case of two consecutive reactions of the type

$$
\begin{aligned}
& \mathrm{F} \longrightarrow \mathrm{x}_{1} \mathrm{~S}_{1}+\mathrm{G}_{1} \\
& \mathrm{~S}_{1} \longrightarrow \mathrm{x}_{2} \mathrm{~S}_{2}+\mathrm{G}_{2}
\end{aligned}
$$

the expression below for the TGA curve applies.

$$
\frac{w_{T}}{w_{0}}=\left(1-a_{1}\left(1-x_{1}\left(1-a_{2}\left(1-x_{2}\right)\right)\right)\right)
$$

Here the fractions reacted are obtained using Eqn. (3) for the original fuel $F$ and for the intermediate $S_{1}$; note that an accurate value of $\mathrm{x}_{1}$ can only be obtained with reasonably separated reactions. Here we note that the final weight fraction is $x_{1} x_{2}$.

Consecutive and independent reactions often behave similarly with regard to changes in heating rate so a distinction between the two modes may often not be possible. Using the same set of kinetic parameters that have been used elsewhere $[16,27]$ to illustrate the difference in behavior of competitive and independent 
reactions we have plotted the TGA curves for consecutivc and independent reactions in Fig. 3. This figure shows that these closely coupled reactions converge as the heating rate is increased for both modes of reaction. At $0.5^{\circ} / \mathrm{min}$, where the reactions are somewhat separated, the consecutive and independent TGA curves are almost identical. At $2^{\circ} / \mathrm{min}$, small differences begin to appear in the central position of the DTG curves and grow at $5^{\circ} / \mathrm{min}$. At $5^{\circ} / \mathrm{min}$ the TGA curve for the consecutive mode is displaced to higher temperature by several degrees so that at $460^{\circ} \mathrm{C}$, about 2-3\% less sample is connected. In this particular example independent and consecutive reactions qive similar (but marginally distinguishable) TGA curves only because the lower activation energy reaction $(E=30)$ was chosen for the first reaction in the consecutive sequence (see Fig. 3 for reverse sequence).

A formal interpretation of the degradative pathway comes when the curves calculated by Equations 4,5 or 6 fit the experimental TGA curves at two heating rates.

B. Application of the Method

A review of the literature $[9,10]$ suggests that the first step in the thermal decomposition of our polyurethane foam is the break-up of the urethane-urea blocks leading to collapse of the cellular structure. In the second step, the more stable polyol segment tragments. Since the chemical and physical changes of the initial step will influence the course of the second step, the consecutive reaction sequence seems more appropriate although the reactions are so widely separated that an independent model is also suitable.

The "reduced rate" values of the DTG curve for the first and second reaction at $a=0.75$ are 1.33 and 1.04 , respectively. From 
Table III these values suggest the two dimensional diffusion mechanism (D2) for the first reaction and a random nucleation mechanism $(R, n(1 / 4$ to 1$))$ for the second reaction.

Using the multiple heating rate method on the central portion of both the first and second reactions at the two heating rates gives expected $E_{a}$ values of a 52 and $40 \mathrm{kcal} / \mathrm{mol}$, respectively. The slope of a plot of $\log \mathrm{g}(\mathrm{a}) / \mathrm{T}^{2}$ against $\mathrm{l} / \mathrm{T}$ for the $\mathrm{D} 2$ rate $\mathrm{law}$ gives an $\mathrm{E}_{\mathrm{a}}$ of $52 \mathrm{kcal} / \mathrm{mole}$ for the first reaction $((E+2 \mathrm{RT})$ in the Gorbachev approximation is assumed constant). A similar plot for an $R(2 / 3)$ rate law for the second reaction gives $E=37 \mathrm{kcal} / \mathrm{mole--acceptably} \mathrm{close}$ to the multiple heating rate value of $40 \mathrm{kcal} / \mathrm{mole}$, in view of the $\mathrm{E}_{\mathrm{a}}$ spread expected in Table III, to verify the suitability of an $R(2 / 3)$ description. From these results we infer that the first overall step, which ends with an abrupt collapse of the foam structure, is diffusioncontrolied (D2 law); the resultant tarry liquid gasifies in the second overall step by a random nucleation mechanism ( $R(2 / 3)$ law). The kinetic data for the two reactions are summarized below.

\begin{tabular}{c|c|c|c|c}
\hline Reaction & Model & $g(\mathrm{a})$ & $\mathrm{E}\left(\frac{\mathrm{kcal}}{\mathrm{mol}}\right)$ & $\mathrm{A}\left(\mathrm{min}^{-1}\right)$ \\
\hline 1 & $2-D$ Diffusion & $(1-\mathrm{a}) \ln (1-\mathrm{a})+\mathrm{a}$ & 52 & $3.4 \times 10^{19}$ \\
2 & Random Nucleation & $(-\ln (1-\mathrm{a}))^{2 / 3}$ & 39 & $6.8 \times 10^{12}$ \\
\hline
\end{tabular}

Using these data with $x_{1}=0.65$ and the expression for the TGA weight loss (Eqn. 6), we obtained the very good agreement between the experimental and calculated curves shown in Fig. 1.

If we assume, as the model suggests, that a diffusion mechanism controls the first reaction step, we may formulate the following global mechanism: 
a) $\mathrm{F}_{(\mathrm{C})} \longrightarrow \mathrm{F}^{\prime}(\mathrm{P})$ (c)

b) $F^{\prime}(P)_{(C)} \longrightarrow F_{(c)}^{\prime}{ }^{P}(S)$

c) $F_{(c)}^{\prime} P_{(S)} \longrightarrow F_{(c)}^{\prime}+P(g)$

Step (a) shows the in-situ formation of fragmentation -depolymerization products. To the extent that the fragmentation forms isocyanate and hydroxyl groups, this step is somewhat reversible. Step (b) shows the diffusion of these fragments to the polymer surface followed by step (c) the desorption of the species (P). Since desorption from a pulymer surface is only rate-controlling at unusually high temperatures $\left(>700^{\circ} \mathrm{K}\right)$ obtained by superheating techniques $[33]$, we shorten the overall mechanism to steps $\underline{a}$ and $\underline{b}$. The overall activation energy is the sum of the heat of step $\underline{a}$ and the activation energy for the diffusion step $\underline{b} ;$ i.e., $E=\Delta H_{a}+E_{b}$. The high water content of the foam formulation (Table I) means that most of the bonds formed in the polymerization reaction will be ureas and the average structure will contain 6.5 TDI units per block, where block termini are urethane bonds. In thermal decomposition, this average TDI unit will be liberated from the block with every 1.16 bonds broken. The heat of reaction of 2,4-TDI with s-butyl alcohol (our polyol is also secondary) to form the solid biscarbamate is $-41.3 \mathrm{kcal} / \mathrm{mole}$ of TDI $[30]$ or about $-20.7 \mathrm{kcal}$ per urethane (urea) bond. These authors also state that the reactions which yield considerable urea give approximately the same heat of reaction as do reactions which yield only urethane as product. Therefore, the heat necessary to liberate one TDI from the block (i.e., $\Delta \mathrm{H}_{\mathrm{a}}$ ) is about $24 \mathrm{kcal}$ per 1.16 urethane (urea) bonds. Subtracting this value from our experimental activation energy (52 kcal/mole) gives 
$28 \mathrm{kcal} / \mathrm{mole}$ for $\mathrm{E}_{\mathrm{b}^{--t h e}}$ diffusion step. The activation energy for the diffusion of monomer in the depolymerization of polymethylmethacrylate varies from 20 to $38 \mathrm{kcal} / \mathrm{mol}$ depending on film thickness and the extent of crosslinking $[33,34]$.

Neglecting diffusion, the activation energy for step a is given by the sum of $\Delta \mathrm{H}_{\underline{a}}$ and $\mathrm{E}_{-\underline{a}}$; the activation energy for the reverse of step a. The activation energy for the reaction of s-butyl alchol with phenyl or tolyl (o, $m$ or $P)$ isocyanate ranges from ca 10 to $13 \mathrm{kcal} / \mathrm{mole}$ depending on the amount of alcohol in the reaction mixture $[31,32]$. Assuming step a is mainly depolymerization, we estimate $\mathrm{E}_{\text {a }}$ as $34-37 \mathrm{kcal} / \mathrm{mol}$. While this analysis gives reasonable values for the steps involved, they are based on the not fully justified, but nevertheless useful, assumption which relates our formal mechanism to the actual chemistry $[35]$.

\section{Acknowledgement}

The authors would like to acknowledge the financial support of the National Bureau' of Standards under Grant 4-9026 and the Products Research Committee. Any conclusions are those of the authors and not the sponsors. 


\section{References}

1. F. E. Rogers, T. J. Ohlemiller, A. Kurtz and M. Summerfield, J. Fire Flamm. , 8 , 5, (1978).

2. F. E. Rogers, T. J. Ohlemiller and M. Summerfield, J. Consumer Product Flamm. 5,59, (1978).

3. T. J. Ohlemillex, F. E. Rogexs, A. Kurtz, J. Bellan and M. Summerfield, "Experimental and Modeling Studies of Smoldering in Flexible Polyurethanes", Princeton University, Department of Mechanical and Aerospace Engineering, Report Nn. AMS, 1337, July 1977 .

4. T. J. Ohlemiller and F. E. Rogers, J. Fire Flamm., 9, 489 (1978).

5. T. J. Ohlemiller and F. E. Rogers, "Smoldering Combustion Studies", Princeton University, Department of Mechanical and Aerospace Engineering, Report No. 1417, December 1978.

6. T. J. Ohlemiller, J. Bellan and F. E. Rogers, "A Model of Smoldering Combustion Applied to Flexible Polyurethane Foams", Princeton University, Department of Mechanical and Aerospace Engineering, Report No. 1419, December 1978; also to be published in Combustion and Flame.

7. F. E. Rogers and T. J. Ohlemiller to appear in J. Fire Flamm.

8. Details of Polyurethane Chemistry can be found in

a) J. H. Saunders and K. C. Frisch "Polyurethanes: Chemistry and Technology", Part I, Interscience, New York 1962

b) "Polyurethane Technology", P. F. Bruins, Editor, Interscience, New York, 1969

c) "Cellular Plastics", Proceedings of a Conference, Nạtirik, Mass. Publication 1462, National Acad. of Sci. 1967. 
9. F. D. Hileman, K. J. Voorhees, L. H. Wojcik, M. M. Birky, P. W. Ryan and I. N. Einhorn, J. Polym. Sci., 13, 571, (1975).

10. W. D. Woolley, Brit. Polym. J., 4, 27, (1972).

11. J. D. Ingham, N. S. Rapp and J. Hardy, J. Polym. Sci., B-2, 675, $(1964)$.

12. H. H. G. Jellinek and K. Takada, J. Polym. Sci., 13, 2709, (1975) .

13. M. D. Kanakia, Ph. D. Thesis, University of Utah, 1973, University Microfilms, Ann Arbor, Mich., No. 73-20147. See also R. W. Mickelson, Thermochim. Acta, 5 , 329, (1973); R. W. Mickelson and I. N. Einhorn, Thermochim. Acta, 1, 147, (1970) for affect of heating rate on kinetics.

14. L. P. Rumäo, K. C. Frisch, J. Polym. Sci., A-1, 10, 1499 (1972). 15. M. J. Antal, Jr., H. L. Friedman and F. E. Rogers to appear in Combust. Sci. Technol.

16. V. Sestak, V. Satava, W. Wendlandt, Thermochim. Acta, 2 , 333, (1973) •

17. W. W. Wendlandt, "Thermal Methods of Analysis", Wiley-Interscience, N. Y., 2nd Edition, 1974 .

18. R. R. Baker, Thesiluchill. Aclá, 23, 201, (1970).

19. A. Lucci and M. Tamanini, Thermochim. Acta, 13, 147, (1975). 20. L. Battezzati, A. Lucci and G. Riontino, Thermochim, Acta, 23, $43,(1978)$.

21. J. Sestak, Thermal Analysis, Vol. 2, Proceedings of Third ICTA, Davos 1971, Birkauser Verlag, Basel 1972, p. 3 (see also Ref. 22). 22. J. M. Criado and M. Morales, Thermochim. Acta, 19, 305, (1977). 23. A. W. Coats and J. Redfern, Nature, 208, 68, (1964). 
24. V. M. Gorbachev, J. Thermal Anal., 8, 348, (1975).

25. M. Balarin, J. Thermal Anal., 12, 169, (1977).

26. J. M. Criado, Thermochim. Acta, 24, 186, (19;8).

27. (a) L. Reich and S. S. Stivala, "Elements of Polymer Degradation", McGraw-Hill, New York, 1971 .

(b) J. H. Flynn and I. A. Wall, J. Res. Nat'l Bur. Std., 70A, $487(1966)$.

28. J. Zsako, J. Thermal Anal., ㅌ, 239, (1973).

29. R. R. A. ABou-Shaaban and A. P. Simonelii, Thermnohtm, Asta, 26, $67,(1978)$.

30. E. G. Lovering and K. J. Laidler, Canadian J. Chem., 40, 31, (1962).

31. E. G. Lovering and K. J. Laidler, Canadian J. Chem., 40, 31, $(1.962)$.

32. E. Dyer, H. A. Taylor, S. J. Mason and J. Samson, J. Amer. Chem. Soc., 71, $4106(1949)$.

33. R. F. Chaiken, W. H. Andersen, M. K. Barsh, E. Mishuck, G. Moe and R. D. Schultz, J. Chem. Phys., 32, 141, (1960).

34. H. H. G. Jellinek and H. Kachi, J. Polym. Sci., 23C, 87 (1968). 35. P. D. Garn, J. Thermal Anal., 13, 581, (1978). 


\section{Table I - Flexible Urethane Foam}

Formulation

Propoxylated triol (3000 mw)

Water

Silicone Surfactant $(L-540)^{a}$

Bis-dimethylaminoethyl ether (Al) ${ }^{a}$

Stannous Octoate

Tolylene diisocyanate (80:20 mixture of $2,4 / 2,6$ isomers)
Parts by wgt.

100

$$
5.0
$$

1

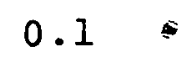

0.30

59.9

a Union Carbide Corporation 
rable =I - Rate Laws for Heterogenous Reactic.ns

Model (symbol) $g(a)$

1) Diffusion (DI) $a^{2}$

(D2) $(1-a) \ln (1-\bar{a})+a$

(D3) $\left[1-(1-a)^{1 / 3}\right]^{2}$

(D4) $\quad(1-2 \bar{c} / 3)-(1-\bar{a})^{2 / 3}$
Parabolic Law; 1-[ Diffusion

2-D Diffusion; Colinarical geometry

3-D Diffusion; Spherical geometry

3-D Diffusion; Spherical geometry

2) Phase Boundary
Reactions
(B) $n^{-1}\left[1-(1-a)^{n}\right]$
$n=1 / 2,1 / 3$

3) Random Nuclea-

tion (F.)

4) Power Laws (P)

$$
\left[-\ln (1-a)^{\top n}\right.
$$

$a^{n}$ $\mathrm{n}=1,2 / 3,1 / 2, i / 3,1 / 4$

$\mathrm{n}=1 / 4,1 / 3,1 / 2,1,3 / 2$ 


\section{COMPARISON OF INTEGRAL APPROXIMATIONS}

KINETIC PARAMETERS: $\quad A=4.2 \times 10^{11} \mathrm{~min}^{-1}, E=30 \mathrm{kcal} / \mathrm{mol}$, $\mathrm{R}$ (1) model, $\mathrm{B}=5^{\circ} \mathrm{C} / \mathrm{min}$

MASS FRACTION

\begin{tabular}{|c|c|c|c|c|}
\hline & $\begin{array}{l}\text { Runge- } \\
\text { Kutta* }\end{array}$ & $\begin{array}{l}\text { Coats \& } \\
\text { Redfern (23) }\end{array}$ & Gorbachev (24 & וכל \\
\hline
\end{tabular}

$\begin{array}{lllll}200 & 0.9840 & 0.9839 & 0.9839 & 0.9839 \\ 210 & 0.9681 & 0.9679 & 0.9678 & 0.9677 \\ 220 & 0.9383 & 0.9381 & 0.9378 & 0.9377 \\ 230 & 0.8854 & 0.8850 & 0.8846 & 0.8843 \\ 240 & 0.7969 & 0.7964 & 0.7956 & 0.7952 \\ 250 & 0.6611 & 0.6606 & 0.6593 & 0.6587 \\ 260 & 0.4782 & 0.4776 & 0.4759 & 0.4751 \\ 270 & 0.2756 & 0.2753 & 0.2735 & 0.2727 \\ 280 & 0.1100 & 0.1099 & 0.1086 & 0.1081 \\ 290 & 0.0244 & 0.0245 & 0.0240 & 0.0237\end{array}$

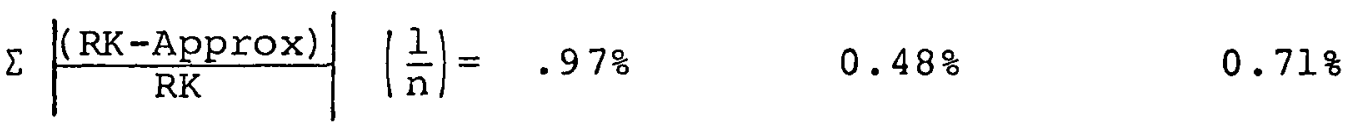

KINETIC PARAMETERS: $A=6 \times 10^{14} \mathrm{~min}^{-1}, E=45 \mathrm{kcal} / \mathrm{mol}$, $\mathrm{R}$ (1) model, $\mathrm{B}=5^{\circ} \mathrm{C} / \mathrm{min}$

MASS FRACTION

$\underline{\mathrm{T}\left({ }^{\circ} \mathrm{C}\right) \quad \begin{array}{l}\text { Runge- } \\ \text { Kutta* }\end{array}} \begin{aligned} & \text { Coats \& } \\ & \text { Redfern(23) Gorbachev(24) Balarin(25) }\end{aligned}$

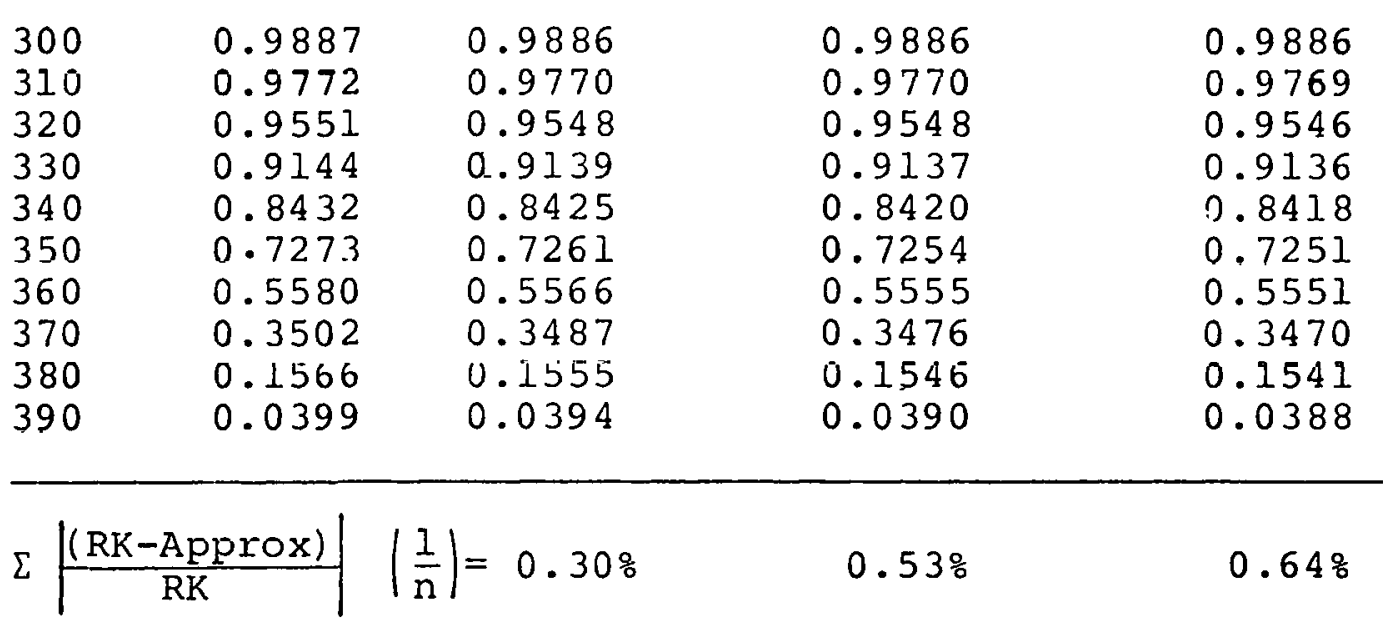

*A fourth order Runge-Kutta integration routine was used. 
Table IV

Dependence of Reduced Reaction Rate on

Fraction Reacted and on Reaction Mechanism

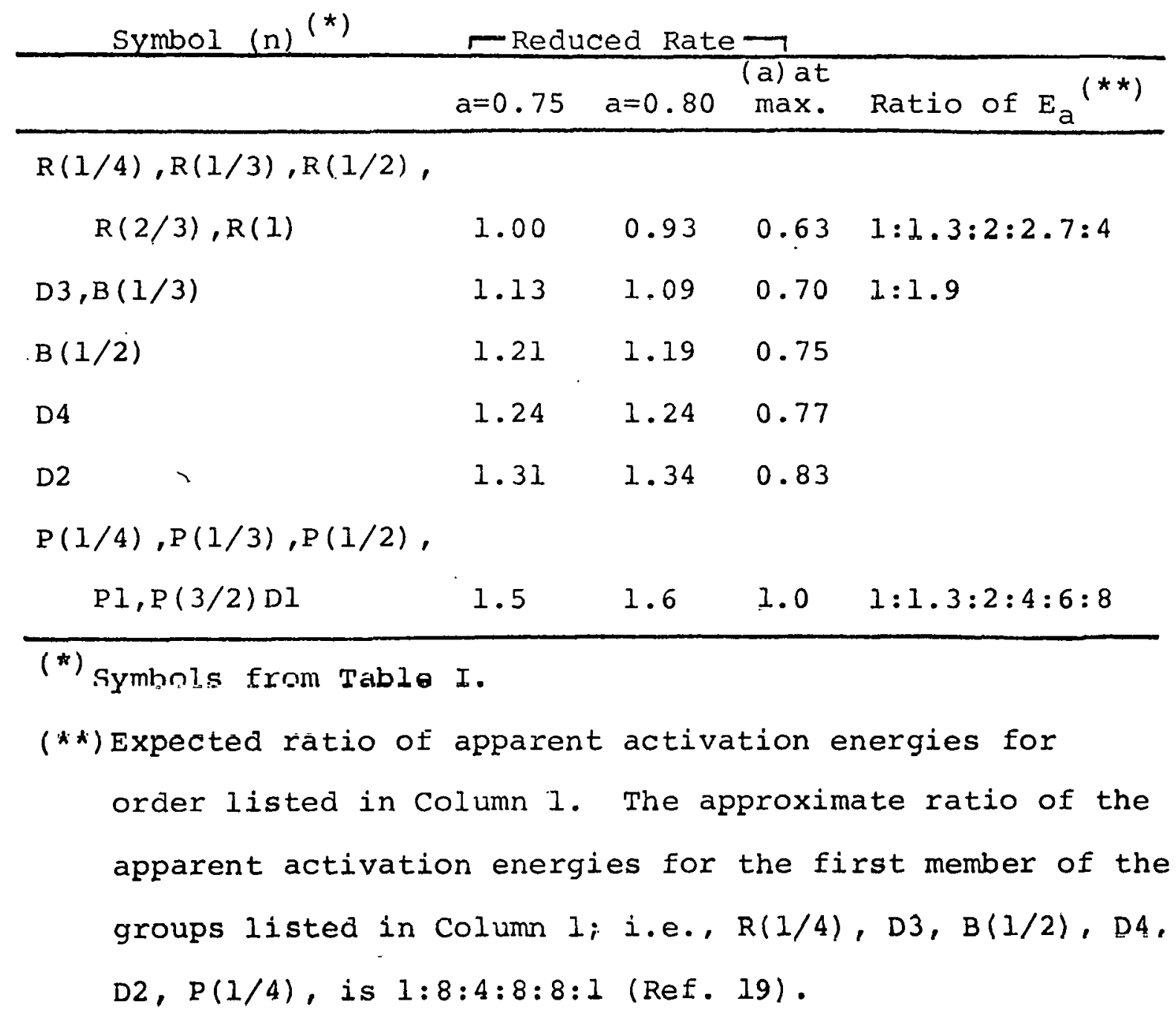




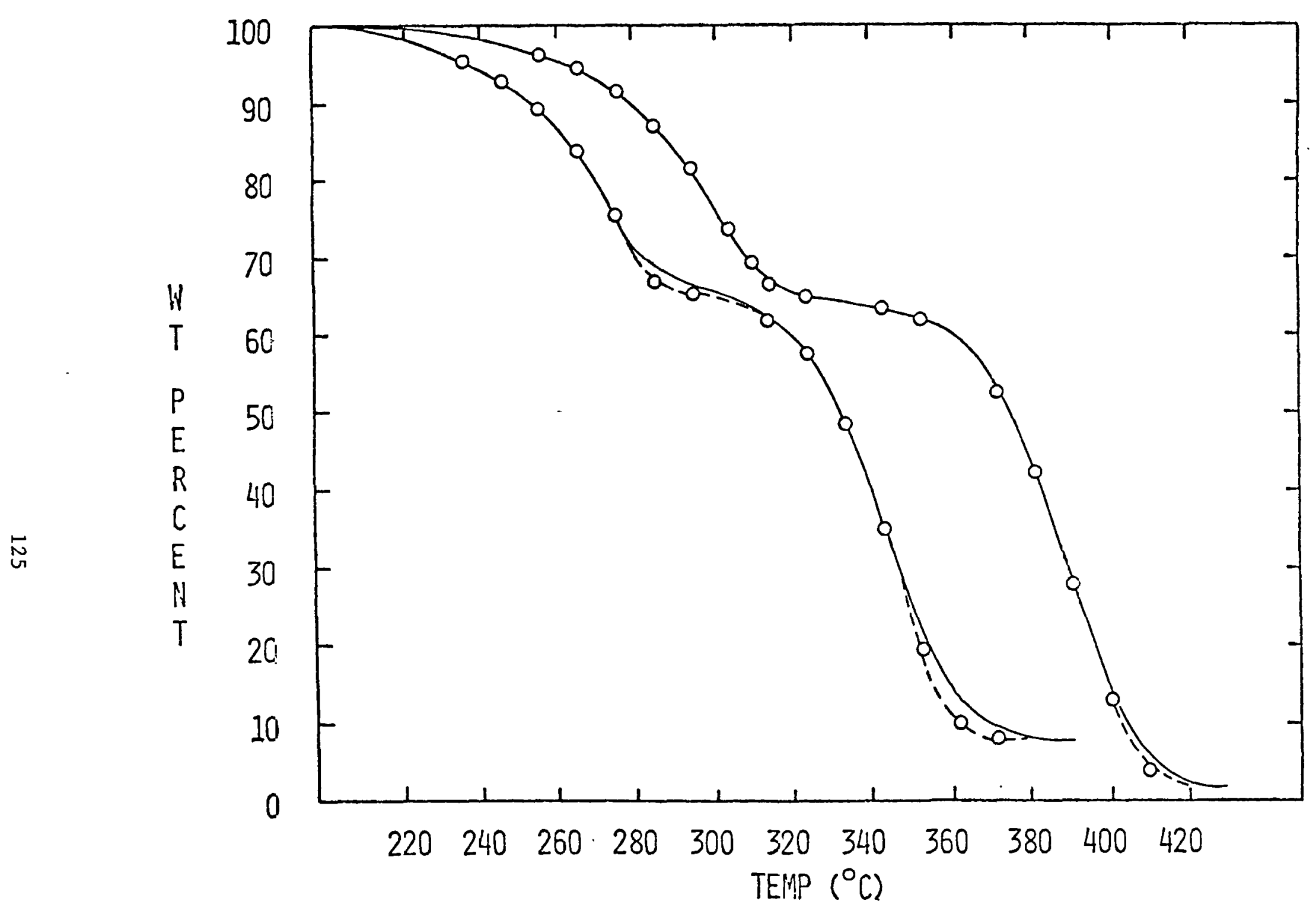

Fig. I Comparison of experimental (-) and theoretical (--o--) TGA curves for the thermal decomposition of a flexible polyurethane foam at experimental heating rates of 2.15 and $22.3 \%$ min using rate laws and kinetic parameters given in text. 
THIS PAGE

\section{WAS INTENTIONALLY LEFT BLANK}




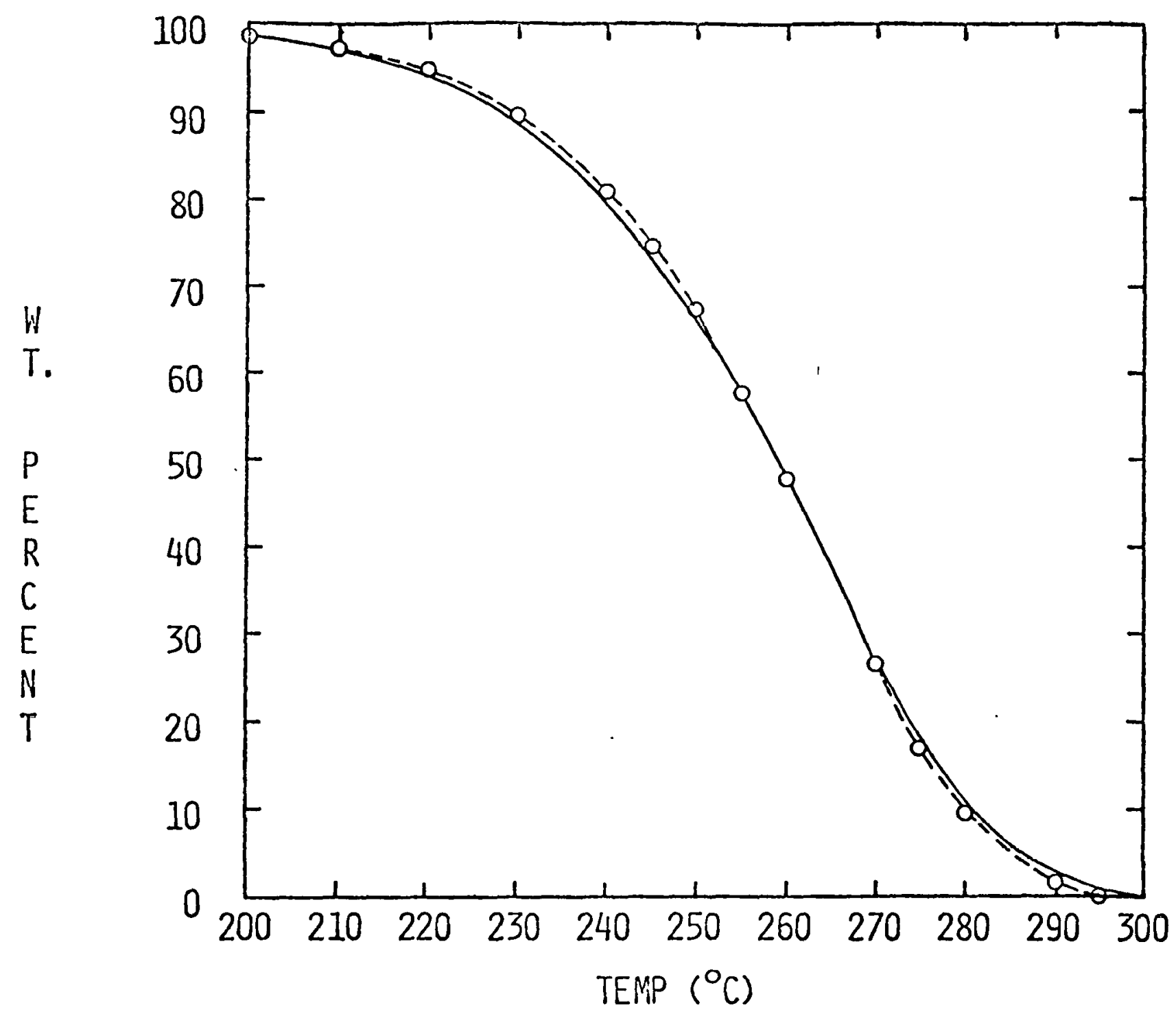

Fig. 2 Theoretical TGA curves obtained with kinetic parameters:

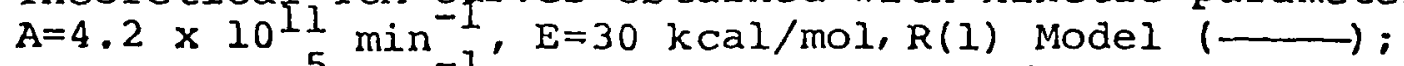
$A=1.84 \times 10^{5} \mathrm{~min}^{-1}, E=15 \mathrm{kcal} / \mathrm{mol}, \mathrm{R}(1 / 2)$ Model (-- $\left.\mathrm{O}---0---\right)$. At low and high conversion, curves, differ by only $1-1.58$. 


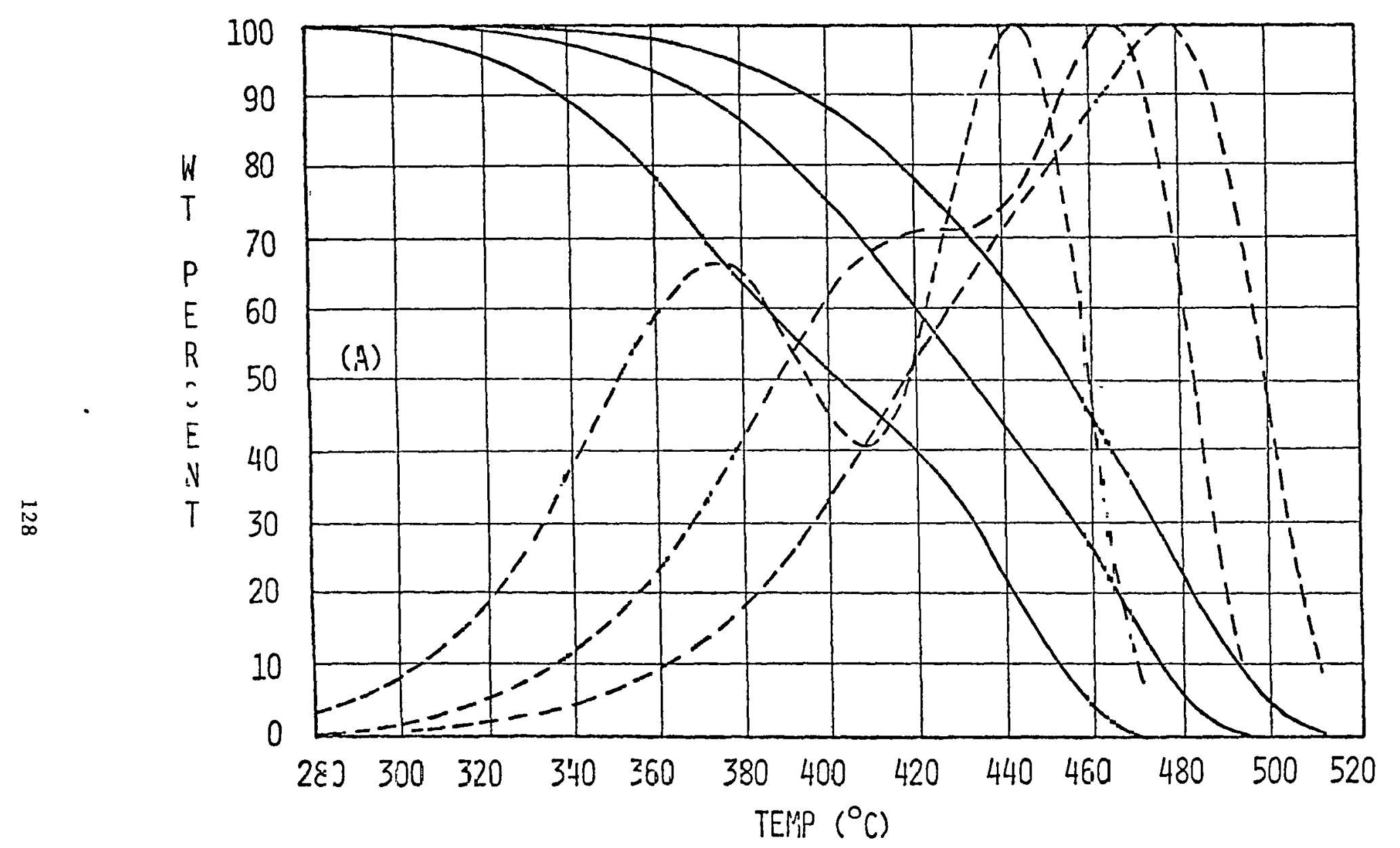

Fig. 3 Theorezical TG and ITG curves for independent (A) and consecutive reactions (B) at heating rates of $0.5,2$ and $5^{\circ} \mathrm{C} / \mathrm{m} n$ where $A$ and $E$ are $4.458 \times 10^{\circ} \mathrm{sec}^{-1}$ and $30 \mathrm{kcal} / \mathrm{mol}^{\prime} A_{2}$ and $E_{2}$ are $10^{15} \mathrm{sec}^{-1}$ and $60 \mathrm{kcal} / \pi \mathrm{l}$ and $\mathrm{n}=\mathrm{I}$ in both reactions. The (alternate) TG curve at $5^{\circ} \mathrm{C} / \mathrm{min}$ for the consecutive sequence with $\mathrm{A}_{2}-\mathrm{E}_{2}$ as first reaction is also shown (-....) 


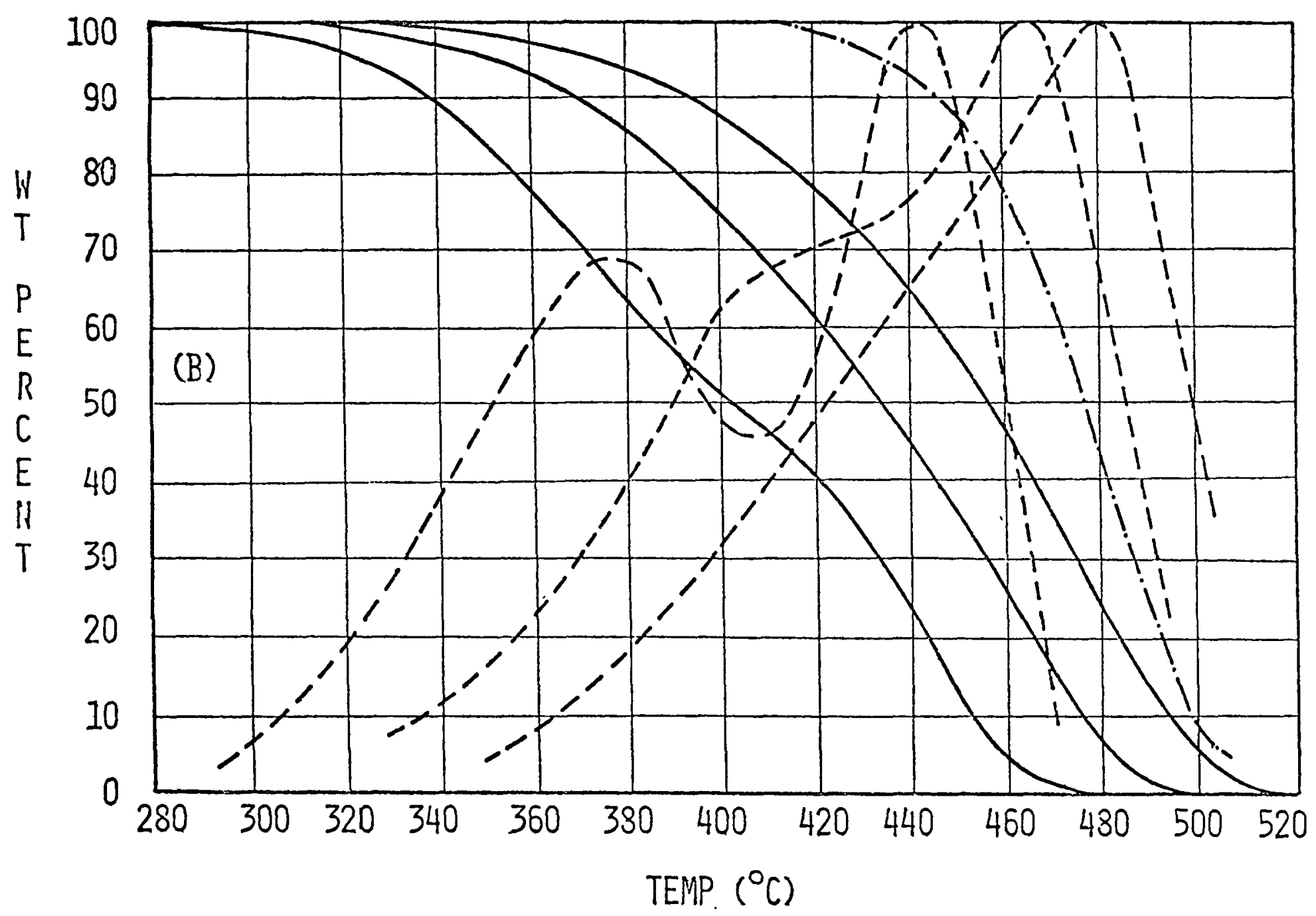

Fig. 3 (b) 


\section{THIS PAGE \\ WAS INTENTIONALLY \\ LEFT BLANK}




\section{INTERNAL DISTRIBUTION}

1-2. Central Research Library

3. Document Reference Section

4-5. Laboratory Records

6. Laboratory Records, ORNL RC

7-56. Metals and Ceramics Division Office

57. ORNL Patent Section

58. J. Blue

59. R. S. Carlsmith

60. P. T. Carlson

61. K. W. Childs

62. F. A. Creswick

63. R. G. Donnelly

64. C. S. Dudney

65. W. Fulkerson

66. D. R. Johnson

67. T. S. Lundy

68. M. C. Matthews

69. D. L. MCETroy

70. J. W. Michel

71. R. E. Minturn

72. E. G. Preston

73. J. N. Robinson

74. M. W. Rosenthal

75. T. F. Scanlan

76. A. C. Schaffhauser

77. D. B. Trauger

78. P. J. Walsh

79. D. J. Wilkes

\section{EXT̈ERNAL DISTRIBUTION}

80. P. R. Achenbach, 1322 Kurtz Road, McLean, VA 22101

81. R. W. Anderson, 7090 Tecumseh Lane, Chanhassen, MN 55317

82. E. L. Bales, DOE/BCS, Washington, DC

83. J. Barnhart, Thermal Insulation Manufacturers Assn. Mt. Kisco, NY

84. A. L. Berlad, State University of New York, Stony Brook, NJ

85. J. J. Boulin, DOE/BCS, Washington, DC

86. R. L. Bullock, National Institute of Buildings Sciences, Washington, DC

87. J. Bushong, Technology Insulation, Inc., Boonton, NJ

88. J. Cable, DOE/BCS, washington, DC

89. S. H. Cady, Mineral Insulation Manufacturers Assn., Summit, NJ

90. G. D. Carver, TVA, Chattanooga, TN 
91. A. Castle, CPSC, Washington, DC

92. M. Chiogioji, DOE/BCS, Washington, DC

93. H. I. Cohen, CPSC, Washington, DC

94. G. E. Courville, Fairleigh-Dickinson University, Teaneck, NJ

95. T. Dolan, DOE, Region X, Seattle, WA

96. W. P. Ellis, H. B. Fuller Company, Spring House, PA

97. A. E. Fiorato, Portland Cement Association, Skokie, IL

98. G. J. Fitzgerald, American Cellulosic Manufacturers Assn., Upper Mariboro, MD

99-123. E. C. Freeman, DOE/BCS, Washington, DC

124. B. F. Gilmartin, Owens-Corning Fiberglas, Granville $\mathrm{OH}$

125. R. F. Hemphill, TVA, Chattanooga, TN

126. C. Hollowe1l, Lawrence Berkeley Laboratory, Berkeley, CA

127. J. G. Hust, National Bureau of Standards, Boulder, CO

128. N. W. Johnston, Owens-Corning Fiberglas, franville, $\mathrm{OH}$

129. D. Lamb, TVA, Chattanooga, TN

130. T.P.R. Lant, Agrement Board, P0 Box 195, Bucknalls Ln., Garston, Watford, Herts WD2 7NG

131. S. Launey, DOE/BCS, Washington, DC

132. K. R. Long, University of Iowa, Oakdale, IA

133. J. T. Miller, GSA, Washington, DC

134. W. V. Miller, Civil Engineering Laboratory, Port Hueneme, CA

135. J. P. Millhone, $D O E / B C S$, Washington, DC

136. D. E. Morgenroth, Owens-Corning Fiberglas, Toledo, $\mathrm{OH}$

137. W. Russel1 Newton, TVA, Chattanooga, TN

138-147. T. J. Ohlemiller, National Bureau of Standards, Gaithersburg, MD

148. A. Paladino, National Bureau of Standards, Gaithersburg, MD

149. R. L. Parks, Underwriters Laboratories, Inc., Northbruuk, IL

150. W. T. Phelan, Owens-Corning Fiberglas, Washington, DC

151. F. J. Powell, National Bureau of Stanndards, faithersburg. MD

152-161. F. E. Rogers, Princeton University, Princeton, NJ

162. H. D. Ross, DOE/BCS, Washington, DC

163. E. Schaffer, Forest Products Laboratory, Madison, WI

164. S. Sēlkōwitz, Lawrence Berkeley Laboratury, Berkeley, CA

165. C. J. Shirtliffe, National Research Council, Ottawa, Canada

166. R. Sonderegger, Lawrence Berkeley Laburalory, Berkeley, CA

167. J. R. Tanck, DOE/BCS, Washington, DC

168. G. J. Teitsma, Dow Chemical Company, Granville, OH

169. J. Thompson, State of Oregon Department of Energy, Salem, OR

170. G. A. Tsongas, Portland State University, Portland, OR

171. R. P. Tye, Dynatech R/D Company, Cambridge, MA

172. C. R. VanderLinden, Johns-Manville Sales Corp.. Denver, CO

173. J. D. Verschoor, Johns-Manville R\&D Center, Denver, CO

174. S. S. Waddle, DOE/ORO

175. R. Wei1, Stevens Institute of Technology, Hoboken, NJ

176. G. R. Williamson, Construction Engineering Research Laboratory, Champaign, IL

177. Office of Assistant Manager for Energy Research and Development, DOE/ORO, Oak Ridge, TN

178-451. For distribution as shown in TID-4500 under category UC-95d. 